\title{
EDITORIAL
}

\section{PSYCHIATRIC ILLNESS AMONG JUVENILES AND ADOLESCENTS IN KENYA}

Twenty years ago, FGN, then working in the Department of Psychiatry at the University of Nairobi set up the first child psychiatry clinic at KNH. RNK has now run the clinic for the past ten years.

A number of changes have taken place in the practice of child psychiatry during this time.

On the one hand, it is now generally accepted that children can and do suffer from psychiatric disorders, a fact that was not in evidence twenty years ago, hence the difficulties encountered in previous attempts to serve children in this way(1).

A large body of knowledge has now developed in child and adolescent psychiatry in Kenya and elsewhere, with respect to classification, diagnostic criteria and tools, and treatment strategies.

During this period, new challenges have emerged, and include HIV/AIDS, increased use/abuse of drugs, high levels of poverty and its relationship to disadvantaged groups such as women and children, post traumatic disorders as a result of natural and man made disasters, all against the backdrop of the traditional problems that confront children and adolescents.

The mental health of children is intimately linked to that of their parents (in particular mothers) for the younger child who is dependent on the mother for his daily needs. Difficulties in obtaining medical and mental health services in shrinking economies must of necessity affect the children.

In this issue, Maru and his colleagues (2), address a question of psychiatric morbidity among a special group of children, who in may respects live in the fringes of society. As would be expected, they find very high levels of psychiatric morbidity in this group.

Forty four percent of their cohort (2), shows conspicuous psychiatric morbidity, which is similar to the figures obtained by Bickel(3). Like in many other studies of a similar nature, the predominance of boys over girls is noted. This study raises a number of important questions, which now cry loudly for scientific enquiry. Firstly, where do these children come from? How many are they, what causes their psychiatric morbidity, what is the relationship between their conditions and poverty? Secondly, and equally importantly, who is addressing their needs, emotional, psychological and economic, using what tools, skills and other resources?. Thirdly, what price shall we pay for ignoring their lot? What will happen to them when they grow up? There is some suggestion that these children will grow up to become future residents of our jails, as they grow to develop formal deviant personality disorders.

It is possible that early intervention in child psychiatric practice can influence the outcome of these and other children in need. The child psychiatry clinic at $\mathrm{KNH}$ has continued to serve hundreds of children each year, and a recent study shows, the problem of school attendance is increasing in our setting(4). In this study, school phobia and conduct disorder were found to be the major causes. The study further delineated the family characteristics of Kenyan children with school refusal.

In other settings in private practice, Attention Deficit Disorder (ADD) has shown itself to be an important (treatable) cause of school related difficulties, which in later life lead to conduct disorders. At the recently concluded Kenya Psychiatric Association/World Psychiatry Association Regional meeting held in Nairobi (April 2003), the authors presented a series of 12 cases of ADD and were able to show their demographic data, symptomatology and associated complications and comorbidity.

Important interventions in the practice of child and adolescent psychiatry currently available include family therapy, art therapy, play therapy, cognitive behaviour therapy, individual and group psychotherapy, addiction counselling and pharmacotherapy. It is hoped that this study will act as a stimulus for more work of a similar nature in this region.

F. G. Njenga, FRC Psych. and R. N. Kangethe, MBChB, MMed (Psych), Upperhill Medical Center, P.O Box 73749,-00200, Nairobi Kenya.

\section{REFERENCES}

1. Njenga, F.G. and Acuda, S.W. Presentation of depressive illness in children at Kenyatta National Hospital. East. Afr. Med. J. 1982; 59:623-626.

2. Maru, H.M. Kathuku, D.M. and Ndetei, D.M. Psychiatric Morbility among children and young persons appering in the Nairobi Juvenile Court, Kenya. East Afr. Med. J. 2003; 80:281-288.

3. Bickel, R. and Campbell, A. Mental health of adolescents in custody: the use of the "Adolescent Psychopathology Scale" in a Tasmanian context. Aust. New Zealand. J. Psychiat. 2002; 36:603-609.

4. Obondo, A. and Dhadphale, M. Family study of Kenyan children with school refusal. East Afr. Med. J. 1990; 67:100-108. 
East African Medical Journal Vol. 80 No. 6 June 2003

PSYCHIATRIC MORBIDITY AMONG CHILDREN AND YOUNG PERSONS APPEARING IN THE NAIROBI JUVENILE COURT, KENYA

H.M. Maru, MBBS (India) MMed (Psych), Consultant Psychiatrist, Deputy Medical Superintendent, Mathari Hospital, Assistant Director of Medical Services, Ministry of Health, P.O. Box 40663, Nairobi, Kenya, D.M. Kathuku, MBChB (Makerere), MMed (Psych) (Nrb), Av Med, Senior Lecturer and D.M. Ndetei, MBChB (Nrb), DPM (Lond), MRCPsych (UK), MD(Nrb), Professor, Department of Psychiatry, College of Health Sciences, University of Nairobi, P.O. Box 19676, Nairobi, Kenya

Request for reprints to: Dr. H.M. Maru, P.O. Box 10139, Nairobi, Kenya

\title{
PSYCHIATRIC MORBIDITY AMONG CHILDREN AND YOUNG PERSONS APPEARING IN THE NAIROBI JUVENILE COURT, KENYA
}

\author{
H.M. MARU, D.M. KATHUKU and D. M. NDETEI
}

\begin{abstract}
Objectives: To estimate the prevalence and pattern of psychiatric disorders among children and young persons appearing in the Nairobi juvenile court, Kenya.

Design: A point prevalence survey.

Setting: The Nairobi Juvenile Court, Kenya.

Subjects: Ninety (sixty-four males and twenty-six females) children and young persons aged 8 to 18 years classified as criminal offenders, group I (60), and those for protection and discipline, group II (30), were selected.

Method: A socio-demographic questionnaire, reporting questionnaire for children (RQC), follow-up interview for children (FIC), present state examination (PSE) and clinical interview were administered to the subjects. International Classification of Diseases, 10th Edition (ICD-10) diagnostic criteria were used.

Results: The crude psychiatric morbidity (CPM) rate was $44.4 \%$. ICD-10 documented psychiatric disorders detected in those with CPM were conduct disorders $45 \%$, mixed disorders of conduct and emotion $20 \%$, emotional disorders with onset specific to childhood $20 \%$, mood disorders $12.5 \%$ and hyperkinetic disorders $2.5 \%$.

Conclusion: This study has shown a high presence of psychiatric morbidity in children and young persons appearing in the Nairobi Juvenile Court. These juveniles need and would benefit from mental treatment as recommended in section 18 of Cap 141 of the laws of Kenya; The Children's and Young Persons Act.
\end{abstract}

\section{INTRODUCTION}

Delinquency comes from the Latin word delinquere "to make mistake". Though not a diagnostic terminology in psychiatric texts, it is an unfortunate term. Russel(1) noted delinquency as a term calling to mind an immediate type: the tough, unruly kid, with no respect for persons, property or society, who makes a practice of mayhem, destruction, stealing and other forms of aggressive antisocial behaviour.

Globally, crime rate is on the rise and most criminals have been shown to have antisocial behaviour. Follow up studies into adult life, of both clinic and nonclinic children, show that antisocial behaviour in childhood is followed by a substantially increased risk of adult criminality. There is increased risk also of marital problems and breakdown, difficulties in parenting, poor job record and unemployment, financial dependency, social alcohol and drug related problems and of mental disorder(2).

Antisocial behaviour has been noted to begin during childhood. Therefore one must focus on its prevention. From an early age any measures that improve the mental health of antisocial children and its families are likely to reduce deviant behaviour(3). Lucien(4) notes that a large proportion of children and adolescents appearing before the courts have no major physical or psychological abnormality. They are simply the victims of adverse external circumstances, characterised by social insecurity or a too low standard of living or a combination of both. Snyder(5) reported from the United States of America an increase in the juvenile courts caseload by $23 \%$ between 1989 and 1993. In Kenya, between 1991 and 1994 the Nairobi Juvenile Court's caseload increased by $21 \%$ (Table 1 ). 
Table 1

Comparison of the number of cases registered at the Nairobi juvenile court from 1981-85 and 1991 upto August 1997

\begin{tabular}{|c|c|c|c|c|c|c|c|c|c|c|c|c|}
\hline Year & 1981 & 1982 & 1983 & 1984 & 1985 & 1991 & 1992 & 1993 & 1994 & 1995 & 1996 & $\begin{array}{l}\text { Aug. } \\
1997\end{array}$ \\
\hline Criminal & 1380 & 1199 & 1435 & 1740 & 1627 & 2153 & 2107 & 2650 & 2528 & $*$ & 2167 & 1357 \\
\hline $\begin{array}{c}\text { Protection \& } \\
\text { discipline }\end{array}$ & 124 & 136 & 47 & 76 & 54 & 175 & 230 & 249 & 284 & 323 & 443 & 457 \\
\hline Total & 1504 & 1335 & 1482 & 1816 & 1681 & 2328 & 2337 & 2899 & 2812 & & 2610 & 1814 \\
\hline
\end{tabular}

* The 1995 register for criminal cases was not available at the juvenile court

The ten most common offences committed by young offenders in Kenya are stealing, assault causing actual bodily harm, breaking into a building and committing felony, housebreaking, stealing by servants, damaging property, indecent assault and possession of cannabis(6). Some of the aetiological factors to delinquency have been documented as: - Genetically inherited characteristics(7), low platelet monoamine oxidase activity(8), high serum triiodothyronine levels(8), extroverts(9), psychiatric morbidity(10,11), brain injury(12), low intelligence quotient(13), epilepsy(14), substance abuse(1) and large families with poor socio-economic support (15). The Nairobi juvenile court is the only permanent juvenile court in Kenya. In other districts of Kenya, the usual courts are converted into juvenile courts whenever a need arises. This court is governed by the Children and Young Persons Act(16).

\section{MATERIALS AND METHODS}

The study was conducted at the Nairobi juvenile court, Kenya. Authority to conduct research was obtained from the Office of the President. As all the children and young persons in this study were below the age of 18 years, consent for interviewing them was requested from the Office of the President. The relevant protocol through the Permanent Secretary, Ministry of Home Affairs, the Registrar of Courts, the Director of Children's Department and the Director of Probation was followed to enable one of the researchers to be present in the juvenile court and to be assisted by the probation officers and children's officers. In criminal offenders, every third child or young person who appeared on the court register during, the study period was interviewed and designated as Group 1. All children and young persons appearing in the court for protection and discipline during the study period were interviewed and designated as Group 11.

A socio-demographic questionnaire was first administered followed by the Reporting Questionnaire for Children (RQC). The latter was to screen for psychiatric morbidity. Children scoring one or more than one positive answer (RQC positive) were subjected to the second stage of screening; the Followup Interview for Children (FIC). Psychiatric diagnosis was assigned according to the ICD-10. Data analysis was done by a computer using the Statistical Package for Social Sciences (SPSS) Version 8.0 and a probability value of equal or less than $0.05(\mathrm{P} \leq 0.05)$ was taken to be statistically significant.

\section{RESULTS}

Psychiatric morbidity: In this study a CPM of 40 out of $90(44.4 \%)$ children and young persons was obtained. Among those with PM, 26 (65\%) were males and $14(35 \%)$ were females.

Sample size - Group $1=60$ males -45 females -15

$$
\mathrm{M}: \mathrm{F} \quad-\quad 3: 1
$$

Group 11 = 30 males -19 females - 11

$$
\begin{array}{ll}
\mathrm{N}=90 \quad \mathrm{~F}-1.7: 1 \\
& \text { males }-64 \text { females }-26 \\
& \mathrm{M}: \mathrm{F}-2.5: 1
\end{array}
$$

Males with PM

- (a) Group I- 17(28.9\%)

- (b) Group II - 9(30\%)

Females With PM

- (a) Group 1- 6 (10\%)

- (b) Group $118(26.6 \%)$

Of the PM samples

$$
\begin{aligned}
& \text { - Group } 1 \text { M:F - 3:1 } \\
& \text { - Group II M:F - 1.1:1 }
\end{aligned}
$$

Socio-demographic factors: Children and young persons included in this study were all between 8-18 years. The total sample size was 90 . Those in the age group $\leq 12$ years were 26 (28.7\%), 13-15 years were $47(52.2 \%)$ and $16-18$ years were $17(18.9 \%)$. 
In the age group $\leq 12$ years, PM was found in 10 out of the 90 children (11. 1\%) and comprised five $(8.5 \%)$ males and two (34\%) females of the 60 children in group 1 whereas $(6.7 \%)$ males and one (3.3\%) female were from group consisting of 30 children.

In the age group 13-15 years, PM was found in 20 out of the total 90 children $(22.2 \%)$ and comprised of eight (13.6\%) males and two (3.4\%) females of the 60 children in group I whereas four $(13.3 \%)$ males and six $(20 \%)$ females were part of the 30 children in group II.
In the age group 16-18 years, PM was found in 10 out of the total 90 children $(11.1 \%)$ and comprised of four $(6.8 \%)$ males and two $(3.4 \%)$ females of the 60 children in group I whereas three $(10 \%)$ males and one $(13 \%)$ female came from the 30 children in group II, (Table 3)

Deviant behaviours: A variety of deviant behaviours were reported in this study. The common deviant behaviours were premature leaving of school, substance use, running away from home, begging, problems with parents, problems with peers, stealing, thefts and robberies (Table 4).

Table 2

Psychiatric disorders detected

\begin{tabular}{|c|c|c|c|c|c|c|c|}
\hline \multirow[t]{2}{*}{$\begin{array}{l}\text { ICD-10 } \\
\text { Code }\end{array}$} & \multirow[t]{2}{*}{ Diagnosis } & \multirow{2}{*}{$\begin{array}{c}\text { Count } \\
\text { Row \% } \\
\text { Column \% } \\
\text { Total \% }\end{array}$} & \multicolumn{2}{|c|}{$\begin{array}{l}\text { Group I } \\
\mathrm{N}=60\end{array}$} & \multicolumn{2}{|c|}{$\begin{array}{l}\text { Group II } \\
\mathrm{N}=30\end{array}$} & \multirow[t]{2}{*}{$\begin{array}{l}\text { Total } \\
\mathrm{N}=90\end{array}$} \\
\hline & & & M & $\mathrm{F}$ & M & $\mathrm{F}$ & \\
\hline \multirow[t]{4}{*}{ F 91} & \multirow{4}{*}{\multicolumn{2}{|c|}{ Conduct Disorders }} & 8 & 2 & 5 & 3 & \\
\hline & & & 44.0 & 11.0 & 27.5 & 16.5 & \\
\hline & & & 47.2 & 33.4 & 55.5 & 37.5 & 18 \\
\hline & & & 20.0 & 5.0 & 12.5 & 7.5 & $(45 \%)$ \\
\hline \multirow[t]{4}{*}{ F 92} & \multirow{4}{*}{\multicolumn{2}{|c|}{$\begin{array}{l}\text { Mixed Disorders of } \\
\text { Conduct and Emotions }\end{array}$}} & 3 & 0 & 3 & 2 & \\
\hline & & & 37.5 & 0.0 & 37.5 & 25.0 & \\
\hline & & & 17.5 & 0.0 & 33.3 & 25.0 & 8 \\
\hline & & & 7.5 & 0.0 & 7.5 & 5.0 & $(20 \%)$ \\
\hline \multirow[t]{4}{*}{ F93 } & \multirow{4}{*}{\multicolumn{2}{|c|}{$\begin{array}{l}\text { Emotional Disorders with onset } \\
\text { specific to childhood }\end{array}$}} & 1 & 3 & 1 & 3 & \\
\hline & & & & 12.5 & 37.5 & 12.5 & 37.5 \\
\hline & & & 5.9 & 51.1 & 11.1 & 37.5 & 8 \\
\hline & & & 2.5 & 7.5 & 2.5 & 7.5 & $(20 \%)$ \\
\hline \multirow[t]{4}{*}{ F30-F39 } & \multirow{4}{*}{\multicolumn{2}{|c|}{ Mood Disorders }} & 4 & 1 & 0 & 0 & \\
\hline & & & 80.0 & 20.0 & 0.0 & 0.0 & \\
\hline & & & 23.6 & 16.7 & 0.0 & 0.0 & \\
\hline & & & 10.0 & 2.5 & 0.0 & 0.0 & 5 \\
\hline \multirow[t]{5}{*}{ F 90} & \multirow{4}{*}{\multicolumn{2}{|c|}{ Hyperkinetic Disorder }} & 1 & 0 & 0 & 0 & $(12.5 \%)$ \\
\hline & & & 100.0 & 0.0 & 0.0 & 0.0 & \\
\hline & & & 5.9 & 0.0 & 0.0 & 0.0 & 1 \\
\hline & & & 2.5 & 0.0 & 0.0 & 0.0 & $(2.5 \%)$ \\
\hline & \multicolumn{2}{|l|}{ Total } & $\begin{array}{c}17 \\
(42.5 \%)\end{array}$ & $\begin{array}{c}6 \\
(15.0 \%)\end{array}$ & $\begin{array}{c}9 \\
(22.5 \%)\end{array}$ & $\begin{array}{c}8 \\
(20 \%)\end{array}$ & $\begin{array}{c}40 \\
(100 \%)\end{array}$ \\
\hline
\end{tabular}

Group I + Group II- $\mathrm{X}^{2}=9.53 ; \mathrm{DF}=5 ; \mathrm{P}=0.0897 \mathrm{NS}$

Group I $-\mathrm{X}^{2}=6.23 \mathrm{DF}=4 ; \mathrm{P}=0.182 \mathrm{NS}$

Group II - Statistical analysis was not done due to the high number of zeros

1. Findings not statistically significant

2. $\mathrm{PM}$ ratio in $\mathrm{M}: \mathrm{F}$ in group $\mathrm{I}$ is $2.8: 1$

3. $\mathrm{PM}$ ratio in $\mathrm{M}: \mathrm{F}$ in group II is $1.1: 1$ 
Table 3

Age vs. psychiatric morbidity

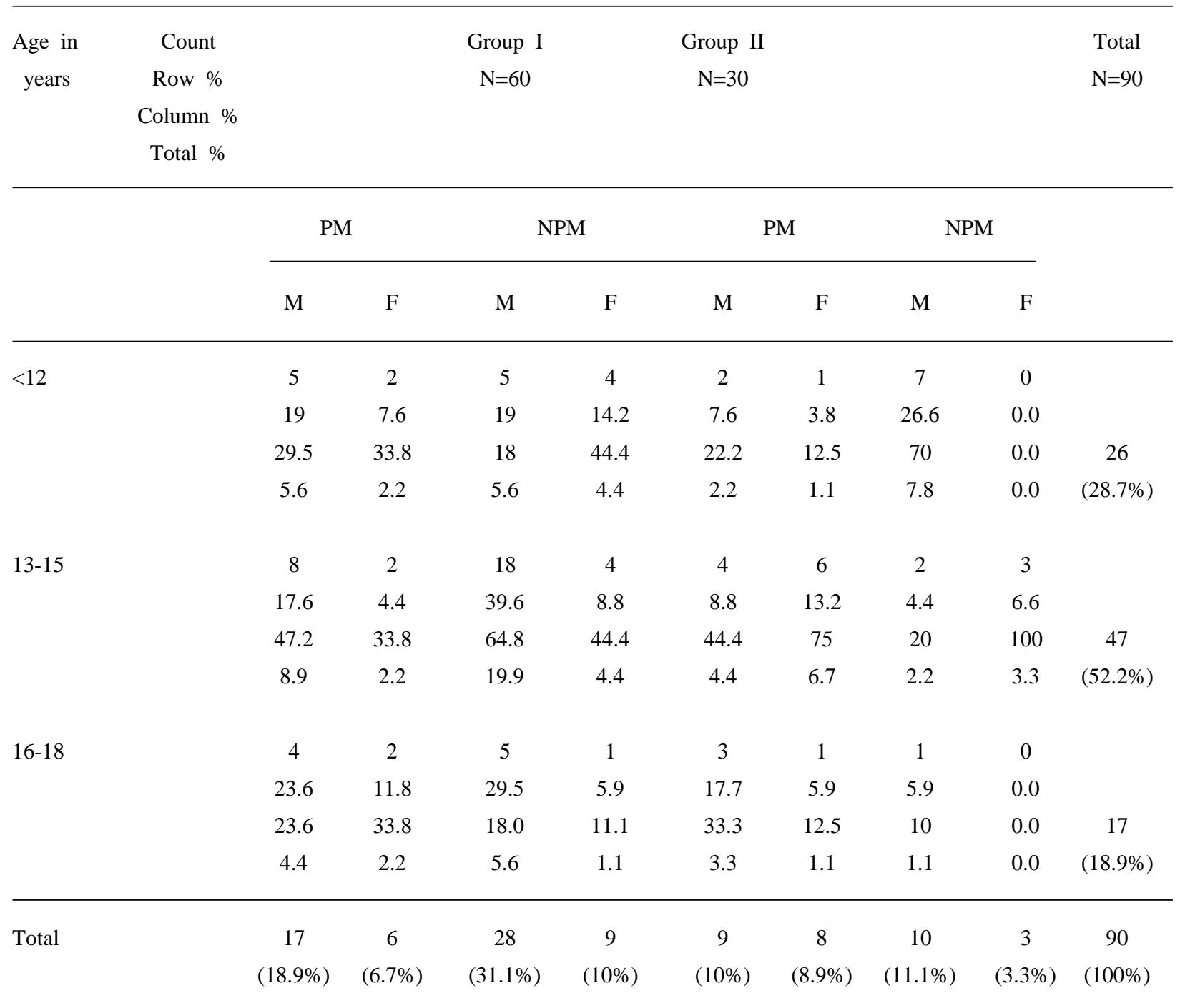

$\begin{array}{lccc}\text { Group I + Group II }-\mathrm{X}^{2}=15.46 & \mathrm{DF}=10 & \mathrm{P}=0.116 \mathrm{NS} \\ \text { Group I }-\mathrm{X}^{2}=14.4 & \mathrm{DF}=10 & \mathrm{P}=0.158 \mathrm{NS} \\ \text { Group II }-\mathrm{X}^{2}=7.4 & \mathrm{DF}=6 & \mathrm{P}=0.286 \mathrm{NS}\end{array}$

1. Findings statistically not significant

2. Children ( $\leq 12$ years) were $28.7 \%$

3. Adolescents (13-18 years) were $71.3 \%$

4. Crude mean age (all children) $=13.7$ years

5. Crude mean age for all males $=13.8$ years

6. Crude mean age for all females $=13.7$ years

7. Mean age of males with $\mathrm{PM}=13.4$ years

8. Mean age of females with $\mathrm{PM}=13.4$ years 
Table 4

Deviant behaviour vs psychiatric morbidity

\begin{tabular}{|c|c|c|c|c|c|c|c|c|c|}
\hline \multirow[t]{3}{*}{ Deviant behaviour } & \multicolumn{4}{|c|}{$\begin{array}{c}\text { Group I } \\
\mathrm{N}=60\end{array}$} & \multicolumn{4}{|c|}{$\begin{array}{c}\text { Group II } \\
\mathrm{N}=30\end{array}$} & \multirow[t]{3}{*}{$\begin{array}{l}\text { Total } \\
\text { Freq. }\end{array}$} \\
\hline & \multicolumn{2}{|c|}{ PM } & \multicolumn{2}{|c|}{ NPM } & \multicolumn{2}{|c|}{$\mathrm{PM}$} & \multicolumn{2}{|c|}{ NPM } & \\
\hline & M & $\mathrm{F}$ & M & $\mathrm{F}$ & M & $\mathrm{F}$ & M & $\mathrm{F}$ & \\
\hline Left school & 16 & 6 & 24 & 7 & 6 & 4 & 9 & 3 & 75 \\
\hline Substance use & 13 & 2 & 12 & 1 & 7 & 3 & 1 & 0 & 39 \\
\hline Running away from home & 16 & 2 & 6 & 2 & 3 & 2 & 0 & 0 & 31 \\
\hline Begging & 10 & 3 & 15 & 2 & 0 & 0 & 0 & 0 & 30 \\
\hline Problems with parents & 7 & 3 & 2 & 0 & 4 & 5 & 1 & 0 & 22 \\
\hline Stealing/thefts/robberies & 5 & 0 & 5 & 0 & 0 & 0 & 0 & 0 & 10 \\
\hline Problems with peers & 5 & 0 & 2 & 0 & 0 & 1 & 1 & 0 & 9 \\
\hline Problems with teachers & 1 & 0 & 1 & 0 & 2 & 1 & 0 & 0 & 5 \\
\hline Problems with members of public & 0 & 3 & 0 & 1 & 0 & 1 & 0 & 0 & 5 \\
\hline Problems with police/administration & 1 & 0 & 2 & 0 & 0 & 0 & 0 & 0 & 3 \\
\hline Problems with siblings & 0 & 0 & 0 & 1 & 1 & 0 & 0 & 0 & 2 \\
\hline Sexual abuser (rapist) & 1 & 0 & 0 & 0 & 0 & 0 & 0 & 0 & 1 \\
\hline Possession of drugs & 0 & 0 & 3 & 0 & 0 & 0 & 0 & 0 & 3 \\
\hline Sexually active & 2 & 2 & 0 & 1 & 1 & 0 & 0 & 0 & 6 \\
\hline Suicide attempt & 0 & 1 & 0 & 0 & 0 & 1 & 0 & 0 & 2 \\
\hline Total & 77 & 22 & 72 & 15 & 24 & 18 & 12 & 3 & 243 \\
\hline
\end{tabular}

1. Due to the large number of zeros, statistical significance was not evaluated

2. The table shows multiple deviant behaviours

\section{DISCUSSION}

This study consisted of 90 children and young persons, formed of 60 offenders (Group I) and 30 others (Group II) in need of discipline and protection. It was found that 40 out of the $90,(44.4 \%)$, children and young persons in the whole sample had a psychiatric diagnosis. These 40 consisted of $26(65 \%)$ males and $14(35 \%)$ females. Of these forty, $23(57.5 \%)$ were from group 1 and $17(42.5 \%)$ were from group II.

Of the 23 from group I, 17 (74\%) were males and six $(26 \%)$ were females. Of the 17 from group II, nine $(52.8 \%)$ were males and eight $(47.2 \%)$ females (Tables 2 and 3 ).

The CPM prevalence rate in this study (44.4\%) was much higher than in findings by other researchers in the Kenyan settings(17-20). A study among 85 children and young persons admitted into an approved school in Nairobi found a PM prevalence rate of $24.8 \%(17)$. This prevalence could possibly have been low as a result of the influence of living in the approved school which would have strict rules and regulations.
In a study of 303 children (164 boys, 139 girls) aged between 5-15 years, attending a primary health care facility in a suburban township in Nairobi, a CPM prevalence rate of $20 \%$ using the RQC and FIC was reported (18). A study among 78 children (37 males, 41 females) aged between $8-18$ years, in a communitybased institution in Nairobi around a PM prevalence rate of $41 \%$ using the RQC and FIC(19). In a comparative study of psychiatric morbidity in rural and urban primary school pupils in Kenya found the crude $\mathrm{PM}$ rates to be $26.4 \%$ (rural) and $41.2 \%$ (urban) using the RQC and FIC(20). Minde(21) found that 18-24\% psychiatric morbidity was present among Ugandan primary school children.

(i) Conduct disorders: Out of the total sample of 90 children, $18(20 \%)$ had conduct disorders and were composed of $13(14.4 \%)$ males and five $(5.6 \%)$ females. Out of these eighteen, $10(55.6 \%)$ were from group I and eight (44.4\%) from group II. Of the 10 from group 1 , eight $(80 \%)$ were males and two $(20 \%)$ were females. Of the eight from group II five $(62.5 \%)$ were males 
and three $(37.5 \%)$ were females. The crude MS ratio for conduct disorders was 2.6:1 (group I, 4:1; group II, 1.7: 1). This shows that conduct disorders are more common in males than females in both groups but more so among males of group I.

Rates for conduct disorders among children from other African countries have been reported as follows; from Ghana 3\% (22), from Nigeria 5.5\% (23) and (24)10\%. from Uganda (21)14\%. In the Isle of Wight study (II), nearly two thirds of the 10-11 year old with psychiatric disorders were found to have conduct disorders. Including the children with mixed neurotic and conduct disorders, the prevalence of conduct problem was $4 \%$.

(ii) Mixed disorders of conduct and emotions: Out of the total sample of 90 children, eight (8.9\%) had mixed disorders of conduct and emotions and were composed of six $(6.7 \%)$ males and two $(2.2 \%)$ females. Out of these eight, three $(37.5 \%)$ were from group 1 and five $(62.5 \%)$ from group II. From group I, all three (100\%) were males. Of the five from group 11 , three $(60 \%)$ were males and two (40\%) females. The crude male female ratio for mixed disorders of conduct and emotions was 3:1 (group 1:3:0 and 1:5:1 for group II). This suggests that mixed disorders of conduct and emotions are more common in males than females in both groups.

Mwangi (20) in his study reported $13.2 \%$ of pupils from a rural primary school and $5.6 \%$ of pupils from an urban primary school with mixed disorders of conduct and emotions. Rutter et al. (11) reported that it is relatively common for children and adolescents with deviant behaviour, and especially those with more widespread conduct disorders, to show emotional disturbances. He further states that the pattern of changing symptomatology between middle childhood and adolescence may show a good deal of shift from conduct disorders to mixed disorders.

(iii) Emotional disorders with onset specific to childhood: Out of a total sample of 90 children, eight $(8.9 \%)$ had emotional disorders with onset specific to childhood and were composed of two $(2.2 \%)$ males and six $(6.7 \%)$ females. Of these eight, four $(50 \%)$ were from group 1 and four $(50 \%)$ were from group II.

Of the four from group I, one $(25 \%)$ was a male and three $(75 \%)$ were females. Of the four from group II, one $(25 \%)$ was a male and three $(75 \%)$ were females. The male:female ratio being 1:3 for both groups. Hence emotional disorders with onset specific to childhood were more common in females than males.

(iv) Mood disorders: Out of the total sample of 90 children, five $(5.6 \%)$ had mood disorders and were composed of four males $(4.4 \%)$ and one female $(1.1 \%)$. All these five children were from group I and consisted of four males $(80 \%)$ and one female $(20 \%)$
. Among the four males who suffered from mood disorders, three $(75 \%)$ had features of depression and one $(25 \%)$ had hypomania. The only female with a mood disorder had depression, a history of one suicide attempt and had been sexually molested twice.

In the Isle of Wight study(11), $13 \%$ of the children studied at the age of 10 years showed depressed mood at interview, $17 \%$ failed to smile and $15 \%$ showed poor emotional responses. At 14-15 years of age, over $40 \%$ reported feelings of misery and depression, $20 \%$ described feelings of self-depreciation, $7 \%$ reported suicidal feelings and $25 \%$ had ideas of reference.

(v) Hyperkinetic disorder: This disorder was found only in one male from group I. A study among boys on probation, in Canada, reported that those who were hyperactive tended to be more antisocial(25).

\section{CONCLUSIONS}

This study showed a high prevalence of morbidity (44.4\%), and 15 different types of deviant behaviours by the children and young persons appearing in the Nairobi juvenile court. These children and young persons definitely need urgent psychological and psychiatric management as stipulated in Section 18, CAP 141 of The Laws of Kenya. The Children's and Young Persons Act states "if it appears to the court on the evidence of a medical practitioner that a child or young person, although not of unsound mind, requires or may benefit from mental treatment the court when making a probation order against him, may require him to undergo mental treatment at the hands or under the direction of a medical practitioner for a period not exceeding twelve months, subject to review by the court, as a condition of the probation order."

\section{RECOMMENDATIONS}

Probation and Children Department officials require more training in the field of psychiatry so as to be able to identify psychiatric morbidity in children on first contact. This will enable them to adequately advise the court in the proper referral of such cases for further psychiatric assessment and treatment as necessary.

The Juvenile court officers (Judiciary, Prosecution, Probation and Children Officers) should be more sensitised to recognise psychopathology more readily and dispose these cases, when and where indicated, as prescribed by relevant statutes for specialised psychiatric assessment and management.

Forensic psychiatric input in the juvenile courts should be more regularly provided by qualified psychiatric personnel assigned to the court in order to screen for PM in the children and young persons prior to disposal of the cases by courts. The aim should be 
the benefits acheived from mental treatment and not just on the "soundness of mind" of the children appearing in the said court as per Section 18 of CAP 141. This screening process shall assist in decongesting the juvenile court by expediting the disposal of the mentally disordered children and young persons.

Children with delinquent behaviour and history of substance use should be identified in the school years and placed into community-based programmes which should include vocational training, increased recreational activities, teaching and enhancement of good social skills as well as life philosophy and theology so as to pre-empt maladjustment.

Court appearances with suspended sentence, as a deterrent to deviant behaviour should be introduced.

Juvenile courts should be transformed into Family Courts in order to effectively execute court recommendations affecting in-community rehabilitation.

\section{FURTHER RESEARCH}

Since this was a point prevalence study, longitudinal studies could be done by assessing PM at the juvenile court and then changes of PM in the same population, over a period of time. This may involve institutional and community-based longitudinal studies of such study population groups.

A high percentage of PM $(44.4 \%)$ was found in this study, it is hereby recommended that a research on the prevalence of PM among children and young persons who are living in the streets as their natural habitat be conducted in order to further elucidate the degree and pattern of PM in the deviant youth in Kenya.

\section{ACKNOWLEDGEMENTS}

To all members of staff of the Probation and Children's Departments, Ministry of Home Affairs, Nairobi, Kenya for their undeniable assistance during this study. This work was in part financed by $\mathrm{m} / \mathrm{s}$ Solvay Pharma through Phillips Pharmaceuticals Limited, Kenya.

\section{REFERENCES}

1. Russel, D.H. Juvenile delinquency. Psychiatry Annal. 1975; 5:3-13.

2. Robbins, L. Deviant children grown up. The Waverly Press Inc., Baltimore. 1966.

3. Kaplan, H.I., Saddock, B.J. and Grebb, J.A. Synopsis of Psychiatry 7th Edition. Williams and Wilkins, Baltimore, 1994.
4. Lucien, B. Psychiatric aspects of child delinquency. Bulletin World Health Org. 1957; 3: 63-162.

5. Snyder, C. Future child. Winter. 1996; 3: 140-146.

6. Torome, S.T. Delinquent child in proceedings of Kenya Paediatric Association Scientific Seminar. UNICEF/ Government of Kenya, 1985.

7. Christiansen, K.O. A Preliminary study of criminality among twins. Biosocial basis of criminal behaviour. Gardener Press New York. 1977; 89-108.

8. Alm, P., Klinteberg, B., Humble, K. et al. Psychopathy, Platelet MAO activity and criminality among former juvenile delinquents. Acta Psychiatr. Scand (Denmark). 1996; 94: 105-111.

9. Eysenck, H.J. Crime and personality. Routledge and Kegan Paul, 3rd Edition: London. 1964.

10. Gelder, M., Gath, D. and Mayuo, R. Oxford textbook of psychiatry. 2nd Edition. Oxford University Press, Oxford. 1993.

11. Rutter, M., Tizard, J. and Whitmore, K. Education, Health and Behaviour. Longmans - London. 1970.

12. Bond, M.R. The psychiatry of closed head injury. Oxford University Press: Oxford, 1984.

13. Ferguson, D.M., Lyriskey, M.T. and Horwood, L.J. ChristChurch Health and Development Study. New Zealand. J. Child Psych/Psychiat. 1997; 24: 533-553.

14. Treiman, D.M. and Delgado-Escueta, A.V. Violence and epilepsy: A critical reviev." Recent Advances in Epilepsy. 1983; 1: 38-43.

15. West, D.I. and Farrington, D.P. Who becomes delinquent? Heinemann: London, 1973.

16. The children and young persons Act (1963). Laws of Kenya Chapter 141. The Kenya Gazette. 1963; Vol. VIII, Supp. 8: $73-118$,

17. Gatangi, A.S.M. Psychiatric morbidity in children and young persons admitted into an approved school in Nairobi. MMed (Psych.) Dissertation U.o.N., 1987.

18. Kang'ethe, R.N. The frequency, pattern and recognition of childhood psychiatric morbidity among children attending Kawangware Health Centre. MMed (Psych.) Dissertation, U.o.N., 1988.

19. Mwangi, S. Psychiatric morbidity among children in Undugu Society of Kenya Homes. MMed (Psych.) Dissertation, U.o.N., 1996.

20. Mwangi, N. A comparative study of psychiatric morbidity in rural and urban primary school students. MMed (Psych.) Dissertation, U.o.N., 1996.

21. Minde, K. Child psychiatry in developing countries. J. Child Psych. Psych. 1976; 17: 79-83.

22. Adamakoh, C.C. The disturbed child in Ghana. paper presented at the Association of Psychiatrists in Africa Workshop. 1973.

23. Izuora, G.E.A. Mental health of children in developing countries. Proceedings, 2nd Pan African Psychiatric Workshop, Mauritius. 1970.

24. Olatawura, M.O. Child Psychiatric Disorders in IbadanNigeria. Nigeria J. Paediatrics. 1976; 3: 9.

25. Rutter, M. and Giller, H. Juvenile delinquency - trends and perspectives. Penguin Publication, Middlesex, 1983. 
East African Medical Journal Vol. 80 No. 6 June 2003

CORONARY HEART DISEASE AND ITS ELECTROCARDIOGRAPHIC MANIFESTATIONS IN WESTERN KENYA

M.S. Jablonski-Cohen, MD, Visiting Lecturer, Moi University Faculty of Health Sciences, Department of Internal Medicine, Assistant Director of ECG Services at Moi Teaching and Referral Hospital, J. Kosgei, Medical student (5th year), A. J. Rerimoi Medical student (5th year) and J. J. Mamlin, MD, Professor, Moi University, Faculty of Health Sciences, Department of Internal Medicine, Director of ECG Services at Moi Teaching and Referral Hospital, P.O. Box 4606 Eldoret, Kenya

Request for reprints to: Dr. M. S. Jablonski-Cohen, Chief Residents' Office, The Miriam Hospital, 164 Summit Ave., Main Bldg, Room 344 Providence, RI 02906, USA

\title{
CORONARY HEART DISEASE AND ITS ELECTROCARDIOGRAPHIC MANIFESTATIONS IN WESTERN KENYA
}

\author{
M. S. JABLONSKI-COHEN, R. J. KOSGEI, A. J. RERIMOI and J. J. MAMLIN
}

\begin{abstract}
Objective: To review the literature on coronary heart disease (CHD) and its electrocardiogram (ECG) manifestations in Eastern Africa and provide medical education by increasing awareness and strengthening recognition skills of myocardial infarction (MI) through discussion of key features from representative ECGs selected from the Moi Teaching and Referral Hospital (MTRH) ECG service in Eldoret, Kenya.

Data source: Peer reviewed published articles found using a Medline search. ECGs were reproduced with one complex from each of the 12 standard leads, without patient's name or other identifying information.

Conclusion: CHD and its risk factors are increasing in prevalence in Eastern Africa over recent years. The ECG remains integral to the diagnosis of acute coronary syndromes, including MI. Representative ECGs from MTRH demonstrate the various features of the common anatomical distributions of MI, enabling medical education. Recognition of CHD and its ECG manifestations is one step on the path to decreasing resultant morbidity and mortality.
\end{abstract}

\section{INTRODUCTION}

Although coronary heart disease is a well established leading cause of morbidity and mortality in the developed world, previous studies have shown that it has been uncommon in many parts of Africa $(1,2)$. However, in several African countries, CHD and its ramifications are being increasingly recognised $(3,4)$. This increase is likely secondary in part to the impact of urbanization, and with it the change of traditional diet and lifestyles evidenced most rapidly by more affluent segments of the population(4-6), as well as acquisition of diagnostic technologies and increasing numbers of tertiary health care centers(3). Undeniably, a majority of the population in Africa suffers from infectious diseases and malnutrition, but with the development of modern cities in African countries, a health population afflicted mainly by diseases of lifestyle and affluence, such as stroke and CHD, becomes increasingly prevalent(1).

Comparative to other cardiac diseases, there is a paucity of literature regarding coronary artery disease in Kenya and even less on ECG manifestations of the same. A Medline search conducted for this review produced only a few articles. More prominent causes of heart disease in black Africans are hypertension, rheumatic fever, congenital heart disease, and cardiomyopathy, with CHD responsible for a smaller but growing proportion( 7,8$)$, up to $6 \%$ of all cardiovascular diseases(9). The lack of data is likely due in part to limitations in technology and availability of diagnostic tests.

Much epidemiological research has been done worldwide in identification of coronary artery disease risk factors in order to prevent morbidity and mortality. The major risk factors include hypertension, dyslipidemia, and tobacco use, particularly cigarette smoking. Many experts also consider physical inactivity, obesity, and diabetes mellitus to be major risk factors. Additional associated risk factors include; male gender, heavy alcohol use, family history of premature coronary disease, left ventricular hypertrophy, and elevated levels of homocysteine or fibrinogen. There are investigations currently beign undertaken to investigate the association of various other factors like hyperuricaemia with an increased risk of cardiovascular disease.

Recent literature from studies done at hospitals in Kenya, have shown that both risk factors for CHD and CHD itself are increasing(1). Yonga et al found a high prevalence of obesity, hypercholesterolaemia, cigarette smoking, and ECG evidence of left ventricular hypertrophy ( $\mathrm{LVH})$ in a hospital-based report of risk factors in Nairobi(1). An epidemiological survey of 145 admitted patients in October 2001 conducted at a referral hospital in Kenya found that hypertension was the most common discharge diagnosis assigned to 
$15.9 \%$ of patients (Cohen, 2003; personal communication). In this same study by Cohen, diabetes was diagnosed in $6.9 \%$ of patients. A risk factor thought to be pertinent to Africans specifically is haemoglobin $\mathrm{S}$ or $\mathrm{C}$ trait, especially in patients with CHD but normal angiography(9). Haemoglobin S trait is thought to have a role in the formation of microthrombi, but this as well as the role of haemoglobin $\mathrm{C}$ needs to be further investigated(9).

Coronary heart disease is typically manifested clinically by myocardial infarction, angina pectoris, congestive heart failure, and cardiac death. Atherosclerosis is linked to almost all causes of CHD, beginning with fatty streaks in adolescence and progressing to plaques in early adult life, finally resulting in coronary occlusions and cardiac events in middle and later adulthood. Myocardial infarction (MI) usually results from coronary artery occlusion from rupture of an atheromatous plaque. However, in some patients, MI results from coronary emboli, thrombotic disease, coronary vasculitis, vasospasm, ostial occlusion, congenital anomalies, or trauma. MI in indigenous Africans shows similar characteristics to patients less than 40 years of age in the west; infarction is frequently the first manifestation of disease, and normal coronary angiography is often found(7,9).

Myocardial infarction and ECG manifestations: Myocardial infarction often clinically presents as acute substernal chest pain lasting more than 30 minutes. Patients often describe the pain as being severe, crushing or squeezing; often there is radiation down the left arm, into the neck, teeth, or jaw. Associated symptoms of nausea, dyspnoea, diaphoresis, weakness, palpitations or a sense of impending doom may be present. In some cases, especially in elderly or diabetic patients, MI may occur without chest pain, also known as a "silent MI". In these patients symptoms may include mental status changes or gastrointestinal symptoms. Diagnosis of MI is based on history, physical examination, ECG findings, and a rise in cardiac enzymes.

The ECG remains integral to the diagnosis of acute coronary syndromes. Through reading the ECG, one is able to get an idea of the infarct's scope (transmural vs subendocardial), localization (anterior versus inferior), and timing (acute versus chronic). Persistent dynamic changes on serial EKGs consistent with ischaemia and infarction improve the diagnostic ability to determine the presence of MI.

The ECG of a normal heart usually has an isoelectric ST segment. With transmural infarcts, the ST segment is usually elevated. When ischaemia and infarct occur in the subendocardium, the overlying ECG leads usually demonstrate ST segment depression. The ECG is helpful in localizing the region of infarct in the heart, and subsequently which of the main coronary arteries was involved. Figure 1 illustrates the anatomy of the coronary arteries and the different areas of the heart that are supplied. It is important to note that in approximately $90 \%$ of people there is right dominance with the posterior descending artery (PDA) branching off the right coronary artery (RCA). In the remaining $10 \%$ of people, the PDA branches off the left circumflex artery (LCA). This obviously has implications for the resulting pattern of infarct seen on the ECG.

\section{Figure 1}

Anatomy of the major coronary arteries

In general, several statements can be made about the pattern of transmural infarction on ECG. With acute transmural anterior wall infarct one or more of the precordial leads (V1-V6) are affected. To break this down further, if leads V1- V3 are solely affected, an anteroseptal infarct has occurred supplied by the left anterior descending artery (LAD). Leads V4-V6 are representative of apical or anterolateral ischaemia supplied by the LCA; leads 1 and aVL, V5 and V6 are indicative of a lateral infarct, also supplied by the LCA. Both the LAD and the LCA branch off the left main coronary artery. Leads II, III, and aVF are affected with inferior infarct supplied by the PDA. Posterior wall infarctions, which are sometimes seen with inferior wall infarctions and are caused by lesions in either the RCA or the LCA, would show ST elevations in leads placed over the back of the heart (V7-V9). However, in the standard 12 lead ECG, posterior infarction is indirectly recognised by reciprocal ST depressions in leads V1-V3 and tall $\mathrm{R}$ waves in leads V1 and V2. Right-sided precordial leads (V4R, V5R) are demonstrative with ST elevations when there is right ventricular infarct supplied by the RCA. With the exception of right ventricular infarct, the other infarct patterns reviewed pertain to left ventricular infarcts.

The ECG is also helpful in determining the 
approximate time of infarct. An acute transmural infarct is usually characterised by elevation of the ST segment, however the earliest change, which is not always seen, is the development of hyperacute or peaked $\mathrm{T}$ waves. Reciprocal changes are sometimes seen during the initial period, often seen as depressions of the ST segments in the leads opposite to the area of acute infarction. For example, reciprocal changes are seen in the inferior leads with anterior wall myocardial infarctions. Then there is ST segment elevation, with initial $\mathrm{Q}$ wave development and loss of $\mathrm{R}$ wave amplitude. As time passes, the infarct evolves on the ECG. Usually, the ST segment returns to the isoelectric baseline, $\mathrm{R}$ wave amplitude becomes reduced and the $Q$ waves deepen. T waves often become inverted; this may resolve after days or weeks or persist for an indefinite period. These changes occur within the first hours to few weeks after the event.

An infarction of indeterminate age or that occurred remotely, is characterised by $\mathrm{Q}$ waves in the area of infarction that are typically deep $(>1 \mathrm{~mm})$ and broad ( $>0.04$ seconds). There are often associated inverted or flattened $\mathrm{T}$ waves. In some cases, there may be no $\mathrm{Q}$ waves; in these cases there is usually loss of $\mathrm{R}$ wave amplitude or in the case of the precordial leads, poor $\mathrm{R}$ wave progression ( $\mathrm{R}$ wave amplitude does not increase from leads V1-V6). In most cases, the ST segment is isoelectric, however, occasionally ST segments can remain elevated from the baseline. Possibilities to consider are aneurysmal formation or wall motion disorders (akinesis or dyskinesis). An old posterior wall infarction is characterised by tall $R$ waves in V1-V2. However, other causes for tall $R$ waves in these leads must first be excluded. The findings of $\mathrm{Q}$ waves in the posterior leads (V7- V9) can help confirm this infarct location.

One must be careful to distinguish ischaemia and infarction from other conditions that can produce $\mathrm{Q}$ waves, T wave changes, or ST segment elevations or depressions. Q waves can also be seen in patients with cardiomyopathies of non-ischaemic origin, ventricular hypertrophy, and ventricular conduction disorders like left bundle branch block. Some causes of $\mathrm{T}$ wave inversions include ventricular hypertrophy, cardiomyopathy, and cerebrovascular injury. Digitalis, ventricular hypertrophy, and hypokalemia can all cause ST depression. ST segment elevations can occur with acute pericarditis or myocarditis, or as a normal variant.

Discussion of ECGs at MTRH: In order to decrease morbidity and mortality from CHD, awareness, recognition and diagnosis are essential. Therefore, we present this review of ECG manifestations of myocardial infarction and ischaemia of select ECGs from the service at MTRH in Eldoret, Kenya.

Figure 2 shows a 12 lead ECG from a 52-yearold man illustrating an old anterolateral infarct in the distribution of the LCA. Note the $\mathrm{Q}$ waves in leads
I, aVL, V4- V6 along with T wave inversions in this same distribution. Accordingly there is lack of $\mathrm{R}$ wave progression precordially.

\section{Figure 2}

Old anterolateral infarct in the distribution of the LCA. Note $Q$ waves in leads I, avl, V4-V6 and T wave inversion. Poor $R$ wave progression precordially

Figure 3

Acute inferior wall infarct. Note ST elevations in leads II, III and aVF and $Q$ waves in leads III and aVF. Reciplrocal changes are present anteriorly (ST depressions VI- V5 and aVL)

Figure 3 is an example of a 12 lead ECG from a 77-year-old woman with an acute inferior wall infarct resulting from occlusion of the PDA with right coronary dominance. The patient was admitted to the medical ward with complaints of diaphoresis and epigastric pain and found to be hypertensive with an elevated blood sugar level. Of note, one of the authors (M.J.) was leading rounds when this patient was presented; MI was not one of the differential diagnoses formulated by the team. The ECG was done immediately as the patient 
was still symptomatic and also complaining of left leg numbness and dyspnoea. Note the ST elevations in leads II, III, and aVF and Q waves in leads III and aVF. Reciprocal changes are also present anteriorly as evidenced by the ST depressions in leads V1 - V5 and aVL. Also, there is a prolonged PR interval representing first degree atrioventricular block which can be seen with inferior infarctions as a result of increased vagal tone.

Figure 4 shows a 12 lead ECG from a 64-yearold man demonstrating a bifasicular block (right bundle branch block and left anterior hemiblock) and an old anterior infarction likely secondary to occlusion in the left main coronary artery. Note the Q waves in leads V1- V5. As the infarct has affected a large portion of the anterior wall, it is most likely responsible for the bifasicular block.

Figure 5 shows a 12 lead ECG from a 60-year-old male with an old anteroseptal infarct most likely secondary to occlusion in the LAD. Note the presence of $\mathrm{Q}$ waves in leads $\mathrm{V} 1$ - V3 and poor R wave progression.

\section{Figure 4}

Old anterior infarction with bifasicular block. Note $Q$ waves in leads VI-V5

Figure 5

Old anteroseptal infarct. Note $Q$ waves in leads VI-V3 and poor $R$ wave progression
Figure 6 shows a 12 lead ECG that illustrates diffuse ST elevations. Infarct is unlikely, however, as the changes fail to follow the anatomical distribution of the coronary arteries and there are no reciprocal changes or $\mathrm{Q}$ waves. PR segment depression and tachycardia are also present further supporting a diagnosis of pericarditis.

\section{Figure 6}

Pericarditis. Note diffuse ST elevations PR segment depression and tachycardia
Figure 7 shows a 12 lead ECG from a 39-yearold male outpatient with a history of diabetes mellitus, hypertension, and complaint of chest pain. It demonstrates an acute massive infarct in the distribution of the left main coronary artery with left dominance. Note the ST elevations in leads I, aVL, II, aVF, V2 - V6 and Q waves in the same distribution. Though the changes are diffuse, this should not be confused with pericarditis, in which $\mathrm{Q}$ waves are not present.

\section{Figure 7}

Acute massive infract versus Myocarditis. Note ST elevations in leads I, aVL, II aVF, V2-V6 and $Q$ waves in the same distribution 
Without serial ECGs, a diagnosis of myocarditis cannot be excluded. Myocarditis can simulate an infarct pattern on ECG in some patients with both regional ST elevations and Q waves. In several of the leads, notably I, II, and aVF, there appears to be some depression of the PR segment. Some possibilities include an atrial current of injury or Dressler's syndrome, an infrequently occurring post-myocardial injury pericarditis which may begin from a few days to six weeks after an MI.

\section{Figure 8}

\author{
Anterolateral subendocardial infarction. Note deep ST \\ segment depressions in leads V4-V6 and mild ST \\ depression in the unferior lead (II, II, aVF)
}

discussed above, and as more diagnostic centers and testing become available, it is essential to have physicians and medical personnel well trained in the recognition of both the clinical and ECG manifestations of ischaemia and infarction. At MTRH, greater than $90 \%$ of myocardial infarctions were not suspected prior to diagnosis on ECG (Mamlin, 2003; personal communication). Clearly, there is a need for increased awareness of the acute coronary syndromes. Eventual goals for western Kenya and Africa, in general, include increasing the availability of therapeutic facilities such as telemetry and coronary care units (CCUs). Morbidity and mortality from acute MI has been significantly reduced by the introduction of CCUs (10). Attention must be given to this growing health problem so that detection of CHD occurs before MI or sudden death.

\section{ACKNOWLEDGMENTS}

To Dr. Jane Carter, Dr. J. Cohen, and Dr. D. Shaffer for editing advice and assistance, as well as Professor J. Nshaho, Ms. J. Ciszkowski, and the library and printing units at MUFHS for their help in procuring the supporting resources and articles.

\section{REFERENCES}

1. Yonga, G.O. Development of risk factors for coronary artery disease in Africans. East Afr. Med. J. 1998; 75: 493-494.

2. Kadiri, S. and Salako, B.L. Cardiovascular risk factors in middle aged Nigerians. East Afr. Med. J. 1997; 74: 303-306.

3. Muna, W.F.T. Cardiovascular disorders in Africa. World Health Statistics Quarterly. 1993; 46:125-133.

Figure 8 shows a 12 lead ECG from an adult woman which demonstrates changes consistent with an anterolateral subendocardial infarction with decreased blood supply from the LCA. Note the deep ST segment depressions in leads V4 - V6. There are some mild ST depressions in the inferior leads (II, III, aVF) which may be significant of ischaemia, perhaps with left coronary dominance, or may be non-specific.

\section{CONCLUSIONS}

Before Africa becomes part of the epidemic affecting the developed world, measures should be taken to prevent CHD from becoming a major health problem. Along with the obvious goals of public education campaigns and preventive medicine to enable primary and secondary risk factor reduction, accurate diagnosis is essential so that effective treatment can be delivered. With the increasing prevalence of CHD as
4. Gebre-Yohannes, A. Coronary heart disease risk factors among blood donors in Northwest Ethiopia. East Afr. Med. J. 1998; 75:495- 500 .

5. Watkins, L.O. Coronary heart disease and coronary disease risk factors in black populations in underdeveloped countries: the case for primordial prevention. Amer. Heart J. 1984; 108:850-862.

6. Seedat, Y.K., Mayet, F.G.H., Latiff, G.H. and Joubert, G. Study of risk factors leading to coronary heart disease in urban Zulus. J Hum. Hyperten. 1993; 7:529-532.

7. Anabwani, G.M. Heart disease in Africa: What is known? East Afr. Med. J. 1996; 73:213-214.

8. Akinkugbe, O.O, Nicholson, G.D. and Cruickshank, J.K. Heart disease in blacks of Africa and the Caribbean. Cardiovasc. Clin. 1991; 21:377-391.

9. Bertrand, E. Coronary heart disease in Black Africans: An overview. East Afr. Med. J. 1995; 72:37-41.

10. Abdul-Mohsen, MT, AI-Quorain, A, Al-Hamdan, A.A., Husain, A, Qutub, H, and Ladipo, G.O.A. Clinical profile of patients admitted to the coronary care unit with possible myocardial infarction without diagnostic ECG and/or enzyme changes. East Afr. Med. J. 1993; 70:777-781. 
East African Medical Journal Vol. 80 No. 6 June 2003

NOISE INDUCED HEARING LOSS AMONG INDUSTRIAL WORKERS IN DAR ES SALAAM

B.M. Minja MBChB (EA), MMed (Surgery) MSc (ORL), N.H. Moshi, MD, MMed (Surgery) MSc (ORL), Department of Otorhinolaryngology, Muhimbili

University, College of Health Sciences, P.O. Box 65001 Dar es Salaam, Tanzania. P. Riwa, MD, MMed, Ministry of Labour, Dar es Salaam, Tanzania

Request for reprints to: Dr. N.H. Moshi, Muhimbili National Hospital, P.O. Box 65001, Dar es Salaam, Tanzania

\title{
NOISE INDUCED HEARING LOSS AMONG INDUSTRIAL WORKERS IN DAR ES SALAAM
}

\author{
B.M. MINJA, N.H. MOSHI and P. RIWA
}

\begin{abstract}
Objectives: To determine whether sound in the study areas was of sufficient intensity to cause hearing loss and if so whether those exposed have been affected and to determine whether workers/employees in the study areas were aware that sound can cause hearing loss and if so whether they knew that this can be prevented by ear protection.

Design: Cross-sectional study

Setting: Industrial area A and B randomly selected from among industries in Dar es Salaam.

Subjects: One hundred and fifty workers from area $A$ and fifty two employees from area B.

Method: A questionnaire was filled and had their hearing thresholds measured by a pure tone audiometer machine.

Results: In both study areas the noise levels were above the safe limit of $85 \mathrm{~dB}(\mathrm{~A})$. In area $A 28$ workers and in area $B$ eight employees had noise induced hearing loss. In area $\mathrm{A} 81.1 \%$ of the workers and in area $\mathrm{B} 85 \%$ of the employees knew that noise causes hearing loss. All workers/employees from both study areas knew that noise induced hearing loss could be prevented by some form of ear protection.

Conclusion: Workers/Employees exposed to noise above $85 \mathrm{~dB}(\mathrm{~A})$ will eventually develop hearing loss. Workers/employees are aware of this hazard. There is therefore a need to educate those exposed on how best to protect their ears from the hazard and provide them with protective gear.
\end{abstract}

\section{INTRODUCTION}

The global prevalence of disabling hearing impairment is estimated to be $2.2 \%$. Tanzania with a population of approximately $30,000,000$ is expected to have 660,000 people with disabling hearing impairment. This assumes, of course, that preventable causes of hearing impairment including ear infections, infectious viral diseases such as mumps, measles and rubella among others are controlled at the same level as in the developed countries of the World(1).

Noisy environments are hazardous to the hearing. It is now well established that exposure to noise of sufficient intensity and duration damages the hearing of those exposed. Sound levels of less than $75 \mathrm{~dB}(\mathrm{~A})$ are unlikely to cause damage to hearing. However, sound levels of $85 \mathrm{~dB}(\mathrm{~A})$ and above for durations of eight hours per day causes damage to the hearing after many years of exposure(2).

The damage to hearing occurs at the level of the cochlear and therefore sensory in nature. In the initial stages, derangement of the hair cells takes place and this leads to temporary threshold shift (TTS). With prolonged exposure permanent damage to the hair cells takes place leading to permanent threshold shift (PTS). While TTS is reversible with withdrawal of the affected person from the hazardous noisy environment, PTS is irreversible.

The frequency centred around the $4000 \mathrm{~Hz}$ is the one initially involved despite the spectra and temporal characteristics of the noise(3). Following this, continued exposure leads to involvement of the higher frequencies giving the typical down slop audiogram.

Noise induced hearing loss is among the top three causes of hearing impairment in Africa(4). This hearing loss is acquired at industrial or social level. Audiological screening of industrial workers in a textile factory in Dar es Salaam has shown that $25 \%$ of the employees exposed to the noise for eight hours of work daily for a period of over five years were found to have permanent threshold shift on pure tone audiometry. The noise level was persistently above $85 \mathrm{~dB}(\mathrm{~A})$.

This study was designed to answer the following questions:

(i) Is noise in the study area of enough intensity to cause damage to hearing?

(ii) If the noise intensity in the study area is higher than $85 \mathrm{~dB}(\mathrm{~A})$ has it affected those exposed?

(iii) Are the workers/employees in their respective industry aware that noise can damage their hearing?

(iv) If the workers/employees are aware that noise can damage their hearing are they using ear protectors? 


\section{MATERIALS AND METHODS}

Two study areas A and B were randomly selected from among the industries in Dar es Salaam.

Study area A: This industrial area is situated in the center of the Dar es Salaam city. The area covered by this is approximately quarter of a square kilometer and the activities taking place in the open include metal fabrication, black smithery, carpentry and tailoring of motor vehicle accessories. Within the same area, there are small shops for marketing the products. The activities involve hammering metal, welding, wood joinery and saw milling as well as grinding of grain.

The whole area was divided into 140 sections as shown on diagram I. In each of the sections, mixed activities including woodworks, hammering of metal and joinery of furniture takes place. The activities are carried out by the various owners of the industries and these industrialists work for ten to twelve hours per day depending on the demand. An apprenticeship take place at almost all places whereby primary school leavers are engaged to have on the job training by their parents or friends so that they can eventually earn a living. Unlike engagement in offices, these people depend wholly on their sweat for survival. They are therefore very committed to their work. Medical examination is not a requirement for engagement in the respective industry/apprenticeship.

Study area B: This is situated in the industrial area of Dar es Salaam. It is organized into twelve sections. Section 1 accommodates offices, a plate section and a store. Sections 23 and 4 accommodate all the printing machines. Sections 5,6 , and 7 accommodate machines for the manufacture of crown corks, batteries and crates. Sections 8, 9, 10 and 11 is where smag, press and tin (debe) manufacturing activities take place. Sections 12 and 13 are for engineering works. In all these sections there is noise the intensity of which is commensurate with the activities taking place at the particular moment. Manufacturing takes place during the day and night in shifts of eight hours each.

Noise measurement in the study areas: In both industrial settings noise was measured using Integrating Sound Level Meter Type 2225 (Briiel \& Kjaer) and Sound Level Calibrator
Model 5274 at $1 \mathrm{KHz} 94 \mathrm{~dB}$. This work was done by a technician well trained in industrial safety from the Ministry of Labour. At each of the sections, two measurements were made; one during the peak of activities and another when there were no activities taking place. The noise levels were recorded for each of the sections.

Data collection on the exposed workers/employees: A questionnaire was designed for collecting information on all the employees/workers. The information sought included age, sex, occupation, duration of employment in the present job, number of continuous working hours per day, previous employment in a different factory or section, nature of work and duration of engagement.

Medical history of the worker/employee focused on previous ear discharge, mumps, measles, use of ototoxic drug including streptomycin and quinine, exposure to explosions and discotheque music, previous head injury or involvement in motor traffic accident.

Besides, the worker/employee was questioned regarding inability to hear clearly in a crowd, trouble in hearing the telephone, and need to ask people to repeat statements. Knowledge on harmful effects of excessive noise and the need to protect oneself was also assessed. All workers/employees had ear examination and the findings recorded. Pure tone audiometry was carried out on all the subjects in the morning before they stated work and having been out of the factory/ work place for sixteen hours or more.

The data collected was then processed and the results computer analysed.

\section{RESULTS}

Noise levels in the work place: Analyses of the noise levels (dBA) in the various sections of area $A$ according to the shed and activity taking place. The minimum peak noise level was $87 \mathrm{dBA}$ and the maximum was $116.5 \mathrm{dBA}$. The average noise level in this open area was 92.6dBA. As expected, maximum noise levels were recorded in the areas with hammering activities taking place. Offices had the least recorded noise levels (Table 1).

Table 1

Noise level measurement: Area B; metal box industry

\begin{tabular}{lllll}
\hline \multirow{2}{*}{ Section } & Point number & \multicolumn{2}{c}{ Noise Level } & \multirow{2}{*}{ Remarks } \\
& & Peak & 60 s Leq & \\
\hline Store & 1 & 92 & 62 & All machines \\
Printing & 2 & 93.5 & 79 & were working \\
“ & 3 & 94 & 80.5 & Press and counter \\
Crown and & 4 & 95 & 81.5 & machines were working \\
Batteries & 5 & 93 & 77 & Smag line \\
Crates & 6 & 100.5 & 85 & in operation \\
Smag press & 7 & 100.9 & 89.5 & \\
$\&$ & 8 & 92 & 76.5 & \\
Debe line & 9 & 91.5 & 77.5 & No machines in \\
“ & 10 & 99.5 & 80.5 & operation \\
\hline
\end{tabular}


Table 2 analyses the noise levels in the various working sections of Study Area B. As shown, the minimum noise level recorded was $87 \mathrm{dBA}$ and the maximum was $11 \mathrm{MBA}$. While in all sections of the factory the noise levels recorded were significantly above the recommended safe noise levels, the Crown and Batteries Case section had the highest noise level.

These results therefore have shown that in both industrial settings, the noise levels were higher than the safe limit of $85 \mathrm{dBA}$ and therefore hazardous to those exposed for prolonged periods of time.

Table 2

Noise level measurement: Area A

\begin{tabular}{|c|c|c|c|c|}
\hline \multirow{2}{*}{$\begin{array}{l}\text { Type of } \\
\text { activity }\end{array}$} & \multirow{2}{*}{ Shed(s) } & \multicolumn{2}{|c|}{ Noise levels } & \multirow[t]{2}{*}{ Remarks } \\
\hline & & Peak & 60s Leq & \\
\hline \multicolumn{5}{|l|}{ Metal } \\
\hline works & 1 to 10 & 104.5 & 75 & \multirow{5}{*}{$\begin{array}{l}\text { Hammering in } \\
\text { some shade } \\
\text { Other not operatin }\end{array}$} \\
\hline & 11 to 20 & 105 & 71.3 & \\
\hline & 21 to 30 & 116.5 & 86.8 & \\
\hline & 31 to 40 & 111.8 & 84.1 & \\
\hline & 41 to 50 & 112.5 & 83.7 & \\
\hline \multicolumn{5}{|c|}{ Woodworks } \\
\hline & 51 to 60 & 93 & 76.1 & \multirow{9}{*}{$\begin{array}{l}\text { All sections were } \\
\text { operational during } \\
\text { the measurement }\end{array}$} \\
\hline & 61 to 70 & 96.9 & 74.6 & \\
\hline & 71 to 80 & 91.1 & 68.8 & \\
\hline & 81 to 90 & 94.6 & 68.1 & \\
\hline & 91 to 100 & 98.7 & 71 & \\
\hline & 101 to 110 & 92.4 & 71.4 & \\
\hline & 111 to 120 & 87 & 69.4 & \\
\hline & 121 to 130 & 98.2 & 79.7 & \\
\hline & 131 to 140 & 96.4 & 73 & \\
\hline
\end{tabular}

\section{Effect of the noise on those exposed}

Area A employees: A total of 140 area A employees were investigated. Of these, complete data was available on 124 . The remaining 16 could not be available for pure tone audiometry because they had changed their working place and could not be traced. These were not considered in the data analysis.

Among those who had the investigation completed, $61(49.2 \%)$ were found to have normal hearing. Sixty three $(50.8 \%)$ were found to have audiogram patterns typical of noise induced hearing loss.

Among the employees with noise induced hearing loss $35(28.2 \%)$ had temporary threshold shift at $4000 \mathrm{~Hz}$. Their ages ranged from 19 to 68 years, had been exposed to the noise hazard for periods ranging from 1 to 31 years. The dip at $4000 \mathrm{~Hz}$ ranged from 40 to $70 \mathrm{~dB}$ HL. The majority of those affected (80\%) were engaged in metal fabrication activities while the rest $(20 \%)$ were carpenters.

There were $28(22.5 \%)$ employees whose pure tone audiogram patterns were typical of permanent threshold shift. These were aged between 17 and 58 years, had been engaged on their respective jobs for 1 to 31 years, their hearing loss at $8000 \mathrm{~Hz}$ ranged from 50 to $80 \mathrm{~dB}$ HL of these $82 \%$ were involved in metal fabrication while the remaining $18 \%$ were carpenters.

Area B employees: Fifty two employees were investigated. Among these, $43(82 \%)$ completed the study and the remaining nine $(18 \%)$ could not be available for audiometry because they had changed employers or had their services terminated.

Among those who completed the study, 20 (46.5\%) had noise induced hearing loss. The affected employees were aged from 28 to 60 years and had been exposed to the industrial noise for periods ranging from 8 to 29 years.

Regarding those with noise induced hearing loss, 12 (27.9\%) had audiograms with dips at $4000 \mathrm{~Hz}$ ranging from 40 to $55 \mathrm{~dB}$ HL consistent with temporary threshold shift.

In this category of employees, seven (58\%) were machine operators, two were technicians and the remaining were supervisors, feeders and line setters respectively. Permanent threshold shift was recorded in eight $(18.6 \%)$ of the employees with noise induced hearing loss. In this category, three were machine operators, two filter turners, 21 were engaged in printing and one was a line setter. Their ages ranged from 31 to 55 years and had been exposed to the noise hazard for periods ranging from 11 to 26 years. The hearing loss in this group was up to $70 \mathrm{~dB}$ HL at 8000 $\mathrm{Hz}$ at the time the examination was done.

Do those exposed know that noise can harm their hearing?: Knowledge about the harmful effects of noise among the area A workers was as shown on Table 3. The majority of the workers $(81.1 \%)$ responded that noise causes hearing impairment. The remaining gave various responses ranging from palpitations (6.2\%), ringing in the ears $(4.2 \%)$ drum perforation, increased blood pressure and even annoyance.

Table 3

Response to the question on effect of noise on hearing by area $A$ workers

\begin{tabular}{lcc}
\hline Response & Frequency & $\%$ \\
\hline Hearing loss & 77 & 81.1 \\
Palpitations & 6 & 6.3 \\
Ringing in the ears & 4 & 4.2 \\
Headache & 3 & 3.2 \\
Annoyance & 1 & 1.1 \\
Increased BP & 1 & 1.1 \\
Pain in the ears & 1 & 1.1 \\
Drum perforation & 1 & 1.1 \\
Can't explain & 1 & 1.1 \\
\hline
\end{tabular}


Table 4 analyses the responses by the area $\mathrm{B}$ workers to the same question. Eighty five per cent of the workers responded that noise causes hearing loss. The remaining had various responses such as noise causes disturbance, harm to the ear drum membrane, hypertension and even ulceration of the ears.

Table 4

Response to the question on effect of noise on hearing by area $B$ employees

\begin{tabular}{lcc}
\hline Response & Frequency & $\%$ \\
\hline Hearing loss & 33 & 87.0 \\
Disturbance & 1 & 2.6 \\
Drum rupture & 1 & 2.6 \\
Harms drum & 1 & 2.6 \\
Causes hypertension & 1 & 2.6 \\
Ulceration of the ears & 1 & 2.6 \\
\hline Total & 38 & 100 \\
\hline
\end{tabular}

Do those who know that noise can harm their hearing know how to protect themselves: Tables 5 and 6 analyse the responses of area A and B workers to this question respectively. In both groups they know how to protect themselves from the harmful effects of noise. While $91 \%$ of the area B employees know specifically that ear plugs are useful in protecting themselves from noise damage to their hearing, only $6.7 \%$ of the area A workers know this. However all know that some form of protection is necessary or useful. It will be noted that area $\mathrm{B}$ employees have a better educational background than the area A workers.

Table 5

Response to the question on how to protect oneself from the effects of noise by area $A$ workers

\begin{tabular}{lcc}
\hline Type of protective Gear & Frequency & $\%$ \\
\hline Ear muffs & 21 & 46.7 \\
Ear protection & 19 & 42.2 \\
Ear plugs & 3 & 6.7 \\
Cotton wool plugs & 2 & 4.4 \\
\hline Total & 45 & 100 \\
\hline
\end{tabular}

\section{Table 6}

Response to the question on how to protect oneself from the effects of noise by the area $B$ employees

\begin{tabular}{lcc}
\hline Type of protective gear & Frequency & $\%$ \\
\hline Ear plugs & 32 & 91 \\
Protection & 2 & 6 \\
Ear muffs & 1 & 3 \\
\hline Total & 35 & 100 \\
\hline
\end{tabular}

\section{DISCUSSION}

It is quite clear from the results that in both industrial settings, the noise level was above the $85 \mathrm{~dB}$ A level and therefore hazardous to the hearing of those exposed. On the average, the noise level at area A was $92.6 \mathrm{dBA}$ while that at area B was $100 \mathrm{dBA}$.

Indeed the effect of the noise on the employees in both industrial settings was quite significant and correlates well with the findings following examination of those exposed. Among the area A workers, 28.2\% and $22.5 \%$ had temporary and permanent threshold shift respectively. Similar results were observed on the area B employees of whom $27.9 \%$ and $18.6 \%$ had temporary and permanent threshold shifts respectively. As expected, those engaged in metal fabrication and operating machines were the worst affected when compared to those engaged in carpentry and other jobs.

It was gratifying to note that the majority of the employees in both industrial settings recognised that noise was harmful to their hearing. Of the area A employees, $79 \%$ knew that excessive noise causes hearing impairment. Similarly $85 \%$ of the area B employees knew that noise causes hearing loss. However, while $91 \%$ of the area B employees specifically knew that ear plugs were useful in protecting themselves from the harmful effects of noise, only $6.7 \%$ of the area $\mathrm{A}$ workers knew this. The only explanation for this difference is their respective educational background. area B employees are secondary school leavers while the area A workers are mostly primary school leavers or have not been to school.

The fact that the workers in both industrial settings recognise that noise causes harm to their hearing renders opportunity for intervention. Well informed of the means at hand to protect themselves, the risk to their hearing can be greatly reduced. Therefore there is need to educate workers engaged in noisy environments on the risk to their hearing and how to protect themselves. Along with this, such workers should be routinely examined so that those who develop temporary threshold shift can be detected early and withdrawn from the hazardous environment.

Apparently, employees in factories undergo medical examination before they are engaged. However, their hearing is not measured during the medical examination. This calls for serious consideration because among the employees there could be some with hearing loss before they are engaged. In this respect if eventually they claim for compensation it will be to the employer's disadvantage for these should have been identified before they are employed.

While medical examination is possible for those engaged in factories, the area A workers may not see the need for it. These workers are self employed and the majority are on the job training. It is therefore necessary to educate them on the risk of losing their hearing after long exposure as well as the available means of protecting themselves. 
Ideally, the noise in industries should be controlled within the safe limit of 85dBA and lower. In developing countries where the machines used are old and the economic situation is not permissive, replacement of the machines may not be possible. Therefore the most reasonable approach is to educate the workers on the need to protect themselves against noise in their respective work places.

In conclusion the noise level in area $\mathrm{A}$ and area B factory is above the safe limit of $85 \mathrm{dBA}$ and therefore hazardous to those exposed. In both industrial setting the noise had caused irreversible damage to $22.5 \%$ and $18.6 \%$ of area A and area B work force respectively. Unless withdrawn from the noise, the $50.8 \%$ and $46.5 \%$ of the area A and area B factory workers respectively are at risk of developing irreversible damage to their hearing. Workers/employees in these setting are, on the majority, aware that noise damages their hearing and that this can be prevented by using some form of protective gear including ear plugs. There is therefore need to educate those exposed on how best to protect themselves from the noise hazard.

We recommend that before employees are engaged into factories they should have ear examination and audiometry done as part of the medical examination. Education on the hazardous effects of noise and how to protect oneself should be given to all employees in noisy factories. This should be a requirement for all employers with noisy factories. Through health education, the Ministry of health should educate the public on the harmfull effects of noise. Regular examination of employees/workers in noisy environments is necessary so that those with temporary threshold shift can be identified early and appropriate action taken well on time.

\section{ACKNOWLEDGEMENTS}

We extend our sincere gratitude to the general managers of area A and B industrial estates in Dar es Salaam for allowing us to conduct this study in their respective areas. We would also want to thank Mr. A. Jacob, clinical officer at the industrial areas for coordinating the examination of the workers and to $\mathrm{Mr}$. A. Machemba for performing the audiometric tests.

\section{REFERENCES}

1. Report on The WHO Workshop on Prevention of Deafness and Hearing Impairment in Africa, Nairobi, Kenya. 1995; 10: 24-27.

2. The National Institute of Health Consensus Development Conference on Noise and Hearing Loss: Consensus Statement. 1990; 8: 1-24, 22-24.

3. Pierso L.L., Gerhardt, M. Rodriguez, G.P., Yanke, R.B. Relationship between outer ear resonance and permanent noise induced hearing loss: Amer. J. Otolaryngology. 1994; 15:37-40.

4. Report on the WHO Workshop on Prevention of Deafness and Hearing Impairment in Africa, Nairobi, Kenya. 1995; 10: $24-27$. 
East African Medical Journal Vol. 80 No. 6 June 2003

MOTHERS' KNOWLEDGE, ATTITUDES AND PRACTICES REGARDING ACUTE RESPIRATORY INFECTIONS IN CHILDREN IN BARINGO DISTRICT , KENYA

D.E. Simiyu, MBChB, MMed, Lecturer, E.M Wafula, MBChB, MMed Professor and R.W. Nduati MBChB MMed, MPH, Senior lecturer Department of Paediatrics and Child Health, College of Health Sciences, University of Nairobi P.O. Box 19676, Nairobi, Kenya

Request for reprints to: Dr. D.E. Simiyu, Department of Paediatrics and Child Health, College of Health Sciences, University of Nairobi P.O. Box 19676, Nairobi, Kenya

\title{
MOTHERS' KNOWLEDGE, ATTITUDES AND PRACTICES REGARDING ACUTE RESPIRATORY INFECTIONS IN CHILDREN IN BARINGO DISTRICT, KENYA
}

\author{
D.E. SIMIYU, E.M WAFULA and R.W. NDUATI
}

\begin{abstract}
Background: Control of acute respiratory infections (ARI) is a major public health problem in developing countries. Implementation of case management protocols requires participation of the community to reduce morbidity and mortality from ARI. Health education programmes can only be effective when designed to take into account the prevailing knowledge, attitudes and practices (KAP) of the community towards ARI in their children.

Objective: To determine the KAP of mothers regarding ARI in their children aged less than five years.

Design: Community based cross-sectional survey.

Setting: Baringo District, Kenya.

Subjects: Mothers with children aged 0-5 years were recruited following stratified random sampling in three areas of Baringo District to represent low, medium and high potential areas based on agricultural productivity.

Intervention: A mixed structured and unstructured questionnaire was administered to each of the respondent mothers by the investigator; with the help of an interpreter where necessary.

Results: A total of 309 mothers were interviewed. Their mean age was 31.5 years (range 16-51) and $34 \%$ had no formal education. Only $18 \%$ of mothers described pneumonia satisfactorily. $60.2 \%$ knew that measles is preventable by immunisation. $87.1 \%$ of the mothers said they would seek health centre services for severe ARI. Formal education had a positive influence on the KAP of the mothers.

Conclusion: The study reveals that the mothers had good knowledge of mild forms of ARI but not the severe forms. Their attitude to ARI was appropriate but subsequent practices were not. Low utilisation of health services for moderate ARI may result in continued high mortality because of delayed identification of seriously ill children.
\end{abstract}

\section{INTRODUCTION}

Acute respiratory infections represent an important cause of morbidity and mortality in developing countries. Together with malnutrition and diarrhoeal diseases, ARI ranks among the top three diseases in terms of morbidity and mortality worldwide(1).

Annual incidence of pneumonia in developing countries in children under five years is 70-100/1,000 rising to 500/1,000 among the malnourished(2,3). Pneumonia causes $30 \%$ of all deaths among under fives in developing countries(4). In developing countries, $80 \%$ of the pneumonias are due to bacterial pathogens and therefore the high mortality is preventable by use of appropriate antibiotics early in course of the disease(5). Using WHO recommended classification and case management protocols, diagnosis and management of moderate to severe ARI can be done without use of sophisticated equipment and by health workers with limited skills(6-8). Mortality from acute lower respiratory infections can be prevented through early diagnosis and management of moderate and severe acute lower respiratory infection(ALRI). In study conditions where active case finding is employed by visiting the homes, mortality is significantly reduced as the victims are identified early by the health workers(9). In practice it is not possible to employ active case finding as the resources are limited.

Passive case finding becomes the only option and requires active participation of parents or care givers. Mothers are usually the primary care providers for their children and their ability to recognise symptoms of ALRI determine the success of controlling mortality from this condition. Campbell et al in 1989 noted that it was possible for semiliterate or illiterate mothers with variable cultural 
medical beliefs to identify ALRI and seek treatment after brief health education $(7,10)$.

In Kenya, ARI is one of the leading causes of morbidity and mortality in young children. Most of the deaths take place outside the health facility suggesting that mothers and primary care givers lack skills in appropriate health seeking behaviour for the management of ARI. Community based studies are needed to identify the specific gaps in knowledge and attitudes towards ARI in order to make health education and advocacy messages for prevention of ARI mortality relevant.

The available outpatient data for Baringo District indicates that the leading causes of morbidity in order of importance are ARI, malaria and diarrhoeal disease. ARI accounted for $48 \%$ of outpatient and inpatient health care attendance in the district during the months of August to October 1990(11).

\section{MATERIALS AND METHODS}

Baringo District covers an area of 10,949 square kilometers. Altitude ranges from 1,000 to 3,000 meters above sea level. Apart from the south-west corner and the Tugen hills, the rest of the district is arid to semi-arid rangeland. Fifty one percent of the population are children below age 15 years. The district can be divided into low, medium and high potential areas based on land agricultural output, population density and per capita income.

The study was carried out in three areas representing the high, medium and low agricultural potential areas.

Sampling: Cluster sampling was employed so as to yield a sample representative of low, medium and high agricultural potential areas. Stratification was employed to include only households with children aged five years and less.

A list of all locations in each division was made and one selected randomly from each division. A list of sublocations in each sampled location was made and again one sub-location randomly selected from the low and high potential areas and two sub-locations in the medium potential area to represent the two divergent climatic conditions in this area.

From the existing four sub-locations, thirty clusters were randomly selected. The distribution of clusters by sublocation was weighted according to population density so that the lower density areas had more clusters. For each cluster selected, probability proportional to size was applied so that those clusters with more households had more of these included in the sample. A list of households in each cluster was made, stratified to only include households with children aged five years and less. The households were serially numbered from 1 and using a table of random numbers, simple random sampling was employed to select the study households.

Procedure: The mothers were interviewed to determine their knowledge of the causes of pneumonia, measles and cough. The researcher also sought to know whether there were traditional names for these conditions. The mothers were also asked to describe how they managed these conditions in their children. The mothers were also interviewed about their health seeking behaviour.

Two interpreters were selected from the pool of clerks in the district statistics office. The selection was based on their previous experience and familiarity with questionnaire administration. They were indigenous to the study area and doubled as guides. One of the selected interpreters in the absence of the other translated the English questionnaire into the vernacular. The other, without having read the English version, translated the vernacular script back into English. Any misinterpretations were identified and corrected with both interpreters by the investigator. The two day training was stopped when the investigator was satisfied after an exercise at the district hospital outpatient department.

The sub-chiefs asked mothers from each cluster to assemble at pre selected central points on selected dates. The mothers were informed to bring any ill children for medical attention on the selected dates if they so wished.

With the guide/interpreters, the investigator visited each center on the selected dates. The list of sampled households was used to identify respondents from each cluster. The questionnaire was administered to each of the respondents by the investigator with the help of an interpreter whenever necessary. At the end of each interview, all medical complaints of both mothers and children were dealt with by immediate treatment or referral to appropriate health facilities.

Mothers who were unable to attend were revisited after arrangement through the sub-chief. If any mother still didn't turn up on revisit she was presumed lost to the study. An effort was made to replace her by selecting another mother from the same cluster with a child/children aged below five years. No further effort was made when no suitable replacement was available on a revisit.

\section{RESULTS}

Three hundred and fifty five households with mothers of children aged $<5$ years were identified. A total of $309(87 \%)$ mothers were interviewed of the expected 355 . Their mean age was 31.5 years with a range from 16-51 years. One hundred and five (34\%) of them had no formal education. One hundred and sixty one $(52 \%)$ of the mothers said their children slept in the same area they cooked in. All used wood fuel for cooking.

Area of origin (low, medium or high potential) had no influence on the results.

Children who slept in the cooking area had more cases of ARI compared to those who did not sleep in the cooking area at the time of interview. However the difference was not significant (Table 1).

Knowledge attitudes and practises towards pneumonia: Inquiry from Kabarnet Hospital personnel and other health units in the study area revealed that they didn't know any local term for pneumonia. The community uses the word pneumonia. $96.1 \%$ of the mothers interviewed said they knew the disease called pneumonia. However, on asking them to describe it only $54(18 \%)$ did so satisfactorily. This included $15(5 \%)$ who described increased respiratory rate, $30(10 \%)$ difficulty in breathing 
and nine $(3 \%)$ cough. Two hundred and forty three women $(80 \%)$ described it as fever with no respiratory association (Figure 1).

Two hundred and seventy (87.5\%) thought pneumonia was caused by cold weather and avoidance of cold conditions would prevent it.

Table 1

Influence of sleeping quarters on number of ARI episodes

\begin{tabular}{lccc}
\hline & \multicolumn{3}{c}{ ARI Episodes } \\
\cline { 2 - 4 } & No & Yes & Total (\%) \\
\hline $\begin{array}{l}\text { Sleeping in } \\
\text { cooking area }\end{array}$ & 20 & 141 & $161(52.4)$ \\
$\begin{array}{l}\text { Not sleeping } \\
\text { in cooking area }\end{array}$ & 19 & 127 & $146(47.6)$ \\
\hline Total & $39(12.7 \%)$ & $268(87.3 \%)$ & $307(100$ \\
\hline
\end{tabular}

$\mathrm{X}^{2}=0.024 \mathrm{DF}=1 ; \mathrm{P}=0.877$ Yates correction; $\mathrm{P}=1.00$

Figure 1

Mother's description of pneumonia

Cough as symptom of pneumonia: The local name for serious cough related disease that was closest to description of pneumonia was "Ngotobjan". 97.8\% knew that cough could develop into a serious disease. Two hundred and thirty two $(75.1 \%)$ knew that cough was serious when the child developed an increased respiratory rate, difficulty in breathing or refusal to feed.

For a child with a serious cough (Ngotobjan), $97.8 \%$ said they would seek help in its management. The reasons for seeking any form of help were difficulty in breathing $143(46.3 \%)$, refusal to feed 65 (21\%), fever $56(18.2 \%)$ and rapid breathing 24 (7.8\%) in that order.

One hundred and eighty four $(59.8 \%)$ said they would seek help in form of traditional herbalist and non-prescription drugs, for the rest only 84 (27.2\%) would seek health center services. Presence of fever didn't alter this behaviour but when fever occurred alone without features of ARI 250 (81.7\%) utilised nonprescription drugs.

Knowledge attitudes and practises towards measles

Measles knowledge: All mothers interviewed said they knew measles and described it adequately. The local name for measles is "sarserek". $4.5 \%$ thought measles was caused by germs or recognised its contagious nature. All the others did not know the cause of measles. However $186(60.2 \%)$ mothers correctly knew that measles was preventable by immunisation while twenty two $(7.1 \%)$ thought it was preventable but not by immunisation. A significant number of mothers with at least primary education knew that measles was preventable compared to those with no education (Table 2).

Table 2

Education level and knowledge of measles prevention

\begin{tabular}{cccc}
\hline None(\%) & Primary(\%) & $\begin{array}{c}\text { Post } \\
\text { primary(\%) }\end{array}$ & Total(\%) \\
\hline
\end{tabular}

Education level

Preventable

\begin{tabular}{lcccc} 
Yes & $49(16)$ & $131(42)$ & $28(9)$ & $208(67.3)$ \\
No & $56(18)$ & $44(14)$ & $1(0.3)$ & $101(32.6)$ \\
\hline Total & $105(34)$ & $175(56.7)$ & $29(9.3)$ & $309(100)$ \\
\hline$X^{2}=36.222$ & DF $=2$ & $P=0.001$
\end{tabular}

Ninety eight percent knew that measles was a serious disease and 283(91.6\%) associated it with high mortality. The mothers were not fully aware of the complications of measles and they did not associate severe measles with respiratory symptoms.

Attitudes towards measles: The attitude towards measles was that it was a serious disease that required intervention. Of the one hundred and twenty three (39.8\%) mothers who didn't know measles was preventable by immunisation, their childrens' clinic cards were scrutinised. These showed that one hundred and one $(82 \%)$ of the children aged over nine months had actually received measles immunisation.

Measles practices: The mothers were told to describe what they do when a child with measles develops hoarsness or loss of voice. Only $42.2 \%$ said they would go to the health center for treatment. Forty six point six percent utilised herbs or off-counter drugs for management of measles croup (Figure 2). 
Figure 2

Practice in measles croup

Nutrition practise: Ninety seven point four percent of the mothers said they would continue feeding their ill children. $96.1 \%$ gave the food in liquid form such as milk, porridge or soup.

\section{DISCUSSION}

The term pneumonia as used in the study area is a label for fever rather than the actual disease in biomedical terms. The local community does not seem to have a specific terminology for pneumonia, the closest being "Ngotobjan" which literally translated means serious cough. As noted by other researchers, most rural communities don't seem to have an explanatory model of ALRI. Where this may actually be in existence, it would need medical anthropologists to determine it. As in the case of pneumonia, some cultures may use biomedical terminology to label an illness which is quite different from the biomedical equivalent(12).

The reasons given for seeking help for a child with Ngotobjan imply knowledge among some mothers of danger signs of ALRI. $75.1 \%$ recognised these signs but only $68.3 \%$ utilised health center services. Recognition of the features of moderate to severe ARI exemplified by difficulty in breathing led to more use of health center services than in case of mild ARI exemplified by cough. Recognition of early signs of ALRI is important for appropriate case management. Moderate ALRI for the purposes of this study was defined to include increased respiratory rate. This has been found by various workers to be a sensitive and specific predictor of ALRI(5,7). There was significant deficiency in knowledge and practices which could deter effective case management.

In this study mothers practices in moderate and severe ARI are inappropriate. The use of herbs and nonprescription medicine was widespread. Tupasi noted an almost similar trend in the Philippines. She found that mothers brought their children to hospital only when cough was accompanied by fever, weakness, inability to feed or the child became blue in colour(13). Health seeking behaviour can be enhanced by health education regardless of the mothers literacy level or cultural background as noted by Campbell et al(7). The widespread use of off-counter drugs as found in this study may be detrimental by drawing parents into a false sense of security and delay appropriate health seeking behaviour with timely management. The cost especially to the parents in the low potential areas could be enormous. The increased use probably reflects the advertisement pressure they face. In this study, the occurrence of fever alone was likely to result in use of non prescription drugs.

The knowledge of measles as a disease is universal in the study area. This is probably a reflection of its prevalence. Its contagious nature however was not mentioned prominently in its aetiology. This is surprising considering that many mothers in developing countries are in the habit of letting their children contract measles early by deliberately exposing them to other children with measles with the underlying belief that measles at a younger age has less mortality and/or severe morbidity.

Adequate immunisation together with good primary health care are essential for control of $\operatorname{ARI}(2,3)$. Immunisation coverage in the study area is good (above $85 \%$ including measles)(14). With an effective coldchain and correct administration, the measles vaccine results in very effective control of measles. In this study $34 \%$ of the respondents had no formal education. It appears that in the study area immunisation is carried out without adequate health education to the mothers. This is shown by the fact that among the mothers who thought measles is not preventable or preventable by means other than immunisation their childrens, cards revealed that most children above age nine months had actually been vaccinated against measles. A study in Port-eau prince in Haiti showed that the greater positive impact on mortality from measles by vaccination was in children borne to mothers who were illiterate and of low socio-economic status (15). In the study area, the knowledge of the preventable nature of measles needs to be enhanced.

Mortality from measles is frequently associated with respiratory complications either due to the virus itself or due to secondary bacterial invasion(2,3). Without prompting, the mothers in the study area didn't mention respiratory involvement although they were agreed on the high mortality associated with measles. Health seeking behaviour for measles respiratory morbidity was inappropriate with over half not taking the children to a health center.

The majority of mothers continued to feed their ill children. The importance of providing adequate nutrition and fluids for ill children is well understood. This should 
be in the most acceptable form to the child. It forms an important part of supportive care for ill children that may influence the outcome favourably $(3,6)$.

Study Limitation: Selection of the replacement mothers may have introduced some minor bias. The mothers who were motivated to come to the revisit interviews although not belonging to the identified sample may have had attributes that the non-respondents didn't have e.g. a well or ill child, different education level or age differences that led to this motivation. A total of thirty mothers $(9.7 \%)$ were replacements. Perhaps the good turnout was also because of the promised medical attention in a background of lack of drugs in the local health facilities. This lack of drugs may have had an influence on the responses to questions pertaining to practices. Some mothers may say they wouldn't go to a health center from the background of lack of drugs in these centres.

In conclusion the knowledge of mothers regarding ARI and measles in the study area is adequate. However attitude and practices are inappropriate for successful management.

We recommend health education to the mothers to: Enhance their knowledge of early signs of ALRI such as increased respiratory rate; Encourage early appropriate health seeking behaviour; Discourage inappropriate, at times harmful health practices, such as over the counter medication.

\section{ACKNOWLEDGEMENTS}

To Dr. K.C. Wafula for his assistance in carrying out the field work. J. Musya for help in data entry and analysis. The research was partly funded by UNICEF and Department of Paediatrics and Child Health, University of Nairobi through the child survival and development programme in Baringo District.

\section{REFERENCES}

1. Jellife, D. Paediatrics in: Morris King - editor. Medical care in developing countries. HrB. Oxford Univ. Press, 1966 Ch. 13.

2. A programme for controlling ARI in children: Memorandum from WHO meeting. Bull. Wld. Hlth. Org. 1984; 62: 47-58.

3. Wafula, E.M. and Onyango, F.E. ARI in developing countries. East Afr. Med. J. 1986; 63: 211-219.

4. Berman, K and Mcintosh, K. Selective primary health care Strategies for control of disease in the developing world XXI: ARI. Rev. of Infect. Diseases. 1985; 7: 516-522.

5. Wafula, E.M., Tukei, P.M. et al. How should primary health workers diagnose and treat ARI. East Afr. Med. J. 1984; 61: 736-744.

6. Clinical management of ARI in children A. WHO Memorandum. Bull. Wld. Hlth. Org. 1981; 59: 707-716.

7. Campbell, H., Byass, P. and Greenwood B.M. ALRI in Gambian children: Maternal perceptions of illness. Ann. Trop. Paed. 1990; 10: 45-51.

8. Usha, N., Katariya, S. and Walia, B.N.S. Simple clinical signs of ALRI. Trop. Doctor. 1990; 20: 158-160.

9. Mtango F.D.E. and Neuvians D. ARI in children under five years: Control project in Bagamoyo district, Tanzania. Trans. R. Soc. Trop. Med. Hyg. 1986; 80: 881-888.

10. Campbell, H., Byass, P., Forgie, I.M. and Lloyd-Evans, N. Clinical Signs of Pneumonia in children. Lancet. 1989; 1: 899-900.

11. Shan, F., Hart, K. and Thomas D. ALRI in children: Possible criteria for selection of patients for antibiotic treatment and hospital admission. Bull. Wld. Hlth. Org. 1984; 62:749-753.

12. Tupasi, T., Health Seeking Practices of Mother. Implication for ARI intervention. Report to WHO Technical advisory group on ARI Geneva. 1987.

13. Ministry of Planning and National Development Socioeconomic Profiles. Govt. of Kenya and UNICEF June. 1990.

14. The John Hopkins University. Institute of International Programmes ALRI and CSD in developing countries: Understanding the current status and direction for the 1990s. Workshop proceeding: Washington D.C U.S.A. 1089; 2-3. 
East African Medical Journal Vol. 80 No. 6 June 2003

POST PARTUM EMOTIONAL DISTRESS IN MOTHERS OF PRETERM INFANTS: A CONTROLLED STUDY

D.I. Ukpong, MBBS, FMCP. sych.(Nig.), Lecturer/Hon. Consultant Psyhiatrist, F.O. Fatoye, BSc(Hon.), MBChB, FMCPsych.(Nig.), Lecturer/Hon. Consultant Psyhatrist, Department of Mental Health, S.B. Oseni, MBChB, FMC Paed.(Nig.), Lecturer/ Hon. Consultant Paediatrician, Department of Paediatrics, A.O. Adewuya, MBChB, Registrar in Psychiatry, Department of Mental Health, College of Health Sciences, Obafemi Awolowo University, Ile-Ife, Nigeria

Requests for reprints to: Dr. D.I. Ukpong, Department of Mental Health, College of Health Sciences, Obafemi Awolowo University, lle-Ife, Nigeria

\title{
POST PARTUM EMOTIONAL DISTRESS IN MOTHERS OF PRETERM INFANTS: A CONTROLLED STUDY
}

\section{D.I. UKPONG, F.O. FATOYE, S.B. OSENI and A.O. ADEWUYA}

\begin{abstract}
Objectives: To investigate whether mothers of preterm infants experience more psychological distress than mothers of normal full term infants in the immediate postpartum period.

Design: Cross sectional prospective study of postpartal women using the Beck Depression Inventory(BDI) and the GHQ-30.

Setting: Neonatal intensive care units and the obstetric units of Wesley Guild Hospital, Ilesa or Multipurpose Health Centre, Ilesa(These are component Units of Obafemi Awolowo University Teaching Hospitals Complex, Osun State Nigeria).

Results: Of the 60 postnatal women recruited into the study, 33 mothers of preterm neonates formed the index group and $\mathbf{2 7}$ mothers of full term normal infants constituted the control group. More mothers of preterm neonates $(27.3 \%$ ) had GHQ-30 scores which categorised them as having significant emotional distress than mothers of full term normal infants $(3.7 \%)$. Similarly more mothers of preterm neonates $(15.1 \%)$ were more depressed than mothers of full term normal infants $(3.7 \%)$. These differences were found to be statistically significant when the mean scores of the two groups on the instrument swere compared.

Conclusion: These problems are not usually detected nor appropriately referred by the paediatrician/obstetrician to the psychiatrist. This has a number of implications for preventive psychiatry. A multidisciplinary approach is therefore essential in the detection and management of these problems.
\end{abstract}

\section{INTRODUCTION}

The postpartum period is a time when women run a high risk of developing psychiatric problems(1). The spectrum of disorders range from mild emotional disturbances at one extreme to florid psychosis at the other end. There is abundant clinical and research work dealing with these conditions(2-5). Some recent studies have demonstrated an association between peri-partum complications and postpartum mental disorders. Preterm delivery has also been implicated as a factor(6,7).

Infant mortality rate is still very high in many developing countries, including Nigeria, with neonatal deaths accounting for over half of such infant deaths(8). This may be responsible for the fatalistic attitude people in this environment have towards ill neonates(8). Neonatal intensive care units are relatively few in developing countries including Nigeria, and the facilities are usually inadequate due to the lean financial resources of most of these countries(9). With the reduced chances of survival of the preterm neonate in Nigeria, the birth of a preterm baby to a family in addition to the stresses associated with childbirth itself may have an adverse effect on maternal psychological well-being.

The present study was designed to investigate whether mothers of preterm infants experience more psychological distress than mothers of full term infants in the immediate postpartum period.

\section{MATERIALS AND METHODS}

The study was carried out at the Obafemi Awolowo University Teaching Hospitals Complex (OAUTHC) which provides tertiary health care services to Osun, Ekiti, Ondo and neighbouring states in Nigeria with a catchment population of over 10 million. Ethics and Research committee approval was obtained. Informed consent was obtained from participants after the aims and objectives of the study had been explained.

The index group consisted of mothers of preterm low birth weight (PLBW) babies consecutively admitted into the Neonatal Unit of Wesley Guild Hospital, llesa (One of the component hospitals of OAUTHC). Preterm low birth weight cases were defined as mothers with babies of less than 2500 grams plus one or more of the following; gestational age less 
than 37 weeks, preterm labour (PTL) or premature rupture of membranes. The mothers were interviewed a week after the babies were born/admitted. This was to allow the mother to adjust to the ward routine and to the admission of the baby. All the babies were assessed by one of us, a consultant paediatrician.

A second group of women who had given birth to normal birth weight infants were used as controls. The controls consisted of women who had delivered at the obstetric unit of Wesley Guild Hospital, llesa, or multipurpose Health Centre, llesa (another unit of OAUTHC). Selection into this group was done by going through the admission and discharge registers of these units, and picking those whose age and educational status matched those of the index group. The women were interviewed in the well baby clinic when they came for BCG immunization usually one week after delivery. Those with a past history of psychiatric illness were excluded in both groups.

Measurements: Socio-demographic information about the mothers was obtained using a specially constructed sociodemographic data schedule. The paediatric data of their babies were also obtained using a prepared proforma and from the hospital records.

The women were then screened using the 30-item General Health Questionnaire (GHQ-30)(10), and the Beck Depression Inventory (BDI)(11). The GHQ-30 and BDI have been standardized and used extensively in Nigeria(12-14). Caseness on the GHQ-30 was defined as a score of 5 and above. The BDI is a 21-item self assessment of depression severity. Item scores ranged from $0-3$, and total scores of 0-9 indicate no significant symptoms, 10-18 mild/moderate, 19-29 moderate/severe, and 30-63 extremely severe depression. The items of the questionnaire were translated into Yoruba, the language of the indigenous of Osun State, and then backtranslated in order to confirm the translation.

Literate subjects completed the screening instruments in English or Yoruba. One of us read out the questions and marked the responses of those subjects who were not literate.

Statistical analysis was carried out using SPSS version 7.5 for windows. Normally distributed data in the two groups, were assessed with the students t-test, and categorical data with the chi-square test. The significant level was set at $\mathrm{P}<0.05$.

\section{RESULTS}

Of the 60 post-natal women recruited into the study, 33 were mothers of preterm babies, and 27 were mothers of normal full term infants. The demographic and some clinical characteristics of these post-natal women are shown in Table 1.

There were no statistically significant differences when the two groups were compared in terms of the sociodemographic characteristics of mother's, age, educational status and marital status.

Table 1

Demographic and Clinical Variables of Mothers and Babies

\begin{tabular}{|c|c|c|c|}
\hline & $\begin{array}{l}\text { Index } \\
(\mathrm{N}=33)\end{array}$ & $\begin{array}{l}\text { Control } \\
(\mathrm{N}=27)\end{array}$ & \\
\hline $\begin{array}{l}\text { Mothers mean age in } \\
\text { years }( \pm \mathrm{SD})\end{array}$ & $\begin{array}{r}28.27 \\
(5.0)\end{array}$ & $\begin{array}{c}28.51 \\
(5.9)\end{array}$ & $\begin{array}{c}\mathrm{t}=0.18 \\
\mathrm{df}=58, \mathrm{NS}\end{array}$ \\
\hline \multicolumn{4}{|l|}{ Marital Status } \\
\hline Single & 2 & 0 & Fisher's Exact \\
\hline Married & 31 & 27 & $=0.497, \mathrm{NS}$ \\
\hline \multicolumn{4}{|l|}{ Parity } \\
\hline Primiparous & 13 & 7 & $\mathrm{X} 2=1.4, \mathrm{NS}$ \\
\hline Multiparous & 20 & 20 & \\
\hline Babies Birth Weight & 1.55 & 2.93 & $\mathrm{t}=16.28, \mathrm{df}=58$ \\
\hline$(\mathrm{Mean} \pm \mathrm{SD})$ & $(0.34)$ & $(0.26)$ & $\mathrm{P}=0.001$ \\
\hline \multicolumn{4}{|l|}{ Mode of Delivery } \\
\hline Normal & 29 & 26 & Fisher's Exact \\
\hline Caesarean Section & 4 & 1 & $=0.367, \mathrm{NS}$ \\
\hline \multicolumn{4}{|l|}{ Abortions } \\
\hline Previous & 9 & 4 & $\mathrm{X}^{2}=2.6, \mathrm{NS}$ \\
\hline No previous & 24 & 23 & \\
\hline \multicolumn{4}{|l|}{ Educational Group } \\
\hline Nil & 3 & 3 & \\
\hline Primary & 9 & 8 & $X^{2}=2.0$ \\
\hline Secondary & 14 & 7 & $\mathrm{df}=3, \mathrm{NS}$ \\
\hline \multirow[t]{2}{*}{ Tertiary } & 7 & 9 & \\
\hline & 3.12 & & $\mathrm{t}=2.932, \mathrm{df}=58$, \\
\hline GHQ-30(Mean+SD) & $(4.05)$ & $0.66(1.73)$ & $\mathrm{P}=0.005$ \\
\hline BECK Inventory & 4.27 & $1.25(2.87)$ & $\mathrm{t}=2.965, \mathrm{df}=58$ \\
\hline$($ Mean \pm SD) & $(4.59)$ & & $\mathrm{P}=0.004$ \\
\hline
\end{tabular}


GHQ-30 scores: There were 10 women who scored above the cut-off point on the GHQ-30; nine $(27.3 \%)$ out of 33 in the index group, and one $(3.7 \%)$ out of 27 in the comparison group.

The GHQ-30 mean score was 3.12 for the mothers of preterm babies and 0.66 for mothers of full term infants. This difference was statistically significant $(\mathrm{t}=2.932, \mathrm{df}=58, \mathrm{P}=0.005)$.

Beck-Depression Inventory (BDI) Scores: The BDI was able to pick six women with mild to moderate depression(BDI scores of 10 to 18 ) in the study sample; five $(15.1 \%)$ out of, 33 in the index group and one (3.7\%) out of 27 in the comparison group.

The mean BDI score was 4.27 for the mothers of preterm babies and 1.25 for the mothers of full term infants. This difference in scores was statistically significant $(\mathrm{t}=2.965, \mathrm{df}=58, \mathrm{P}=0.004)$

Obstetric Factors: There were no significant differences when the two groups were compared in terms of parity (primiparous vs multiparous; $\mathrm{X}^{2}=1.4, \mathrm{NS}$ ), mode of delivery (Normal delivery vs caesarean section; Fisher's Exact $=0.367$, NS), or previous abortions (previous abortions vs no previous abortions; $X^{2}=2.6$, NS).

Comparison within the index group: The mothers of the preterm infants were divided into two groups according to the birth weight of their babies for the purpose of possible analysis. Mothers of very low birth weight (VLBW) (birth weight less than or equal to 1,500 grams) and low birth weight(LBW)(birth weight greater than 1,500 grams but less than 2500 grams) infants. There were 13 mothers of VLBW infants and 20 mothers of LBW infants. The mothers of VLBW infants had higher GHQ-30 mean scores(3.53), than mothers of LBW infants (2.85). This difference did not reach statistical significance $(\mathrm{t}=0.471, \mathrm{df}=31, \mathrm{NS})$. No significant relationship found between GHQ-30 caseness and non caseness GHQ-30<5 vs GHQ-30>5) and the birth weight groups (Fisher's Exact=1.00, NS). Mothers of VLBW infants also had higher mean BDI scores(4.76) than mothers of LBW infants (3.95). This difference did not reach statistical significance $(\mathrm{t}=0.495, \mathrm{df}=31$, NS). Of the 33 mother-infant pairs, 31 babies (93.9\%) had complications. Twenty four(72.7\%) of these babies had neonatal Jaundice (NNJ). Out of the 24 babies with NNJ, eight had apnoeic attacks in addition, four also had convulsions and two had apnoeic attacks with convulsions. Of the nine babies who did not have neonatal jaundice four had apnoeic attacks, two had apnoeic attacks with convulsions and one had intestinal obstruction. There were only two babies out of the 33 who had no complications.

\section{DISCUSSION}

The study has shown that significant levels of post-natal emotional distress are experienced by mothers of high-risk infants in the immediate post partum period.

The mothers of preterm infants had more GHQ30 caseness $(27.3 \%)$ than mothers of normal full term infants $(3.71 \%)$. Maternal depression also occurred more frequently in mothers of preterm infants (15.1\%) in contrast to $(3.7 \%)$ rate shown by mothers of full term infants. These findings in mothers of preterm infants are in support of previous studies $(15,16)$. Even through the prevalence of depression $(15.1 \%)$ in our sample is lower than $55 \%$ reported by Locke et al (15), this could have been due to methodological differences, but our findings are comparable. In their study they found that 17 out of 31 mothers manifested depression on the Centre for Epidemiologic studies-Depression Scale(CESD), and maternal depression was related to severity of initial neonatal illness.

It is noteworthy that thirty one $(93.9 \%)$ out of 33 preterm babies in our cohort had various complications, and 24 of them(72.7\%) had neonatal jaundice in contrast to full term babies in the control group who had no associated problems. The neonatal health status could have adversely affected maternal well being in our study sample. It was also observed that mothers of babies weighing 1,500 grams, or less had higher mean GHQ-30 and BDI scores than mothers of babies weighing more than 1,500 grams but less than 2500 grams, even though these differences did not reach statistical significance. A previous study carried out by Demier et al(16) showed birth weight to be a risk factor for postnatal emotional distress.

Emotional problem are thus common in mothers of high risk preterm infants in the immediate postpartum period and they are not usually detected nor appropriately referred by the obstetrician/ paediatrician to the psychiatrist. This has a number of implications for preventive psychiatry. A multidisciplinary approach, is therefore essential for appropriate detection and management of these problems.

\section{REFERENCES}

1 Cox, J.L. Psychiatric disorders of childbirth. In Kendell R.E., Zeally A.K. [Eds). Companion to psychiatric studies. Churchill Livingstone, London. 1995.

2. Makanjuola, R.O.A. Psychotic disorders after childbirth in Nigerian women. Trop. and Geogr. Med. 1982; 34: 67-72.

3. Newport, D.J., Hostetter, A., Arnold, A. and Stowe, Z.N. The treatment of postpartum depression: Minimizing infant exposures. J. Clinical Psychiat. 2002; 63:31-34.

4. Regmi, S., Sligl, W., Carter, D. and Grut, W. A controlled study of postpartum depression among Nepalese women: Validation of the Edinburgh postpartum depression scale in Kathmandu. Trop. Med. Int. Health, 2002; 7: 378-382. 
5. Danaci, A.E., Dinc, G., Deveci, A., Sen, F.S. and Iceli, I. Postpartum depression in Turkey: epidemiological and cultural aspects. Soc. Psychiatry. Epidemiol. 2002; 37:125129.

6. Videbech, P. and Govliaev, G. First admission with puerperal psychosis: 7-14 years of follow-up. Acta. Psychiatr. Scand. 1995; 91: 167-173.

7. Cooper, P.J., Tomlinson, M., Swatz , L., Woolgar, M., Murray, L. and Molteno, C. Postpartum depression and the mother infant relationship in a South African Peri-urban settlement, Brit. J. Psych. 1999; 175: 554-558.

8. Owa, J.A., Esimai, V.C. and Adejuyigbe, E.A. Severe Burns in a preterm Neonate: The tragedy of poor access to medical care service. Niger. Med. J. 1995; 28: 127-129.

9. Brewster, D. Neonatology in the developing world, part 2. Tropical Doctor. 1989; 19: 147-151.

10. Goldbelg, D. and Hiller, V.F. A scaled version of the General Health Questionnaire. Psychol. Med. 1979; 9: 139145.
11. Beck, A.T., Ward, C.H., Mendelsohn, M., Mock, J. and Erbaugh, J. An inventory for measuring depression. Archives of General Psychi. 1961; 4: 561-571.

12. Abiodun, O.A., Adetoro, O.O. and Ogunbode O.O. Psychiatric morbidity in a pregnant population. General Hosp. Psychi. 1993; 15:125-128.

13. Awaritefe, A. The Beck Depression Inventory in Relation to some commonly used Tests in Nigeria. Nigeria J. Basic Applied Psych. 1988; 1:23-28.

14. Osinowo, H. Standardization of the Beck Depression Inventory for the Nigerian Population. Unpublished Ph.D. Thesis, 1988; University of lbadan.

15. Locke, R., Baumgart, S., Locke, K., Goodstein, M., Thies, C. and Greenspan, J. Effect of maternal depression on premature infant health during initial hospitalization. J. Am. Osteopath. Assoc. 1997; 3: 136-139.

16. Demier, R.L., Hynan, M.T., Hatfield, F.F. et al. A measurement model of perinatal stressors: identifying risks for postnatal emotional distress in mothers; of high-risk infants. J. Clin. Psychol. 2002; 56: 89-100. 
East African Medical Journal Vol. 80 No. 6 June 2003

INTENTION-TO-TREAT ANALYSIS IN THE CHRONIC SUPPURATIVE OTITIS MEDIA TRIALS

K.N. Otwombe, BEd (Sc), MSc (Stats), Research Statistician and B.Ogutu, MBChB, MMed (Paed), KEMRI/ Wellcome Trust Research Laboratories, P.O. Box 230, Kilifi, Kenya

Request for reprints to: K.N. Otwombe, KEMRI/ Wellcome Trust Research Laboratories, P.O. Box 230, Kilifi, Kenya

\title{
INTENTION-TO-TREAT ANALYSIS IN THE CHRONIC SUPPURATIVE OTITIS MEDIA TRIALS
}

\author{
K.N. OTWOMBE and B. OGUTU
}

\begin{abstract}
Objectives: To determine the extent of application of the intention to treat principle in the chronic suppurative otitis media (CSOM) randomised controlled trials.

Design: Data were extracted from 28 CSOM randomised controlled trials.

Main outcome measures: Conceptual and methodological approaches of dealing with protocol deviations with respect to withdrawal, missing response and non-compliance. Results: Of the 28 CSOM trials included in this study, only one (4\%) trial mentioned intention-to-treat (ITT) analysis. However, 10(36\%) other trials which did not mention ITT, had no protocol deviations and thus carried out an ITT analysis by default. It is highly likely that a biased treatment effect existed in the trial that mentioned ITT since the authors undertook a complete case analysis disregarding the $22 \%$ protocol deviators. There were no attempts in any of the trials to impute for missing responses and carrying out a sensitivity analysis. For trials with a big percentage of protocol deviations, the validity of their results are brought to question.

Conclusions: In practice, not all those entered into a randomised-controlled trial will complete the trial. Thus intention-to-treat analysis is an important aspect of randomised controlled trials of health care interventions which tries to bridge this gap. It is important for authors to explicitly state the protocol deviations, the methods used to handle them and the potential effect with reference to bias and study outcome.
\end{abstract}

\section{INTRODUCTION}

An analysis on the intention-to-treat principle tests the strategy of offering a certain treatment to a group of randomised subjects in a trial, irrespective of whether they receive or tolerate the treatment $(1,2)$. Basically, it requires inclusion of all randomised patients in the analysis regardless of whether they remain on protocol for the duration of study. Favoured by statisticians, intention-to-treat analysis seeks to answer the question, "Is it better to adopt a policy of treatment A if possible, with deviations if necessary, or a policy of treatment B if possible, with deviations if necessary?"(3)

However, the implementation of the ITT principle still remains a controversial issue(1,4-6) There are a lot of definitions on this principle and authors seem to have different meanings $(5,7)$ Irrespective of all these, there is a consensus in analysing all those who were randomised into the trial. It is worth noting that an ITT analysis uniquely preserves the qualities of bias reduction of randomisation $(7,8)$.

An ITT analysis should be as pragmatic as possible to ensure representativeness and generalisability(9). It is generally agreed that a pragmatic scenario closely resembles the clinical scenario as opposed to explanatory. Comparing a pragmatic and an explanatory analysis of the same data can reveal possible bias in the explanatory case (5,8-10). No matter how meticulously a trial is planned, it is inevitable some patients will deviate from the protocol specifications $(1,11)$. This is bound to happen more often in the long-term trials or stringent treatment schedules. The main protocol deviations we consider in this study are non-compliance, withdrawal from the trial and missing data.

Non-compliance may be defined as non-adherence to therapeutic advice and its occurrence may radically alter the interpretation of a trial result. Compliance is known to be highly prognostic and a clinical trial where good compliers performed significantly better than poor compliers is questionable(10). The existence of patients who withdraw from intervention is a serious failing which can lead to inappropriate conclusions about treatment efficacy. Subjects maybe withdrawn from a trial because they default or do not comply with the protocol. The most important patients are those whose withdrawal is related to the trial endpoints. These must be accounted for in treatment comparisons $(10)$. 


\section{MATERIAL AND METHODS}

Inclusion criteria: In this study, we considered all the trials that mentioned ITT and/or those that had no protocol deviations.

Types of studies: Any randomised controlled trial was included that compared the different methods of management outlined in the CSOM review.

Types of participants: Any subject suffering from CSOM as defined by the CSOM review, including unilateral and bilateral cases.

Search strategy:

1. The Cochrane Library (Issue 3, 2001).

2. Medline search (1966-1997).

3. Searching the Hearing Network database consisting of a bibliographic collection developed by the, Hearing Impairment Research Group in Liverpool over the last ten years.

4. Hand searching two journals known to publish CSOM trials: Archives of Otolaryngology - Head and Neck surgery (1975-2000) and Clinical Otolaryngology (19761997).

5. Contacting members of the International Hearing Network run by the hearing impairment research group in Liverpool.

\section{RESULTS}

In all the 28 trials included in this study, only one trial (Table 1) mentioned ITT. However, despite mentioning ITT in its discussion section, it is interesting to note that the analysis done was a complete case (as per protocol). The numbers initially randomised to both treatment arms was also not provided hence making it difficult to impute for missing values.

A good number of the trials reported protocol violations although most of them did not mention ITT or use it. In the one trial where ITT was mentioned, there were protocol violations. The total drop out rate for this particular trial was $22 \%$. It is also imperative to note that the protocol deviations were not documented. The deviations in this trial were overlooked and the analysis was done for only the cases who completed the trial. This paper indicated that the authors' intention was to carry out an ITT analysis. However, the analysis done did not comply with the ITT principle.

In Connolly's paper, it was reported that cases of non-compliance were hard to fully identify and hence all those who took at least one dose were included in the analysis. Of the 28 trials in this study, there were ten trials that had no protocol violations (Table 2).

Table 1

Features of the connolly trial

\begin{tabular}{lllll}
\hline Trial & No. & Intervention & Primary Outcome & $\begin{array}{l}\text { No. (\%) of } \\
\text { exclusions }\end{array}$ \\
\hline Connolly et al. (13) & 147 & $\begin{array}{l}\text { Neomycin/dexamethasone } \\
\text { Spray vs drop preparation }\end{array}$ & $\begin{array}{l}\text { Resolution of } \\
\text { discharge }\end{array}$ & $32(14)$
\end{tabular}

Table 2

Trials that did not mention ITT and had no deviations

Trial

Somekh and Cordora (15)

Cooke and Raghuraran (16)

Esposfto et al(17)

Tutkun et al(18)

Esposito et al(19)

Gyde et al(17)

Gyde et al(20)

Papastavros et al(14)

Wilde et al(22)

Lilholdt et al(23)
No.

30

31

60

44

60

60

55

90

70

26
Intervention

Ceftazidime vs Aztreonam

Clindamycin plus surgery vs surgery alone.

Oral ciprofloxacin vs

Topical ciprofloxacin vs

Oral and Topical ciprofloxacin

Topical ciproflox Topical gentamicin

Topical ciprofloxacin vs Intramuscular

Gentamicin

Trimethoprim-polymyxin B vs

Trimethoprim-sulfacetamide-polymyxin B

Gentamicin otic solution vs Colistin

neomycin-hydrocortisone otic solution

Several systemic treatments vs several topic treatments

TAC on ribbon gauze vs TAC with $\mathrm{Fg}$

lacrimal cannular

Ceftazidime in surgery vs

no antibiotic in surgery 
The primary outcome in all these ten trials was resolution of discharge but none of these ten trials mentioned the need to carry out an ITT analysis. However, they applied the ITT principle inadvertently during the analysis by using all the available information on each subject. In these trials, none of the authors applied the imputation method in trials that had missing data. Further to this, there was no trial that carried out a sensitivity analysis. There were five (18\%) trials that had cases withdrawn after randomisation but before start of treatment.

\section{DISCUSSION}

There are many times when the event of interest, such as death, occurs after randomisation but before treatment has commenced. This event could also happen before an intervention has had an effect(24). In this study, the exclusion of patients who did not start the allocated intervention was not very common. This however breaches the ITT principle. It is desirable to design a trial so that there is a minimal delay between randomisation and the start of treatment where it is practical $(7,24)$ At other times, it is often unclear whether the outcome of interest is related to the medical condition. Thus it is unwise to exclude such subjects from the analysis $(1,7,11,24)$. Hence, the application of ITT seems to be the most preferred. A good example to illustrate this is the surgical versus medical therapy in bilateral carotid stenosis reported by Pocock(11). The risk reduction using the explanatory and pragmatic approaches gave different conclusions, which cast doubt on the validity of the presented results.

Any trial requires a precise definition of inclusion criterion. However in practice, one will usually find that a small proportion of ineligible patients is included by mistake. These false inclusions should generally not be excluded from the analysis $(7,14)$. If the proportion of ineligible patients becomes unduly large, this may reflect a generally poor standard of trial organisation.

Investigators should always aim at a high degree of compliance from patients. We further note that this is an important aspect of a well administered trial. Most of the trials in this study involved drugs and these are known to contribute significantly towards noncompliance especially when administered by the patient. The greatest step in reducing non-compliance should be taken at the point of entry. At this point, it is imperative to explain carefully the treatment schedule and objectives of the trial to the subjects. Other safety measures to reduce non- compliance have been explained in the works of Pocock(11) amongst others. The issue of non-compliance is delicate and should be approached with a lot of caution(7). It is in this regard that there have been suggestions for carrying out a pilot study that will assess compliance for a major trial(11). If the rate of non-compliance is high, this may affect the validity of the trial results.

In the papers included in this study, there were no methods employed to take care of the missing responses. Indeed, there are many mechanisms, as explained below, that can be employed to handle missing responses $(6,7,25)$. In most of the trials in this study, complete case analysis was employed.

However, this is known to violate the principle of intention-to-treat analysis and hence introducing bias(5$7,25,26)$. One of the most common approaches is imputing for missing responses. However, we do have a lot of alternatives under this option. The most conservative approach is using the last observation carried forward $(6,7,25)$. But this method assumes in effect that outcome remains constant at the last observed value after drop out, which seems unlikely in many applications(6).

In other situations, an investigator might elect to rank the observed response variables and assign a rank to those participants with missing data. The highest rank could be assigned to all such participants in the intervention group, while assigning the lowest ranks to those in the control group and vice-versa. This is the extreme case analysis method that is unlikely to yield a conclusive answer in practice(7). Complex statistical methods are available for imputing missing outcomes $(6,10,25,26)$. It is generally agreed however that imputations can never lead to an outcome that is unbiased. This is especially true due to the validity of the assumptions made on the mechanisms employed(7). How true are these assumptions? The general idea is that the ITT analysis and the per protocol analysis represent different extremes so that, if they lead to die same conclusion, then the strength of the conclusion is considerably increased. It is when they lead to different conclusions that troubles arise(5). Thus it is important to perform a sensitivity analysis on your dataset $(6,7)$.

Thus our findings in this study are consistent with other findings on the quality of reporting of clinical trials $(7,8)$. It is our hope that in future studies, authors shall present imputation methods used to estimate missing data and a statement on the perceived success or failure of imputation methods applied. It is also our hope that the ITT principle will be applied together with a sensitivity analysis.

\section{CONCLUSION}

A current method of adopting an ITT approach within primary research is to assume that the event of interest occurred in all patients for whom the outcome is not known. This aims to develop and implement an approach that: does not assume the same endpoint for all patients whose outcome is unknown and allows for the fact that there may be differences between the proportions of patients (for whom the outcome is unknown) who experience the event on treatment and control groups. 
We strongly recommend that future trials of CSOM and others be analysed on the intention-to-treat basis.

\section{ACKNOWLEDGEMENTS}

We gratefully acknowledge the co-operation and assistance of the Wellcome Trust Research Laboratories and Liverpool School of Tropical Medicine.

\section{REFERENCES}

1. Dunn, G. and Everitt, B. Clinical Biostatistics-An introduction to Evidence Based Medicine. London: Edward, 1995; 133-136.

2. Campbell, M.J and Machin, D. Medical Statistics-A Common Sense Approach, Chichester: Wiley, 1999; 117.

3. Gibaldi, M. and Sullivan, S. Intention-to-treat analysis in randomised trials: who gets counted? J. Clin. Pharmacol. 1997; 37:8:667-672.

4. Kannel, W.B., Coronary Artery Surgery Study RevisitedLimitation of the intent-to treat principle. Circulation. 1990; 82:1859-1862.

5. Lewis, J.A. and Machin D. Intention to treat-Who should use ITT? Brit. J. Cancer. 1993; 68:647-650.

6. Little, R. and Yau, L. Intent-to-Treat Analysis for Longitudinal Studies With Dropouts. Biometrics. 1996; 52:1324-1333.

7. Hollis, S. and Campbell, F. What is meant by intention to treat analysis? A survey of published randomised controlled trials. Brit. Med. J. 1999; 319:670-674.

8. Schulz, K.F., Grimes, D. A, Altman D.G and Hayes R.J. Blinding and exclusions after allocation in randomised controlled trials: survey of published parallel group trials in obstetrics and gynaecology. Brit. Med. J. 1996; 312:742744.

9. Roland, M. and Torgerson D.J. What are pragmatic trials? Brit. Med. J. 1998; 316:285.

10. Hogan, J.W and Laird, N.M. Intention to Treat Analysis for Incomplete Repeated Measures Data. Biometrics. 1996; 52:1002-1017.

11. Pocock, S.J Clinical Trials-A practical approach, Chichester: Wiley 1988; 179-186.

12. Acuin, J., Smith, A. and Mackenzie, I. The Cachrane Library, Issue 3. 2001.

13. Connolly A.A.P, Picozzi, G.L and Browning, G.G Randomised trial of neomycin/dexamethasone spray vs drop preparation for the treatment of acute chronic mucosal otitis media clin. Otolaryngol. 1997; 22:529-531.

14. Papastavros, T., Giamarellou, H. and Varlejides S. Preoperative Therapeutic Considerations in Chronic Suppurative Otitis Media. Laryngoscope. 1989; 99:655659.

15. Somekh, E. and Cordova Z. Ceftazidime Versus Aztreonam in the Treatment of Pseudomonal Chronic Suppurative Otitis Media in Children. Scand. J. Infect. Dis. 2000; 32:197-199.

16. Cooke, E.T.M and Raghuvaran, G. Clindamycin in Conjuction With Surgery of the Chronic Suppurative Ear. Brit. J. Clinical Practice. 1974; 28:2:57-59.

17. Esposito, S., D'Errico, G and Montanaro, C. Topical and Oral Treatment of Chronic Otitis Media With Ciprofloxacin. Arch Otolaryngol Head Neck Surg. 1990; 116:557-559.

18. Tutkun, X, Ozagar, A., Koc A., Batman C., Uneri C. and Sehitoglu M.A. Treatment of Chronic Ear Disease. Arch Otolaryngol Head Neck Surg. 1995; 121:1414-1416.

19. Esposito, S., Noviello S., D'Errico G. and Montanaro, C. Topical Ciprofloxacin vs Intramuscular Gentamicin for Chronic Otitis Media. Arch otolaryngol Head Neck Surg. 1992; 118:842-844.

20. Gyde, M.C. A double-blind comparative study of Trimethoprim-Polymyxin B versus TrimethoprimSulfacetamide- Polymyxin B otic solutions in the treatment of ottorhea. J. Laryngology and Otology . 1981; 95:251259.

21. Gyde, M.C., Norris D. and Kavalec, E.C. The Weeping Ear: Clinical Re-Evaluation of Treatment. J. Int. Med. Res. 1982; 10:333-340.

22. Wilde, A.D., England, J. and Jones, A.S. An alternative to regular dressings for otitis externa and chronic suppurative otitis media? J. Laryngology and Otology. 1995; 109:101103.

23. Lilholdt, T., Felding, L.U., Juul, A., Kristensen, S. and Schouenborg, P. Efficacy of perioperative ceftazidime in the surgical treatment of chronic otitis media due to pseudomonas aeruginosa. Arch Otorhinolaryngol. 1986; 243:167-169.

24. Altman, D.G. Practical Statistics for Medical Research, Boca Raton: Chapman. 1999; 463-464.

25. Mazumdar, S., Liu K.S., Houck P.R and Reynolds III C.F., Intent-to-treat analysis for longitudinal clinical trials: coping with the challenge of missing values. J. Psychol. Res. 1999; 33:87-95.

26. Frangakis, C.E and Rubin D.B., Addressing complications of intention-to-treat analysis in the combined presence of all-or-none treatment non-compliance and subsequent missing outcomes. Biometrika. 1999; 86:365-379. 
East African Medical Journal Vol. 80 No. 6 June 2003

EPIDEMIOLOGY OF MEASLES IN THE CENTRAL REGION OF GHANA: A FIVE-YEAR CASE REVIEW IN THREE DISTRICT HOSPITALS

W.K. Bosu, MPH, MSc, DTM\&H, S. Odoom, Certificate Epidemiol and Stats, P. Deiter, Dip. Health Sc. Educ, Regional Public Health Services, P.O. Box 63, Cape Coast, Ghana and Essel-Ahun, MBChB, BMedSci, MTrop Paed, Programme Manager, National Expanded Programme on Immunization, Ghana Health Service, P.O Box KB 493, Accra, Ghana

Request for reprints to: Dr.W. K. Bosu, Deputy Director, Regional Public Health Services, Ghana Health Service, P.O. Box 63, Cape Coast, Ghana

\title{
EPIDEMIOLOGY OF MEASLES IN THE CENTRAL REGION OF GHANA: A FIVE-YEAR CASE REVIEW IN THREE DISTRICT HOSPITALS
}

\author{
W.K. BOSU, S. ODOOM, P. DEITER and M. ESSEL-AHUN
}

\begin{abstract}
Objective: As part of a national accelerated campaign to eliminate measles, we conducted a study, to define the epidemiology of measles in the central region.

Design: A descriptive survey, was carried out on retrospective cases of measles.

Setting: Patients were drawn from the three district hospitals (Assin, Asikuma and Winneba hospitals) with the highest number of reported cases in the region.

Subjects: Records of outpatient and inpatient measles patients attending the selected health facilities between 1996 and 2000 . Data on reported measles cases in all health facilities in the three study, districts were also analysed.

Main outcome measures: The distribution of measles cases in person (age and sex), time (weekly, or monthly, trends) and place (residence), the relative frequency, of cases, and the outcome of treatment.

Results: There was an overall decline in reported cases of measles between 1996 and 2000 both in absolute terms and relative to other diseases. Females constituted $48 \%$ $52 \%$ of the reported 1508 cases in the hospitals. The median age of patients was 36 months. Eleven percent of cases were aged under nine months; $66 \%$ under five years and $96 \%$ under 15 years. With some minor variations between districts, the highest and lowest transmission occurred in March and September respectively. Within hospitals, there were sporadic outbreaks with up to 34 weekly cases.

Conclusion: In Ghana, children aged nine months to 14 years could be appropriately, targeted for supplementary, measles immunization campaigns. The best period for the campaigns is during the low transmission months of August to October. Retrospective surveillance can expediently inform decisions about the timing and target age groups for such campaigns.
\end{abstract}

\section{INTRODUCTION}

While tremendous progress has been made in increasing immunisation coverage in Ghana, the national targets have not been met since the launch of the Expanded Programme on Immunisation (EPI) in 1978. The national measles immunisation coverage increased markedly from $24 \%$ to $84 \%$ from 1980 to 2000 . Corresponding with this increase, the number of reported cases fell by $72 \%$ from 82,684 to 23,068 over the same period(1). However, the measles coverage still falls short of the national target of $90 \%$ (2). A target was set to reduce reported measles from 40,000 in 1998 to 10,000 per year by the year 2000. Meanwhile, sporadic measles outbreaks occurred; one large outbreak in 1995 involved 43,177 cases and 85 deaths.

In line with a recent global initiative by the World Health Organization (WHO) and the United Nations Children's Fund (UNICEF) to halve measles mortality(3), Ghana developed a national strategic plan to control measles with the objective of reducing measles morbidity by, $90 \%$ and measles mortality by, $95 \%$ from pre-vaccination levels by the end of 2003 ; preventing measles outbreaks in all ten regions by the end of 2002; and eventually eliminating measles with near zero deaths by 2005 (1).

Based on a high EPI performance, the central region was selected as the initial region for accelerated campaign towards the elimination of measles. In the year 2000, the region recorded 2,378 measles cases and two deaths. Measles immunisation coverage in 2000 was $84 \%$. In preparation for planned measles supplemental activities (SIAs), we conducted a study to obtain information on the local epidemiology of the disease to guide the selection of target age groups and the timing of the campaign.

\section{MATERIALS AND METHODS}

For reasons of cost and expediency, we conducted a retrospective review of measles in the three districts in the central region with the highest reported cases - the AsikumaOdoben-Brakwa (AOB), Assin and Awutu-Effutu-Senya (AES) 
districts. The study had two components. First, we examined EPI surveillance forms and communicable diseases forms at the district disease control office and the regional surveillance unit for trends on reported monthly measles cases (and measles immunisation coverage) from each sub district of the three study districts for the period 1996-2000. We also collected data on the monthly trends of reported measles in the region as a whole.

In the other component, we collected retrospective data on the age, sex, address, date of visit, date of onset or symptoms, admission status, vaccination status and outcome of treatment on all patients attending the district hospitals of the three study districts during the five-year period, 19962000. In each hospital, we obtained a list of outpatients with measles from consulting room registers, measles registers or disease surveillance forms. The unique identity numbers of patients so obtained were then used to retrieve the patient notes. Where a line list of patients was not available, we searched all available patient notes to locate those containing a diagnosis of measles. Inpatient lists or measles cases were prepared from an admission and discharge register and a nonmaternity nominal roll.

We collected data on all new outpatient attendants by age and sex in each hospital and calculated the proportion by age-sex groups diagnosed with measles for each year from 1996 to 2000. Patient data were captured using Epi Info 6.04d and analysed with Epi Info 2000.

Study area: The three districts of Assin, AOB and AES had respective populations of 193,888, 87,796 and 165,193 in the year 2000 according to a national census. The capitals of the study districts are Assin Foso, Asikuma and Winneba respectively. The proportion of infants (representing about $4 \%$ of the total population) immunised with measles in the districts ranged between $78 \%$ and $100 \%$. Assin district is divided into eight sub-districts based on the location of key health facilities in the district. The AOB and AES districts are made up of three and four sub-districts respectively. The district hospitals in Assin and AOB are mission-owned while that in AES is government-owned. There are also communityclinics, health centres and private clinics which operate in the catchment area of the hospitals.

\section{RESULTS}

Measles cases in the three study districts: Only the district aggregate of measles trend is presented here. All three districts registered a decline in reported cases from 1995 to 2000 (Figure 1). The most rapid decline occurred in the AOB district where the number of cases dropped by $85 \%$ from 940 in 1996 to 145 in 2000. This translates to a decline from 95 per 10,000 population in 1995 to 17 per 10,000 population in 2000 . The district share of the Central regional population versus share of the total reported measles over the period 1996-2000 was respectively $12 \%$ versus $15 \%$ or Assin, $6 \%$ versus $16 \%$ for $\mathrm{AOB}$ and $10 \%$ versus $5 \%$ for the AES districts.

The highest transmission of measles in the central region as a whole occurred in March with a second smaller peak in December while the lowest transmission occurred in September (Figure 2). The monthly trends in the study districts were slightly more erratic but they were broadly similar to the regional trend. In all three districts the peak frequency occurred in March (with smaller peaks in November or December) while the lowest transmission occurred in September.

\section{Figure 1}

Annual trends in reported measles cases in three districts of the central region 1996-2000

Figure 2

Monthly trends of measles in the central region, 19962000

\section{Measles in the three district hospitals}

Age and sex of measles cases: Overall, 1,508 recorded cases of measles were identified over the period from 1996-2000. Three hundred and forty eight at the Assin hospital, 1042 at the Asikuma hospital and 118 at the Winneba hospital (Table 1). Females constituted $48 \%$ of cases at Asikuma and Winneba 
hospitals and $52 \%$ of cases at the Assin hospital. In total, patients came from more than 200 communities. The proportion of patients from outside these districts attending these hospitals was about $5 \%$ for Winneba, $16 \%$ for Assin and 36\% for the Asikuma hospitals.

The age of patients ranged from one month to 60 years with a median and mean of 36 months and 56 months respectively (Table 2). The age distribution among children aged $<9$ months, 9 months- 4 years, 5 years- 14 years and $>5$ years was $11 \%, 55 \%, 30 \%$ and $4 \%$, respectively (Figure 3). One hundred and sixtyone patients $(11 \%)$ were aged between six and nine months. By health facility, $8 \%-19 \%$ were below age nine months. The mean age of patients differed significantly between facilities. Patients at Assin hospital were youngest while those at the Winneba hospital were the oldest (Kruskal-Wallis $\mathrm{H}=11.3, \mathrm{p}<0$. 005).

On the whole, the median age of patients fell from 31 to 24 months from 1996 to 2000 (Table 2). Between hospitals, the change in the median age over time was inconsistent-increasing at Asikuma hospital while decreasing at the Winneba hospital. In each hospital, female patients were older than the male patients although, overall the difference did not reach statistical significance (Table 3).

Table I

Sex distribution of reported measles cases by health facility, 1996-2000

\begin{tabular}{|c|c|c|c|c|c|c|}
\hline Facility & 1996 & 1997 & 1998 & 1999 & 2000 & Total \\
\hline \multicolumn{7}{|l|}{ Asikuma } \\
\hline Female & 111 & 194 & 150 & 27 & 22 & 504 \\
\hline Male & 131 & 191 & 163 & 34 & 19 & 538 \\
\hline Sub-total & 242 & 385 & 313 & 61 & 41 & 1042 \\
\hline \multicolumn{7}{|l|}{ Assin } \\
\hline Female & 31 & 14 & 51 & 55 & 29 & 180 \\
\hline Male & 25 & 15 & 39 & 57 & 32 & 168 \\
\hline Sub-total & 56 & 29 & 90 & 112 & 61 & 348 \\
\hline \multicolumn{7}{|l|}{ Winneba } \\
\hline Female & 7 & 21 & 14 & 8 & 7 & 57 \\
\hline Male & 6 & 29 & 14 & 7 & 5 & 61 \\
\hline Sub-total & 13 & 50 & 28 & 15 & 12 & 118 \\
\hline \multicolumn{7}{|l|}{ Total by sex } \\
\hline Female & 149 & 229 & 215 & 90 & 58 & 741 \\
\hline Male & 162 & 235 & 216 & 98 & 56 & 767 \\
\hline Total & 311 & 464 & 431 & 188 & 114 & 1508 \\
\hline
\end{tabular}

Table 2

Summary of age distribution of reported measles cases in months by health facility, 1996-2000

\begin{tabular}{lcccccccccccc}
\hline & \multicolumn{2}{c}{1996} & \multicolumn{2}{c}{1997} & \multicolumn{2}{c}{1998} & \multicolumn{2}{c}{1999} & \multicolumn{2}{c}{2000} & Total \\
\cline { 2 - 13 } Facility & Mean & Median & Mean & Median & Mean & Median & Mean & Median & Mean & Median & Mean & Median \\
\hline Asikuma & 58 & 30 & 54 & 36 & 53 & 36 & 58 & 48 & 81 & 48 & 56 & 36 \\
Assin & 54 & 31 & 33 & 15 & 60 & 30 & 61 & 28 & 40 & 22 & 54 & 24 \\
Winneba & 51 & 44 & 94 & 51 & 63 & 24 & 40 & 24 & 23 & 13 & 68 & 36 \\
\hline Total & 57 & 31 & 57 & 36 & 55 & 36 & 58 & 36 & 53 & 24 & 56 & 36 \\
\hline
\end{tabular}


Table 3

Summary of age-sex distribution of reported measles cases in months by health facility, 1996-2000

\begin{tabular}{|c|c|c|c|c|c|c|c|c|c|c|}
\hline \multirow[t]{2}{*}{ Facility } & \multicolumn{5}{|c|}{ Female } & \multicolumn{5}{|c|}{ Male } \\
\hline & Obs & Min & Mean & Median & Max & Obs & Min & Mean & Median & Max \\
\hline Asikuma & 504 & 1 & 62 & 36 & 720 & 538 & 1 & 50 & 36 & 672 \\
\hline Assin & 180 & 3 & 24 & 24 & 552 & 168 & 2 & 48 & 24 & 684 \\
\hline Winneba & 57 & 6 & 76 & 44 & 516 & 61 & 6 & 60 & 30 & 624 \\
\hline Total & 741 & 1 & 62 & 36 & 720 & 767 & 1 & 51 & 32 & 684 \\
\hline
\end{tabular}

Figure 3

Age distribution of measles cases in three district hospitals, central region, Ghana, 1996-2000
Figure 4

Admitted measles cases from three district hospitals by age group, central region, Ghana, 1996-2000
The proportion of cases in children under five years of age in the three hospitals increased from $66 \%$ in 1996 to $71 \%$ in 2000 (Figure 3). That for children under 15 years of age increased slightly from $95 \%$ to $96 \%$ over the same period. The proportion of outpatient morbidity due to measles in children aged under five years in the three hospitals declined from $0.7 \%$ (range $0.6 \%-1.1 \%$ ), in 1999 to $0.4 \%(0.3 \%-0.8 \%$ ) in 2000. The trend for the relative morbidity for children under 15 years of age was similar.

Trends in reported measles: Only about $8 \%$ of the reported measles increases cases specified the date of onset of the illness on the clinical notes. These cases reported to the health facility on either the day of onset of the illness or up to two weeks later. The median interval between onset of symptoms and attendance was 3.5 days for Asikuma and 3 days each for Assin and Winneba hospitals.
Consistent with district level trends, there were three clear outbreaks of measles at the Asikuma hospital from March to May 1997, March 1998 and January 1999. In the worst outbreak, 34 cases were recorded in a single week in May 1997. Assin hospital recorded outbreaks from December 1998 to April 1999 with a peak of three weekly reported cases. In the Winneba hospital, there was an outbreak during the first and third quarters of 1997.

Vaccination status: The vaccination status was only available for $66(6 \%)$ patients at the Asikuma hospital and for three $(0.9 \%)$ patients at the Assin hospital. Of these, 45 patients in Asikuma and none at Assin Foso had been vaccinated against measles.

Severity and outcome of illness: Overall, 275 (18\%) measles cases were admitted; $11 \%$ in Asikuma, $28 \%$ in Assin and 53\% in Winneba. Cases admitted were significantly younger (median 24 months, mean 
43 months) than those who were not admitted (median 36 months, mean 59 months) (Kruskal Wallis $\mathrm{H}=20.5$ $\mathrm{p}<0.005)$. Forty-seven $(17 \%)$ of the admitted cases were younger than nine months and five $(2 \%)$ were older than five years (Figure 4).

Fourteen measles patients $(0.9 \%)$ died. In total the case fatality in females $(1.1 \%)$ was not significantly higher than in males $(0.8 \%)$. The case fatality rates (CFR) over the five year period were $0.5 \%$ in Asikuma, $1.4 \%$ in Assin and 3.4\% in Winneba hospitals. Among the deaths, four were younger than nine months of age, eight were five years nine months and two were older than five years. Thus, the case fatality, for cases below age five years was $1.2 \%$ and that for those over five years was $0.4 \%$.

\section{DISCUSSION}

As with other retrospective studies, there were some general deficiencies in data availability and completeness. These were due to the use of multiple reporting forms, loose storage or patient cards without jackets, torn sheets, incomplete or illegible entries, annual changes in the patient identifier numbers and the lack of computerised data storage. We maximised completeness by retrieving any available data from registers. Establishing, a prospective case-based surveillance would eliminate some of these deficiencies and permit laboratory, confirmation of the cases.

Despite these limitations, our study revealed a number of important findings relating to the epidemiology of the measles in the central region of Ghana. On the whole, measles cases declined in absolute and relative terms in all the health facilities from 1996 to 2000 . This decline has been reported by other workers $(5,6)$ and has been attributed to successful EPI and vitamin A supplementation(7). Even so, sporadic outbreaks occurred in the central region during this period.

The affected age of patients has implications for the current measles immunisation schedule; a single dose using the Schwarz vaccine at nine months of age. Eleven percent of our cases were younger than nine months. The vulnerability of younger infants in Ghana has been reported since the early 1970s. At the Korle$\mathrm{Bu}$ Teaching Hospital, the peak age of admissions of children with measles was 7-12 months in 1973-1982 (5). However, the currently, available measles vaccine does not produce adequate sero-conversion rates when administered to younger infants(8). In view of this, Ghana has been interested in other vaccines, such as the AIK-C vaccine, which may be more effective in younger infants(9).

Most of the cases $(96 \%)$ were in children under 15 years; $30 \%$ of them in children between the ages of five and 14 years. Thus, the age group nine months to 14 years could be targeted for mass campaign in the central region of Ghana as in Malawi where measles morbidity and mortality have been reduced to near zero(10).

WHO recommends that where a large proportion of cases occur in children aged between six and nine months, children as young as six months may be vaccinated(11). This strategy would however impose higher financial and logistical costs, as was the case in Uganda. Moreover, expanding the target group to cover these younger infants may not be necessary if routine coverage of over $60 \%$ in infants could be achieved and a good quality SIA could reach over $90 \%$ of children aged nine months to 14 years. As has been observed in many countries of East and West Africa, such coverage would rapidly and drastically remove the source of infection for the younger infants and so prevent cases and deaths in the latter group(12). Hence, we propose that the target age group, nine months to 14 years be maintained in the central region despite having, $11 \%$ of cases in younger infants.

The challenge therefore, is for the central region to achieve a high SIA coverage. This can be daunting if communities no longer perceive measles to be a threat and there are financial, logistical and human resource constraints. However, Ghana and other African countries have the experiences gained in recent poliomyelitis supplemental immunisation campaigns on their side. These experiences could be deployed to the new wave of measles vaccination campaigns particularly in the area of social mobilisation.

Significant measles morbidity and mortality in children older than five years has also been observed in other African countries in which an average of 50\% of cases occurs in children aged 5-14 years(13). This morbidity pattern holds in countries such as Kenya and Tanzania with high routine measles coverage (70\%$80 \%$ ) and in those such as Mali and Cameroon with lower routine measles coverage (50\%-60\%).

The peak transmission of measles differed slightly between districts probably, as a result of the differences in the populations attending the district hospitals. The lowest transmission for measles occurs from August to October suggesting that this could be the best time for mass vaccinations in the central region.

In conclusion, we have demonstrated that retrospective surveillance data quickly provides information on the local epidemiology of measles relevant for the planning of mass vaccination campaigns in Africa.

\section{ACKNOWLEDGMENTS}

The study was funded by the WHO Ghana and the Ghana Health Service. Dr. A. Fall and Dr. R. Kezaala of WHO AFRO provided technical assistance. We thank Dr. E.K. Sory, the central regional Director of Health Services, Mr. J.F. Quainoo and other officials of the Regional Health Administration for their support. We are also grateful to the DHMTs and management 
of the district hospitals for their co-operation. We acknowledge assistance from records officers, nurses and other personnel with data collection.

\section{REFERENCES}

1. Ghana Health Service. Expanded Programme on Immunisation; five year measles plan of action. 2001; 3:2001-2005.

2. Ministry, of Health Ghana. Ghana EPI Policy Draft Guidelines, 1997.

3. Joint WHO/UNICEF Press Release. UN agencies launch new plan to have mortality of measles, a major childhood killer, 29 March 2001; http://www.who.int-inf-Pr-2001/en/index.

4. Dean, A.G, Arner T.G., Sangam, S. et al. Epi Info 2000, a database and statistics program for public health professionals for use on Windows. 95, 98, NT and 2000 computers. Centers for Disease Control and Prevention. Atlanta, Georgia, USA. 2000.

5. Commey, J.O. and Richardson, J.E. Measles in Ghana, 1973-1982. Ann Trop. Paediat. 1984; 4:189-194.

6. Commey, J.O. and Dekyem P. Measles in southern Ghana, 1985-1993. West Afr. J. Med. 1994; 13:223-236.
7. Ministry of Health, Ghana. The health of the nation: analysis of health sector programme of work, Accra, May 1997-2001. 2001; 5.

8. WHO Expanded Programme on Immunization. Measles control in the 1990s: protocol for analysing, the age distribution and age-specific incidence of measles cases in a given population or region. WHO/EM/GEN/94.7. Geneva. 1994.

9. Nkrumah F.K., Osei-Kwasi, M., Dunyo, S.K., Koram., K.A., and Afari E.A. Comparison of AIK-C measles vaccine in infants at 6 months with Schwarz vaccine at 9 months., a randomised controlled trial in Ghana. Bull World Health Organ. 1998; 76:353-359.

10. Success story in Malawi. Reported by WHO/AFRO/EPI Newsletter, Issue No. 003, September 2000 and published in Measles Bulletin, Issue 5. December 2000.

11. WHO AFRO. Measles supplementary immunisation activities field guide. 2001; 4.

12. Kezaala, R., WHO/AFRO. Personal communication. 2001; 9.

13. WHO/AFRO. Target age for supplemental immunization WHO/AFRO's Accelerated Measles Control Initiative. $2001 ; 10$. 
East African Medical Journal Vol. 80 No. 6 June 2003

EFFECTS OF KHAT (CATHA EDULIS) CONSUMPTION ON REPRODUCTIVE FUNCTIONS: A REVIEW

J.M. Mwenda, MPhil, PhD, M.M. Arimi, BSc, M.C. Kyama, BSc and D.K. Langat, MSc, PhD, Institute of Primate Research, P.O. Box 24481, Karen, Nairobi,

Kenya

Request for reprints to: Dr. J.M. Mwenda, Institute of Primate Research, P.O. Box 24481, Karen, Nairobi, Kenya

\title{
EFFECTS OF KHAT (CATHA EDULIS) CONSUMPTION ON REPRODUCTIVE FUNCTIONS: A REVIEW
}

\author{
J.M. MWENDA, M.M. ARIMI, M.C. KYAMA and D.K. LANGAT
}

\begin{abstract}
Objectives: To review research findings on the effects of khat (Catha edulis) chewing on reproductive functions.

Data sources: Retrieval and critical review of relevant articles and abstracts cited in international and local journals, literature searches on Medline and Medchem from 1961 to 2002.

Data synthesis: Analysis of published data and limited interviews of regular khat users revealed that khat chewing lowers libido in humans and may also lead to sexual impotence following long term use. In pregnant women, consumption of khat affects growth of foetus by inhibiting utero-placental blood flow and as a consequence, impairs foetal growth.

Conclusion: Detailed studies on the effects of khat on reproduction are lacking. However, the limited available data reveal that chewing of khat has a negative impact on human reproductive health. Khat is genotoxic and has teratogenic effects on the foetus if regularly consumed by pregnant mothers. Since low birth weight is a well-established risk factor for both perinatal and young infant death, khat chewing during pregnancy may be one of the factors contributing to infant mortality in communities where khat is commonly chewed. Khat consumption affects the potency of male sexuality by affecting spermatogenesis and plasma testosterone concentration. However, the precise mechanisms by which khat may affect the male reproductive physiology have not been elucidated.
\end{abstract}

\section{INTRODUCTION}

Khat (Catha edulis) is the name of an evergreen tree grown in the Middle East, Somalia, East Africa and Ethiopia. It belongs to the sub-order Rosidae and family Celastraceae (the bitter-sweet family of plants). It grows to a height of seven metres and spreads to cover an area three metres wide. The flowers are whitish and are five petalled, occurring in small auxiliary clusters. In Kenya, khat, commonly called miraa, is cultivated on a commercial scale around Nyambene hills found in Meru North, $320 \mathrm{~km}$ North East of Nairobi. A few khat trees are also grown in Mbooni in Machakos district and in central province of Kenya. Some khat trees were also found to be growing in the wild in Koibatek district in Rift Valley province. Harvesting of khat leaves is done in the morning and wrapped in bundles with large fresh leaves such as banana leaves to conserve moisture and keep the khat cool. Those harvested during dry and sunny season are more potent than those harvested during cool months of the year.

Khat is generally chewed when fresh, although occasionally they are dried and then consumed as pleasantly stimulating beverage. Khat is occasionally consumed with coffee. Habitual khat chewing is mainly a male activity but it has become increasingly popular among women(1). In Muslim countries like Yemen, Ethiopia, and Somalia, khat consumption rate is high because all other drugs are forbidden by religious laws. It is regarded as a gift from God handed over to a monk to enable them pray overnight. Traditionally, consumption of khat is concentrated around Eastern Africa and the Middle East. However, chewing of khat is spreading worldwide and particularly in Europe and North America.

\section{CHEMICAL COMPOSITION}

Khat contains a lot of chemical components that have different effects on the body system. Since it is most commonly chewed for its effects on the nervous system, these were the first chemicals studied. Cathine was the first active component to be isolated from dried plant sample as reported by Alles et al., and Zelgher et al (2,3). This compound is also called (+)-/norephedrine, pseudonorephedrine

or norpseudoephedrine(3). Khat use results in modest central nervous stimulation effects(3), which is attributed to Cathine(2). Another compound which is more potent 
than Cathine was also identified in 1961(2). This new compound was isolated and identified as 1(s)-(-)-alphaaminopriopiophenone or Cathinone(2). Cathinone was believed to be the precursor of Cathine, which degrades to enol derivative on drying. However, cathinone can be found in dry plant material if drying is carefully done(3).

\section{Figure 1}

\section{Pseudoephendrine}

\section{Figure 2}

Cathinone

Cathinone is one of the optical isomers of benzylketoamphetamine and has amphetamine-like characteristics(4-6). (-)Cathinone is more potent than its enantiomer (+)cathinone. However both enantiomers have identical absolute stereochemistry in that they possess absolute configuration(4). Cathinone is known to stimulate excess release of dopamine in the central nervous system. Excessive dopamine replenishes the intermediate compound in the synthesis of adrenaline, which is a glycolytic hormone. This results in release of glucose, hence provision of energy for flight(8). Cathinone also affects the production of dopamine in the central nervous system $(7,8)$. The $\mathrm{N}$-methyl analogue of Cathinone is called methcathinone and was shown to be more potent than Cathinone $(4,7)$.

Experiments conducted by Glennon and colleagues in 1987 to compare the drug effect of khat and cocaine using animals trained in behaviour paradigm to discriminate cocaine from vehicles showed that cathinone and methcathinone were indistinguishable from cocaine(4). These investigators further showed that the three compounds could not be distinguished from amphetamine by animals trained to discriminate amphetamine from a vehicle(4). In their studies Zelgher et al. argued that Cathinone produced qualitatively similar locomotor stimulation in mice and comparable stereotype in rats similar to amphetamine(3).

Cathinone interacts with brain catecholamines by indirect mechanisms $(3,8)$. Blocking synthesis of catecholamines by alpha-methyl-p-tyrosine completely abolishes the stereotyped behaviour in Cathine and Cathinone treated animals, and these effects mimic those associated with amphetamine(3). It has been suggested that there is a significant association between the habit of khat chewing and both development of haemorrhoidal disease(11) and mental distress(12). Khat chewing may also cause psychosis(13-15). However, conclusive evidence is lacking.

In addition to the chemicals described above, khat also contains other chemicals that have various effects on the body. A recent study showed that khat affects the levels of various enzymes in the liver(16). These investigators showed that there was a significant increase in plasma levels of alkaline phosphatase (ALP), alanine aminotransferase (ALT) and aspartate aminotransferase (AST) in long-term users (observations made over a six month period). The increase of ALP was more prominent than both ALT and AST at the higher level of $30 \%$. Plasma levels of AST though were only moderately increased at the higher level of $30 \%$ at the early stage of treatment (3 months) it significantly increased with all levels of $C$. edulis leaves in the long term (4-6 months). In addition, a time-dependent gradual increase in indirect bilirubin with a concomitant decrease in direct bilirubin levels were observed with the lower level of $C$. edulis (10\%) with no signs of haemolysis. Histopathology of tissue sections of liver display evidences of increasing chronic inflammation(16).

\section{KHAT AND REPRODUCTIVE HEALTH}

There is limited documentation on the effects of khat consumption on various reproductive parameters (Table 1). There is need to understand the impact of khat consumption on the health of the society and then develop intervention strategies to control the abuse. This is especially important because there are suspected effects of khat on various reproductive heath parameters such as fertility, pregnancy, infant and child survival(17). These effects are discussed. 
Table 1

Possible effects of khat on various aspects of reproduction

\begin{tabular}{llll}
\hline Reproductive organ/function & Khat extract & Effects & Reference(s) \\
\hline Semen volume & Cathinone & Reduced & $10,18-20$ \\
Sperm motility & Cathinone & Reduced & $18-20$ \\
Sperm motility index & Cathinone & Reduced & 19 \\
Sperm count & Cathinone & Reduced & $18-20$ \\
Abnormal sperm & Cathinone & Increased & $18-19$ \\
Utero-placental blood flow & Cathine & Reduced & 21,22 \\
Post implantation losses & ME & Increased & 23 \\
Maternal weight gain & Cathine \& ME & Reduced & $19,24,25$ \\
Placental vascular resistance & Cathine & Increased & 21,22 \\
Maternal blood pressure & Cathine & Increased & 21,22 \\
Maternal myoendometrial blood flow & Cathine & Reduced & 21,22 \\
Sex organs size & Cathine & Reduced & 18 \\
Sex ratio & ME & No effects & 26 \\
Pup/pup size & ME & Reduced & $21,22,24,25$ \\
Plasma testosterone & Cathino & Reduced & 19 \\
Fertility & ME & Reduced & 23 \\
Potency & Cathinone & Reduced & 18 \\
Maternal milk production & ME & Reduced & 26 \\
\hline
\end{tabular}

$\mathrm{Nb}$ : ME Methanolic khat extract.

Effects of khat on female reproductive health: Intrauterine growth retardation, low foetal birth weight and infant mortality are some of the most important reproductive health problems affecting most developing countries. Khat chewing during pregnancy is on the increase among women of reproductive age(1) and questions have been raised on the potential effects of khat on foetal development. In an experiment to determine genotoxic potential of khat, a methanolic khat extract was tested on male germ cells using a lethal assay procedure in Swiss albino mice(23). The extract was administered following a regime of $500 \mathrm{mg} / \mathrm{kg}$ orally once daily, for five days. The effects were studied during the different stages of spermatogenetic cycle, on the of pregnancy rates and post implantation losses. The results showed that khat reduced the percentage pregnancy rates and increased the mean post-implantation losses in the treated groups while there was no change in the controls which received the vehicle (saline) only(23).

The effects of khat alkaloid (+)norpseudoephedrine on utero-placental blood flow in guinea pig was also evaluated by Jansson and colleagues in 1987(21). These investigators found that (+)norpseudoephedrine causes vasoconstriction in the utero-placental vascular bed which may in turn impair foetal growth through reduction of placental blood flow(21). They also showed that in the pregnant pig, the pressure of the regional uteroplacental blood increased by $25 \%$ and heart rate by $9 \%$ during (+)norpseudoephedrine infusions. Myoendometrial blood flow was reduced by $31 \%$ and placental vascular resistance increased by $56 \%(23)$. In a separate experiment to determine teratogenic potential of khat in rats, a methanolic khat extract was administered orally using different doses, to rats in their 6th to 15 th day of gestation. It was found out that khat reduced the food efficiency index but had no effect on sex ratio(29). Administration of khat doses of $125 \mathrm{mg} / \mathrm{kg}$ or higher was found to increase significantly the resorption and foetal wastage. Khat administration in utero also produced intrauterine growth retardation.

Examination of the external, visceral and skeletal regions of the foetuses of treated dams showed several types of malformations and variations in the treated animals(29). These embryonic and teratogenic properties were found to be dose related. Eriksson and co-workers found out that a khat-chewing mother produces less milk than non-users(26). In another study comparing pregnant khat chewers and non-chewers, it was observed that there was no difference in rates of stillbirth or congenital malformation(26). It was also shown that administration of khat to female pregnant guinea pigs resulted in the birth of smaller pups $(21,22,24,25)$. This was attributable to decreased blood flow to the uterus(21). The concentration of pseudoephedrine in pregnant guinea pig urine was found to be directly related to the amount of khat extracts consumed(22). Khat chewing in the third trimester of pregnancy was also found to significantly reduce the maternal weight gain(10,24,25).

Effects of khat on male fertility: Long-term and regular consumption of khat may also lead to progressive and diminished sex performance, and this suggests 
chronic consumption of khat maybe the cause of sexual impotence(10). Most of the available scientific data available in the literature is derived from animal experiments. Our informal discussions and interviews with regular khat chewers in Kenya suggest that khat consumption may lower libido and sexual performance in men of reproductive age (Mwenda, personal communication).

Studies done by Islam et al in 1990 revealed that feeding male rats with khat resulted in significant effects on reproduction(18). These investigators demonstrated that male rats treated with the active constituent, cathinone had testicles, epidydimis and seminal vesicles that were smaller than controls, and had lower circulating testosterone levels(18). Microscopic examination of testicles from these animals showed degenerative changes in the leydig cells (that produce testosterone) and sertoli cells(18). Both enantiomers had deleterious effects on the reproductive system but (-) cathinone, the psycho-stimulant in khat was more toxic(18). In another study with male mice, methanolic extracts derived from khat produced a dosedependent reduction in the fertility rates in the first week of mating $(23,27)$. Khat extracts also induced post implantation loss during the first weeks of pregnancy, and showed a reversible pattern of dominant lethality $(23,27)$.

Studies in our own laboratory on adult male olive baboons (Papio anubis) showed that oral administration of khat extracts significantly increases testosterone but down-regulates prolactin and cortisol levels in blood plasma compared to the basal levels before khat administration(30). In these studies, the animals were given sterile saline for one month and the levels of prolactin, testosterone and cortisol measured daily to obtain the basaline levels. The animals were then fed with khat extracts in saline and the levels of the same hormones monitored daily for two months. Khat administration was then stopped but the levels of hormones monitored for a further two months. The plasma testosterone level was found to be $14.1 \pm 0.6$ $\mathrm{nmol} / \mathrm{l}, 19.1 \pm 1.1 \mathrm{nmol} / \mathrm{l}$ and $23.3 \pm 0.6 \mathrm{nmol} / \mathrm{l}$ in the animals before, during and after oral administration of crude khat extract respectively (Table 2).

Table 2

Concentration of testosterone, cortisol and prolactin before, during and after oral administration of crude khat extract

\begin{tabular}{lccc}
\hline Hormones & Before khat & With khat & After khat \\
\hline Testosterone & $14.1 \pm 0.6$ & $19.1 \pm 1.1$ & $23.3 \pm 0.6$ \\
Prolactin & $87 \pm 5.9$ & $86.3 \pm 3.9$ & $64.6 \pm 2.4$ \\
Cortisol & $569 \pm 45.3$ & $364 \pm 23.7$ & $272 \pm 10.8$ \\
\hline
\end{tabular}

Note: Values are means $\pm \mathrm{SE} \mathrm{P}<0.05$ was considered to be statistically significant
There was significant difference in prolactin concentrations before and after oral administration of crude khat extract. The concentration before and after khat administration was $87 \pm 5.9 \mathrm{mIU} / \mathrm{l}$ and $64.6 \pm 2.4$ $\mathrm{mIU} / 1$ respectively. During the period of khat intake, prolactin concentration was $86.3 \pm 3.9 \mathrm{mIU} / \mathrm{l}$. The concentrations of cortisol before and during oral administration of crude khat extract were $569 \pm 45.3$ $\mathrm{nmol} / \mathrm{l}$, and $364 \pm 23.7 \mathrm{nmol} / \mathrm{l}$ respectively. The concentration was reduced to $272 \pm 10.8 \mathrm{nmol} / \mathrm{l}$ after withdrawal of oral administration of crude khat extract. It was also observed that khat consumption lowered food appetite and a reduction in body weight.

There was no effect on the histology of the testis, epididymis, liver and pituitary gland of the treated baboons. There was a significant decrease $(p<0.05)$ in the body weight after oral administration of crude khat extract. The average body weights were $23.8 \pm$ $0.06 \mathrm{~kg}$ and $23.6 \pm 0.07 \mathrm{~kg}$ before and during khat administration respectively. The body weight of the animals after withdrawal of crude khat extract was 24.1 $\pm 0.04 \mathrm{~kg}$. In some of the animals, the mean body weight dropped by as much as $10 \%$. The body weight remained low during this time and an increase was observed from the 13th week after withdrawal of crude khat extract.

Consistent penile erection was observed at different times in the baboons during oral administration of crude khat extract and this recurred twice in the course of sample collection. Pupillary dilation was observed within 30 minutes of oral administration of crude khat extract. An increase in blood pressure (by 36\%) was also observed during oral administration of crude khat extract. The mean blood pressure before, during and after khat administration was 93/62, 127/72 and 109/ 72 respectively. The results of these studies indicate that khat might affect male fertility and libido by interfering with circulating reproductive hormones.

Limited experiments have also been performed in humans as reported in the literature. In experiments carried out to determine the effects of khat consumption on semen parameters, El-shoura and colleagues in 1995 used a group of 65 khat addicts and a control group of 50 non-users(19). In a similar experiment, Hakim (20) examined 214 male patients with history of infertility who, with the exception of 31 people (control group), used khat regularly(20). In both studies, it was established that khat addicts had a reduced semen volume, low sperm count and reduced sperm motility. In addition, there was an increase in the number of abnormal sperm(19,20). El-shoura et al. also showed that the sperm motility index decreased(19) and Hakim(20) established that the above effects were more pronounced when khat was taken in conjunction with coffee, alcohol and smoking. Khat consumption was found to modify masculine pattern behaviour(20). 


\section{GENERAL PHYSIOLOGICAL EFFECTS OF KHAT CONSUMPTION}

Khat appears to have specific effects on reproductive health as well as general physiological effects and behavioral patterns. Some of the instant physiological effects of Cathinone/khat intake are increased blood pressure and respiration, loquacity, thirst after chewing and a tendency of uncontrollable laughter $(8,9)$. The psychological effects of Cathinone/ khat consumption include euphoria, hallucinations, feeling of paranoia and failure of mental clarity. It also causes psychological and physical dependence(9). Excess production of dopamine in the nervous system (stimulated by cathinone) in turn causes hallucinations, bizarre thoughts, schizophrenia, lethargy, mild depression, nightmares and alertness $(7,8)$.

Khat consumption has been implicated in a wide variety of diseases and disorders in humans. It has been suggested that khat consumption may lead to oral cancer(31,32). The effect is enhanced when khat is taken with alcohol and tobacco(32). Research has shown that regular khat-chewing airline flight attendants had less perpetual-visual memory and a reduction in decision-making speed than occasional khat-chewing and non khat-chewing flight attendants(33). Khat chewing was found out to cause a delay in gastric emptying(34). The constipating and antispasmodic effects of khat were found to be similar to that caused by D-amphetamine(35). Nasher et al. suggested that khat chewing might have a side effect on the urinary system in reducing the maximum and average urine flow rate(36). It has been reported that there are toxic fungi associated with khat leaves that may be harmful to the khat consumers(37). Attef and colleagues also established that khat consumption might affect the bio-availability of therapeutic drugs that may subsequently be taken after khat(38). The effect is more pronounced when the drug is taken almost two hours after consumption of khat. Yousef also showed that khat consumption may cause psychosis(39). Additionally, a case report in Ethiopia showed heavy khat chewing caused episodic psychosis(40). On the other hand, khat was found to act as a pain reliever, similar to amphetamine, although the mode of action was different(41).

\section{CONCLUSION}

Detailed studies on the effects of khat on reproduction are lacking. However, the limited data available show that khat may have drastic negative effects on reproductive health. It is possible that khat use affects both male and female reproductive systems. The mechanisms of action has not been elucidated. Although rodent studies give useful insights to elucidate the mechanism of action of khat/cathinone, there are major differences in the physiology of rodents and humans that place a limitation in the interpretation of data from these experimental animals. Non-human primates are phylogenetically closely related to humans and would form useful models for further studies. The results from our studies on the effect of khat in male baboons strongly suggest this may be an appropriate model to study the medical implications on the use of khat. Further studies are under way to determine the mechanism by which khat affects reproductive functions in baboons.

\section{REFERENCES}

1. Kennedy, J.G., Teague, J. and Fairbanks, L. Khat use in North Yemen and the problem of addiction: a study in medical anthropology. Cult. Med. Psychiat. 1980; 4: 311344.

2. Alles, G., Fairchild, D. and Jensen, M. Chemical pharmacology of Catha edulis. J. Med. Chem. 1961; 3: 323352.

3. Zelgher, J.L., Schorno, H.J. and Carlini, E.A. Behavioral effects of cathinone, an amine obtained from Catha edulis forsk: Comparisons with amphetamine, norpseudoephedrine, apomorphine and nomifensine. OCDCCP Bulletin on Narcotics. 1980; 32: 67-81.

4. Glennon, R.A., Yousif, M., Naiman, N. and Kalix, P. Methcathinone: A new and potent amphetamine-like agent. Pharmacol. Biochem. Behav. 1987; 26:547-551.

5. Kalix, P. Cathinone, a natural amphetamine. Pharmacol. Toxicol. 1992; 70: 77-86.

6. Kalix, P. Khat, an amphetamine-like stimulant. J. Psychoact. Drugs. 1994; 26:69-74.

7. Pehe, E.A., Schechter, M.D. and Yamamoto, B.K. Effects of cathinone and amphetamine on the neurochemistry of dopamine in vivo. Neuropharmacol. 1990; 29:1171-1176.

8. Patel, N.B. Mechanism of action of cathinone: The active ingredient of khat (Catha edulis) East. Afr. Med. J. 2000; 77:329-332.

9. Glennon, R.A. and Showalter, D. The effect of cathinone and several related derivatives on locomoter activity. Res. Comm. Subst. Abuse 1981; 2:186-191.

10. Dalu, A. Impact of long term consumption of khat on public health. The Sudama Concern 2000; 5:15-16.

11. Al-Hadrani, A.M. Khat induced hemorrhoidal disease in Yemen. Saudi Med. J. 2000; 21:475-477.

12. Belew, M., Kassaye M. and Enquoselassie F. The magnitude of khat use and its association with health, nutrition and social economic status. Ethiopian Med. J. 2000; 38:1126.

13. Jager, AD. and Siring L. Natural history of khat psychosis. Australian and New Zealand J. Psychiat. 1994; 28:331-332.

14. Yousef, G. Khat chewing as a cause of psychosis. Brit. J. Hosp. Med. 1995; 54:322-326.

15. Balint, G.A. and Balint, E.E. On the medico-social aspects of khat (Catha edulis) chewing habit. Hum. Psychopharmacol. 1994: 9:125-128.

16. Al-Habori, M., Al-Aghbari, A., Al-Mamary, M. and Baker, M. Toxicological evaluation of Catha edulis leaves: a long term feeding experiment in animals. J. Ethnopharmacol. 2002; 83:209-217.

17. Fathala, M.F. Reproductive health: A global overview. In: Frontiers in Human Reproduction. Ann of the NY Acad of Sci. 1991; 626:1-10.

18. Islam M.W., Tariq M., Ageel A.M., El-Feraly F.S., El-Meshal I.A. and Ashraf I. An evaluation of the male reproductive toxicity of cathinone. Toxicol. 1990; 60:223-234. 
19. El-Shoura, S.M., Abdel, Aziz Ali, M.E, EL-Said, M.M., et al. Deleterious effects of khat addiction on semen parameters and sperm ultrastructure, Hum. Reprod. 1995; 10:2295-2300.

20. Hakim, L.Y. Influence of khat on seminal fluid among presumed infertile couples. East. Afr. Med. J. 2002; 79:2228.

21. Jansson, T., Kristian, B. and Qirbi, A. Effect of khat alkaloid (+)norpseudoephedrine on uteroplacental blood flow in the guinea pig. Pharmacol. 1987; 34:98-95.

22. Jansson, T., Kristian, B. and Qirbi, A. Effects of khat on uteroplacental blood flow in wake, chronically catheterized, late pregnant guinea pigs, J. Ethnopharmacol. 1988; 23:1926.

23. Tariq, M., Al-Meshal, I.A., Parmar, n.S., Ageel, A.M and Qureshi, S. Evaluation of Genotoxic Potential of Khat (Catha edulis) in Swiss albino mice. Mutag. 1986; 1:381382.

24. Abdul, G.A., Eriksson, M., Kristiansson, B. and Qirbi, A. The influence of khat chewing on birth-weight in full term infants. Soc. Sc. Med. 1987; 24:625-627.

25. Jansson, T., Kristian, B. and Qirbi, A. Effects of khat on maternal food intake, maternal weight gain and fetal growth in the late-pregnant guinea pig. J. Ethnopharmacol. 1988; 23:11-17.

26. Eriksson, M., Ghani N.A. and Kristiansson B. Khat chewing during pregnancy-effect upon the offspring and some characteristics of the chewers. Afr. Med. J. 1991; 68:106111.

27. Kalix, P., Taha, S.A., Ageel, A.M., Islam, M.W. and Ginawi, O.T. Effect of (-)-cathinone, a psychoactive alkaloid from khat (Catha edulis) and caffeine on sexual behavior in rats Pharmacol. Res. 1995; 31:299-303.

28. Tariq, M., Quresh, S. and Ageel, M. The induction of dominant lethal mutations upon chronic administration of Qhat (Catha edulis) in albino mice. Toxicol. 1990; 50:349553.

29. Islam, M.W., al-Shabanah, O.A., al-Harbi, M.M. and alGharably, N.M. Evaluation of teratogenic potential of khat (Catha edulis) in Rats. Drug Chem. Toxic. 1994; 17: 51-68.

30. Mwenda, J.M., Kyama, M.C., Arimi, M.M., Achieng, R.O. and Langat, D.K. The possible biological effects of khat (catha edulis) extract on the reproductive functions of the male baboons (papio anubis). Proceedings of the 9th international symposium on spermatology, Cape Town, South Africa, Octiber 6th-11th 2002, Monduzzi Editore, international proceedings division, editors; G. Van Der Horst, D. Franken, R. Borman, T. De Jager and S. Dyer, pages 158-166, 2002.

31. Gunaid, A.A., Sumairi, A.A., Shidrawi, R.G., et al. Oesophageal and gastric carcinoma in the Republic of Yemen. Brit. J. Cancer 1995; 71:409-410.

32. Kassie, F., Drroud, F., Kundi, M., et al. Khat (Catha edulis) consumption causes genotic effects in humans. Int. J. Cancer 2001; 92:329-332.

33. Khattab, N.Y. and Amer, G. Undetected neuropsychophysiological sequelae of khat chewing in standard aviation medical examination. Aviat. Space Environ. Med. 1995; 66:739-744.

34. Heyman, T.D., Bhupulan, A., Zureikat, N.E., et al. Khat chewing delays gastric emptying of a semi-solid meal. Pharmacol Ther. 1995; 9:81-83.

35. Makoneen, E. Constipating and spasmolytic effects of khat (Catha edulis) in the experimental animals. Phytomed. 2000; 7:309-312.

36. Nasher, A.A., Qirbi, A.A., Ghafoor, M.A., et al. Khat chewing and bladder dysfunction. A randomized controlled trial of alpha 1-adrenergic blockade. Brit. J. Urol. 1995; 75:597-598.

37. Mahmoud, A.L. Mycotoxin-producing potential of fungi associated with khat (Catha edulis) leaves in Yemen. Folia Microbiol (praha) 2000; 45:452-456.

38. Attef, O.A., Ali, A.A. and Ali, H.M. Effects of khat chewing on the bioavailability of ampicillin and amoxycillin. Antimicrob. Chemother. 1997; 39:523-525.

39. Yousef, G., Hup, Z. and Lambert, T. Khat chewing as a cause of psychosis. Brit. J. Hosp. Med. 1995; 54:322-326.

40. Alem, A. and Shibre, T. Khat induced psychosis and its medico-legal implication: Ethiop. Med. J. a case report 1997; 35:137-139.

41. Connor, J., Makonnen, E. and Rostom, A. Comparison of analgesic effects of khat (Catha edulis) extract, Damphetamine and ibuprofen in mice: J. Pharm. Pharmacol. 2000; 52:107-110. 
East African Medical Journal Vol. 80 No. 6 June 2003

CRYPTOSPORIDIUM OOCYSTS IN GHANAIAN AIDS PATIENTS WITH DIARRHOEA

A. Adjei, Department of Pathology, M. Lartey, Department of Medicine, T.K. Adiku, Department of Microbiology, University of Ghana Medical School, Korle-Bu, Accra, O. Rodrigues, Department of Child Health, Korle-Bu Teaching Hospital, Korle-Bu, Accra, L. Renner, Department of Child Health, Korle-Bu Teaching Hospital, KorleBu, Accra, E. Sifah, Department of Child Health, Korle-Bu Teaching Hospital, Korle-Bu, Accra, J.D. Mensah, Korle-Bu Polyclinic, Korle-Bu, Accra, B. Akanmori, J. Otchere, B.K. Bentum and K.M. Bosompem, Noguchi Memorial Institute for Medical Research, Legon, Accra, Ghana

Request for reprints to: Dr. K.M. Bosompem, Noguchi Memorial Institute for Medical Research, P.O. Box LG581, Legon, Accra, Ghana

\title{
CRYPTOSPORIDIUM OOCYSTS IN GHANAIAN AIDS PATIENTS WITH DIARRHOEA
}

\author{
A. ADJEI, M. LARTEY, T.K. ADIKU, O. RODRIGUES, L. RENNER, E. SIFAH, J.D. MENSAH, \\ B. AKANMORI, J. OTCHERE, B.K. BENTUM and K.M. BOSOMPEM
}

\begin{abstract}
Background: Although Cryptosporidium spp. infections in acquired immunodeficiency syndrome patients (AIDS) with chronic diarrhoea have been reported in several African countries, there is no information regarding cryptosporidial diarrhoea in Ghanaian AIDS patients. Objective: To investigate the occurrence of $C$. parvum and other gastrointestinal parasitic agents in Ghanaian AIDS patients with chronic diarrhoea.

Design: Prospective study of HIV/AIDS patients with diarrhoea over a nine month period. Setting: Korle-Bu Teaching Hospital and Korle-Bu Polyclinic. Accra, Ghana.

Methods: Cryptosporidium oocysts was stained using modified Ziehl Neelsen staining technique and examined microscopically. Other enteric organisms were identified using standard microbiological techniques.

Results: Analysis of stool specimens from clinically diagnosed HIV/AIDS (n=2I; mean CD4 count was 288 cells per microliter, $95 \%$ confidence interval of 237 to 340 cells per microliter) and HIV-seronegative $(\mathrm{n}=27)$ patients revealed $C$. parvum in six $(\mathbf{2 8 . 6 \%})$ of HIV/AIDS and $10(37.0 \%)$ of the HIV-seronegative patients, respectively. Three other HIV/AIDS cases had other infections involving Strongyloides stercoralis $4.8 \%(1 / 21)$ and Salmonella spp. $9.5 \%$ (2/21). There was no concomitant association between $C$.parvum and any other parasites found. Also, no enterobacteria was found in the HIV-seronegative patients.

Conclusion: This study demonstrates the prevalence of Cryptosporidium sp. in both HIV/ AIDS and HIV-seronegative individuals in Ghana. However, there was no statistical association between cryptosporidiosis and HIV/AIDS ( $p>0.05$ ).
\end{abstract}

\section{INTRODUCTION}

Enteric cryptosporidiosis, caused by the coccidian parasite Cryptosporidium sp., has become of increasing interest since the first case of human cryptosporidiosis was reported in 1976(1). Much of this interest is due to its opportunistic behaviour in immunocompromised patients, particularly in those with acquired immune deficiency syndrome (AIDS)(2,3). AIDS predisposes individuals to several parasitic diseases, and among the intestinal parasites, the intracellular coccidia, Isospora belli and Cryptosporidium parvum, are important(4). As a result of increased cryptosporidial related diarrhoea in HIV/AIDS patients, the disease was recently listed as one of the AIDS-defining opportunistic infections(5).

Cryptosporidiosis develops in an estimated 10-15\% of patients with AIDS in the United States of America and Europe $(3,6,7)$ and $30-50 \%$ of patients with AIDS in the developing countries $(8,9)$. Previous studies in Ethiopia, Zambia, D.R. Congo and other African countries have shown high prevalence rates of $C$. parvum infections in AIDS patients(10-12). The role of cryptosporidiosis in HIV/AIDS related diarrhoea in Ghana is virtually unknown.
With a continuous rise in the number of HIV/AIDS infected persons, and with a prevalence rate currently estimated at 4\% (National AIDS/STD Control Programme, Ministry of Health, Accra, Ghana). It is likely that Cryptosporidium sp. related diarrhoea may be prevalent in Ghana. This is even more likely because various animals that are potential sources of transmission (dogs, cats, cattle and pigs) and in some cases rats and mice share human habitations. Additionally, the common sources of drinking water including tap water, may be contaminated because of inadequacy of standard water treatment methods to remove the parasite. The aim of this study was to determine the prevalence of Cryptosporidium and other gastrointestinal parasitic agents in Ghanaian AIDS patients with chronic diarrhoea.

\section{MATERIALS AND METHODS}

Study area and subjects. This study was conducted at the Fevers Unit and the Polyclinic Unit of the Korle-Bu Teaching Hospital, Accra, Ghana, between February and September, 2001. Korle-Bu Teaching Hospital is a leading tertiary hospital which serves the city of Accra, surrounding urban population and the southern part of Ghana. Accra, the capital city of Ghana 
is a rapidly expanding city with a population of about 2 million. Twenty one HIV/AIDS patients (aged 8 months 54 years 11 males and 10 females) with chronic diarrhoea on admission at the Fevers Unit, and twenty seven HIV-seronegative individuals (control; aged 6-60 years 16 males and 11 females) who reported at the Polyclinic Unit with chronic diarrhoea were recruited in the study. The protocol for this study was approved by the Ethical and Protocol Review Committee of the University of Ghana Medical School, and written and informed consent was obtained from the patients. Following informed consent, a detailed demographic questionnaire including history and clinical status was completed with the help of a study nurse. The guidelines for the classification of HIV/AIDS in adults from the Centers for Disease Control (CDC), USA (13) were applied to both groups of patients. HIV testing was done by the particle agglutination test (Serodia HIV-1 and HIV-2: Fujirebio inc., Tokyo, Japan ) and confirmed by Western Blot analysis (New Lav Blot I and II) or the synthetic peptide-based immunoassay (PeptiLav I and II), both obtained from Sanofi Diagnostic Pasteur, Marnes-laCoquette, France.

Definition of diarrhoea episodes: The World Health Organization (WHO) criteria was used to determine diarrhoeal episodes (14). A total of three or more unformed stools in one 24hour period was determined to be a diarrhoeal day.

Specimen Collection and processing: Diarrhoeal samples from each patient was collected directly into sterile disposable containers and a portion of each sample subsequently preserved in a tube containing $10 \%$ formalin for parasitological examination. Fresh stools were transported to the laboratory for parasitologic and microbiologic evaluation within 24 hours. Preserved stool specimens were concentrated using formalin-ethyl acetate at $800 \mathrm{xg}$ in a faecal parasite concentrator and two slides were made from the resulting pellet. One slide was stained with Lugol's iodine and examined microscopically at 400x magnification for the presence of endemic parasites: Giardia lamblia cysts, Trichuris trichiura, Ascaris lumbricoides, Strongyloides stercoralis, Ancylostoma spp., Schistosoma mansoni and Entamoeba spp. The second slide prepared with faecal pellet was used to detect $C$. parvum oocysts by modified Ziehl Neelsen technique. Briefly, slides were stained for 20 min with carbol fucshin and de-stained for 30-60 seconds with a $10 \%$ solution of sulphuric acid. After washing, slides were counterstained with methylene blue for $1 \mathrm{~min}$. Red-stained $C$. parvum oocysts were observed microscopically using a 40x objective. Fresh wet stool preparations stained with Lugol's iodine were also examined for parasites. Unstained, fresh stool specimen were plated onto various bacteriological agar media to isolate bacteria: MacConkey (Shigella species, Salmonella species), xylose-lysinedeoxycholate (Yersiniaenterocolitica). thiosulphate-citrate-bilesucrose, trypticase soy with 5\% defibrinated sheep blood and ampicillin(Campylobacter jejuni). Culturing for enterotoxigenic Escherichia coli and demonstration of rotavirus could not be performed.

Statistical analysis: Statistical analysis were performed by Fisher's exact or Wilcoxon rank test. Results were considered significant when the P-value was less than 0.05.

\section{RESULTS}

All the $21 \mathrm{HIV} / \mathrm{AIDS}$ (with a single infection from HIV-1) patients fell within the CDC clinical staging AIC3 categories, representing asymptomatic AIDS to severe AIDS conditions. The patients had mean CD4 counts of 288 cells per microliter (95\% confidence interval of 237 340 cells per microliter).

All patients reported watery stools lasting from 3-90 days (diarrhoea episodes, 3-10 stools/day). In addition to diarrhoea, the most common symptoms in both groups of patients (HIV/AIDS and HIV-negative patients) included abdominal pain, nausea, vomiting and fever. Presence of blood in stools was, less frequently reported (Table).

As shown in Table 1, significantly more HIV-negative patients 11 (40.7\%) had abdominal pains compared to HIV/AIDS patients $5(23.8 \%)(\mathrm{p}<0.05)$. Nevertheless, none of the HIV/AIDS patients with abdominal pain and two out of 11 HIV-negative patients had Cryptosporidium oocysts in their stools. Of the 21 HIV/AIDS and 27 HIVnegative patients, six $(28.6 \%)$ and $10(37.0 \%)$, respectively had C. parvum only (Table 2).

There was no concomitant association between $C$ parvum and any other intestinal parasites found in the stools of both categories of patients. Of the remaining HIV/AIDS cases, one patient had $S$. stercoralis and two had Salmonella spp, however, no enterobacteria was found in the HIV-negative patients (Table 2). Major risk factors such as drinking of untreated/ unboiled water and close association with domestic animals (chickens, pigs, cattle, sheep, goats, dogs, cats) had no significant effect on Cryptosporidium infections ( $\mathrm{p}>0.05)$.

Table 1

Symptoms associated with chronic diarrhoea in HIV/AIDS and HIV-seronegative patients

\begin{tabular}{|c|c|c|c|c|}
\hline \multirow{2}{*}{$\begin{array}{l}\text { Characteristic } \\
\text { Symptoms }\end{array}$} & \multicolumn{2}{|c|}{ HIV/AIDS (n=21) } & \multicolumn{2}{|c|}{ HIV-seronegative $(n=27)$} \\
\hline & Number $(\%)$ & $\begin{array}{l}\text { Cryptosporidium spp } \\
\text { positive }\end{array}$ & Number (\%) & $\begin{array}{c}\text { Cryptosporidium spp } \\
\text { positive }\end{array}$ \\
\hline Abdominal pain & $5(23.8)$ & 0 & $11(40.7)$ & 2 \\
\hline Nausea & $9(42.8)$ & 2 & $12(44.4)$ & 5 \\
\hline Vomiting & $7(33.3)$ & 3 & $9(33.3)$ & 6 \\
\hline Fever & $8(38.1)$ & 2 & $13(48.1)$ & 3 \\
\hline Blood in stool & $1(4.8)$ & 0 & $3(11.1)$ & 0 \\
\hline
\end{tabular}

\footnotetext{
* Stool samples were loose and take the shape of the container.
} 
Table 2

Pathogens identified in HIV/AIDS and HIV-seronegative patients with chronic diarrhoea

\begin{tabular}{lcc}
\hline Pathogen & $\begin{array}{c}\text { HIV/AIDS } \\
\mathrm{n}=21(\%)\end{array}$ & $\begin{array}{c}\text { HIV-seronegative } \\
\mathrm{n}=27(\%)\end{array}$ \\
\hline Cryptosporidium spp. & $6(28.6)$ & $10(37.0)$ \\
Strongyloides stercoralis & $1(4.8)$ & 0 \\
Salmonella spp. & $2(9.5)$ & 0 \\
\hline
\end{tabular}

\section{DISCUSSION}

Cryptosporidiosis is a highly infectious illness with multiple modes of transmission through water, person-toperson and zoonosis(16). It has a serologic prevalence as high as $30-60 \%$ in industrialized countries $(17,18)$ and $95 \%$ in some tropical and developing countries (16). Cryptosporidia are etiologic agents in 10-35\% of' cases of AIDS-associated diarrhoea, and cryptosporidiosis results in a significant morbidity and mortality in patients with AIDS world-wide $(5,7)$. However, there is little or no information available on the prevalence, significance, and prognosis of Cryptosporidium infection in Ghana, particularly in HIV/AIDS patients.

In this study, Cryptosporidium parvum oocysts were identified by the modified Ziehl Neelsen method whose sensitivity and specificity are reported to be comparable to that of the immunofluorescence assay(19). C. parvum was isolated as the dominant pathogen from both HIV/AIDS and HIV seronegative groups of patients with diarrhoea than any of the other enteric pathogens investigated $(\mathrm{p}<0.05)$. This finding suggested that Cryptosporidium may be an unrecognized pathogen of diarrhoea and other gastrointestinal disorders in the Ghanaian population. However, there is the need to determine the importance of other agents of diarrhoea, such as enteropathogenic $E$. coli, viral and microsporidia infections which were not investigated in this study.

The results of this study are in agreement with that of Lucas (1990) who noted that the more 'common' intestinal parasites, G. lamblia, T. Trichiura, A lumbricoides and $S$. stercoralis are not opportunistic in HIV/AIDS patients (20), Even though Cryptosporidia and other diarrhoea-causing pathogens produce similar symptoms, Tzipori (1988) reported that abdominal pains is associated with cryptosporidial diarrhoea(21). Nevertheless, the absence of abdominal pains in most Cryptosporidium infected diarrhoeal patients in this study may therefore suggest other causes of diarrhoea. Cryptosporidial diarrhoea is self limiting in immunocompetent hosts and may be found in active disease. Furthermore, the lack of clear association with possible risk factors of acquiring cryptosporidiosis (such as consumption of contaminated drinking water and contact with domestic animals) calls for more work to identify the major routes of infection in the study area.
In summary, the data presented herein demonstrates the occurrence of Cryptosporidium among HIV/AIDS and HIV-seronegative diarrhoeal patients in Ghana. The disease was however not significantly associated with HIV/AIDS, and the high prevalence of infection in the HIV-seronegative population suggested that the transmission of Cryptosporidium in the study communities is high. In view of the increasing prevalence of HIV/AIDS in Ghana. findings from future studies will be useful in developing preventive measures for reducing infection among immunodeficient groups.

\section{REFERENCES}

1. Nime, F.A.,. Burek, J.D., Page, D.L., Holscher, M.A. and Yardley, J.H. Acute enterocolitis in a human being infected with the protozoan Cryptosporidium. Gastroenterol. 1976; 70: $592-598$.

2. McGowan, L., Hawkins, A.S. and Walker, I.V.D. The natural history of cryptosporidial diarrhoea in HIV infected patients. AIDS .1993; 7: 349-354.

3. Peterson, $\mathrm{C}$, Cryptosporidosis in patients infected with human immunodeficiency virus. Clin. Infect. Dis. 1992;15:903-909.

4. Fleming, A.F. Opportunistic infections in AIDS in developed and developing countries.Trans. Roy. Trop. Med. Hyg. 1990; 84 (Suppl 1): 1-5.

5. J. Kuby The Immune System in AIDS, In. imunology. ed., 1997; pp523-554, . WH Freeman and Company, New York, USA.

6. Laughon, B.E., Druckman, D.A. and Vernon, A.A. Prevalence of enteric pathogens in homosexual men and without acquired immunodeficiency syndrome. Gastroenterol. 1988; 94: 984993.

7. Colford, J.M.,Tager, I.B., Hirozawa, A.M., Lemp, G.F., Aragon,T. and Petersen, C. Cryptopsoridiosis among patients infected with human immunodeficiency virus. Am. J. Epidemiol. 1996; 144: 807-816.

8. Sanchez-Mejorand, G. and Ponce-de-Leon, S, Clinical patterns of diarrhoea: etiology and prognosis. Rev. Invest. Clin. 1994; 46: $187-196$

9. Wuhib, T., Siva, T.M.J. and Newmann, R.D. Cryptosporidial and microsporidial infections in human immunodeficiency virus-infected patients in northeastern Brazil. J. Infect. Dis. 1994; 170: 494-497.

10. Fisseha, B., Petros, B. and Woldemichael, T. Cryptosporidium and other parasites in Ethiopian AIDS patients with chronic diarrhoea. E. Afr. Med. J. 1998; 75: 100-101.

11. Kelly. P., Sri Baboo. K., Ndubani, P., Nchito, M., Okeowo, N.P., Nkandu, P.L., Feldman, R.A. and Farthing. M.J.G. Cryptosporidiosis in Adults in Lusaka, Zambia, and its relationship to oocysts contamination of drinking water. $J$. Infect. Dis. 1997; 176: 1120-1123.

12. Colebunders, R. Persistent diarrhoea in Zairean AIDS patients: an endoscopic and histologic study. Gut 1990; 29: 1687-1691.

13. Levy, J.A. Revised classification systern for HIV infection and expanded AIDS surveillance case definition for adolescents and adults. In HIV and pathogenesis of AIDS. American Society of Microbiology pp 241-246, 1994, (ASM) Press, Washington. DC.

14. World Health Organization. Persistent diarrhoea in children in developing Countries: Memorandum from a WHO meeting. Bull WHO. 1988; 66: 708-717.

15. Dupont, H.L., Chappell, C.L. Sterling, C.R., Okhuysen. P.C. and Rose, J.B. The infectivity of Cryptosporidium parvum in healthy volunteers. N. Engl. J. Med 1995; 332:855-859. 
16. Newman, R.D., Zu, S.X., Wuhib.T., Guerrant, R.L. and Sears, C.L. Hosehold epidemiology of Cryptosporidium parvum infection in an urban community in northeast Brazil. Ann. Intern. Med. 1994; 120: 500-505.

17. Goodgame, R.W. Understanding intestinal spore-forming protozoa: cryptosporidia, microsporidia, isospora and cyclospora. Ann. Intern. Med. 1996; 124: 1429-1441.

18. KuhIs, T.L., Mosier, D.A., Crawford, D.L. and Griffis, J. Seroprevalence of cryptosporidial antibodies during infancy, childhood, and adolescence. Clin. Infect. Dis. 1994; 18: 731735 .

19. Macpherson, D.W. and McQueen, R. Cryptosporidiosis: multiattribute evaluation of six diagnostic methods. J. Clin. Microbiol. 1993; 31: 198-202.

20. Lucas, S.B. Missing infection in AIDS.Trans. Roy. Soc. Trop. Med. Hyg. 1990; 84(Suppl): 34-38.

21. Tzipori, S. Cryptosporidiosis in perspective. Adv. Parasitol. 1988; 27:64-129. 
East African Medical Journal Vol. 80 No. 6 June 2003

GASTRO INTESTINAL HYPERPERMEABILITY: A REVIEW

M. Viljoen, PhD (Physiology), Professor, A. Panzer, MBChB, PhD, Senior Lecturer and N. Willemse, PhD, Lecturer, Department of Physiology, University of Pretoria, P.O. Box 2034 Pretoria 0001, South Africa

Request for reprints to: Prof. M. Viljoen, Department of Physiology, University of Pretoria, P.O. Box 2034 Pretoria 0001, South Africa

\title{
GASTRO INTESTINAL HYPERPERMEABILITY: A REVIEW
}

\author{
M. VILJOEN, A. PANZER, and N. WILLEMSE
}

\begin{abstract}
Objectives: To present a wide overview of the recent developments in the understanding of the aetiopathogenesis of gastrointestinal hyperpermeability.

Data sources: Medline, from 1985, was sourced for relevant articles. Review articles were included in order to minimise the number of references in the reference list.

Study selection: Results from experiments and observations on humans and other mammalian species were studied.

Data synthesis: The major mechanisms elucidated in the aetiopathogenesis of the gastrointestinal hyperpermeability were integrated and consolidated into a flow diagram and the major factors responsible for normal permeability presented for comparison.

Conclusion: The occurrence of increased gastrointestinal hyperpermeability is probably vastly underestimated. In addition to the hyperpermeability commonly associated with chronic gastro intestinal disorders, an increase in gastrointestinal permeability may occur in any condition of metabolic depletion, enterocyte ATP-depletion, stimulation of gastrointestinal pro-inflammatory cytokine production and disturbances of the normal gastrointestinal flora as with prolonged use of antibiotics.
\end{abstract}

\section{INTRODUCTION}

The main function of the gastrointestinal tract is to absorb nutrients efficiently. However, just as important to the host's survival is its seemingly contradictory role of preventing the transit of pathogens across the gastrointestinal wall. In this review, the factors involved in the maintenance of gastrointestinal barrier integrity are illustrated and the aetiopathogenesis of hyperpermeability is discussed. We conclude with a short summary of clinical tests and therapeutic options.

Mechanisms involved in maintenance of gastrointestinal barrier integrity: Bacteria and antigens in the lumen of the gut are separated from the enterocytes by both non- specific and immunologic barriers (Figure 1). The enterocyte layer can be crossed by either transcellular or paracellular routes. A major factor in the maintenance of normal permeability is the structural integrity of the enterocytes. Transcellular transport, including diffusion, as well as symport and antiport by means of carrier proteins and ion channels can occur. Many of these transcellular transport processes require ATP, and any factor, which depletes the energy stores, will generally increase gut permeability. If potential antigens cross into the enterocyte immune activation can occur, as enterocytes may act as antigen-presenting cells.

The paracellular space is enclosed by tight junctions, which consist of several strands formed by the fusion of outer membrane proteins of adjoining enterocytes(1-3). The number of strands determines the tightness of the junctions and acts as a rate-limiting factor regulating the selective permeability of the paracellular areas(1-4). Intracellular signals transmitted to the tight junctions normally regulate the permeability by inducing dynamic cytoskeletal re-arrangements. Any factor that either damages a component of the tight junctions or prohibits the necessary cytoskeletal re-arrangements will alter normal gut permeability.

The aetiopathogenesis of hyperpermeabillity of the gastrointestinal barrier: Various factors may lead to gastrointestinal hyperpermeability with a resultant increase in microbial translocation and overwhelming of the normal defense against translocated microbes and microbial products. A number of causes are known to result in a pathological increase in gut permeability (Table 1)(5,6). 


\section{Figure 1}

Maintenance of normal gastrointestinal barrier integrity

Foreign antigens in the lumen of the gut are prevented from translocating by non-specific and immunologic factors. Passage through the gut wall has been described through transcellular or paracellular routes. Adapted from(30) and(43). 


\section{Table 1}

Potential causes of pathological increase in gut permeability

Bacterial overgrowth

Starvation and malnutrition

Thermal injury

Trauma

Biliary obstruction

Immunosuppression

Disturbance of the normal intestinal flora by antibiotics

Circulatory shock and reperfusion injury

Endotoxaemia

Metabolic depletion and acidosis

Inflammation and infection

Non- steroidal anti-inflammatory drugs

Sometimes in non-gut related surgery

Prolonged exercise

Travellers' diarrhoea

Ischaemia and oxidative stress

The major theories proposed for an increase in gastrointestinal barrier permeability illustrated in figure 2 are discussed in the following sections.

\section{Figure 2}

Factors involved in gastrointestinal hyperpermeability

Increased pro-inflammatory cytokine production (A) can stimulate the induction of nitric oxide synthase (iNOS) (B), which leads to NO and ONOO- production which may lead to stimulation of the caspases complex - with eventual apoptosis. Proinflammatory cytokines can also change paracellular and transcelfular translocation (C). A decrease in normal intestinal flora (D) can also increase paracellular as well as transcellular bacterial translocation. Genetically determined increases (E) in transcellular and paracellular permeability may underlie some diseases. Various conditions (F) can cause apoptosis by a decrease in ATP production. 
Nitric oxide: In the gut, as elsewhere in the body, NO is produced during conversion of arginine to citrulline under influence of the enzyme nitric oxide synthase (NOS). All three NOS isoforms may be involved in gut physiology and pathology: a) the neuronal derived nNOS (NOS1), expressed in the myenteric plexus, b) the endothelial eNOS (NOS3) which is involved in gut perfusion and c) inducible NOS or iNOS (NOS2) which is only present to any significant extent in the gut in the presence of inflammatory and other stimulatory influences(7-9). Under normal conditions, NO plays a gastrointestinal homeostatic role through the regulation of blood flow, regulation of gut permeability and in the defense against pathogenic organisms. Clinical evidence for the role of $\mathrm{NO}$ in gastrointestinal tract pathology of humans is derived from the finding of increases in iNOS activity in patients with inflammatory bowel disease(10) and in infants undergoing surgical resection for necrotising enterocolitis(11) where upregulation of iNOS was found in association with apoptotic areas. During sustained overproduction of $\mathrm{NO}$, both $\mathrm{NO}$ and the subsequently produced peroxynitrite $\left(\mathrm{NO}+\mathrm{O}_{2}^{-}=\mathrm{ONOO}^{-}\right)$, can lead to deleterious effects such as dilation of intercellular tight junctions (12) and enterocyte apoptosis(12,13). One would logically presume that suppression of excessive NO production could be of benefit to patients. However, indications are that gastrointestinal mucosal injury caused by ischaemia and reperfusion(14), endotoxaemia(15), platelet activating factor activation(16) and endothelin(2) could be worsened by suppression of the endogenous NO production. In fact, on several occasions, it has been reported that stimulation of NO production ameliorates mucosal injury(17). Possible mechanisms involved in this protective effect of NO include the suppression of mast cell-derived inflammatory mediator-release, inhibition of leukocyte adhesion to endothelial walls $(18,19)$, protection against certain bacterial toxins by inhibition of mast cells and neutrophils(20) and stimulation of intestinal mucosal recovery after mesenteric ischaemia(21). However, excessive $\mathrm{NO}$ production can contribute to gastrointestinal hyperpermeability.

Hypoxia, oxidative stress, reperfusion injury, metabolic inhibition and acidosis: Conditions which cause hypoxia of the gastrointestinal wall can affect permeability due to depletion of ATP, accumulation of reducing equivalents in the cells or by a number of reactions with free iron(2).

Oxidative stress, including the formation of the superoxide anion, hydrogen peroxide and the hydroxyl radical may lead to increased permeability of both enterocytes and endothelial cells through activation of phospholipase C-dependent hydrolysis, lipid peroxidation, perturbation of transport processes and disturbance of mitochondrial function with subsequent depletion of ATP stores and enterocyte actin-dependent cytoskeletal malfunctioning(2). This would lead to an increase in both the paracellular and transcellular transport processes. It could further contribute to the NO-induced apoptosis, both by reducing the ATP stores and by providing the reactive oxygen species for peroxynitrite production.

The danger of reperfusion lies in the excessive formation of reactive oxygen species. Intestinal ischaemia and reperfusion aggravate barrier damage even further because it also activates the phagocytic system and, in combination with an increase in cytokine production, may lead to inflammatory damage as well as to NO induction. The final result is increased bacterial translocation(22).

Any factor that leads to metabolic inhibition can increase gut permeability by reducing the ATP stores, leading to enterocyte apoptosis with subsequent bare areas of increased permeability. With metabolic inhibition, general destabilization of the enterocyte tight junction cytoskeleton will further increase paracellular transport $(23,24)$.

Several mechanisms underlying increased gut permeability are ascribed to acidosis. The most important actions are probably the fact that acidosis can, even in the absence of metabolic depletion, give rise to ATP depletion, and that the production of reactive oxygen species are enhanced in conditions of acidosis(25). The latter process may further be augmented by the release of iron from protein-bound stores(26). However, several protective mechanisms of acidosis against damage to the intestinal wall have also been described(2).

Cytokines and other inflammatory mediators: The gut is constantly exposed to intralumen endotoxins as well as to inflammatory mediators from macrophages and lymphocytes and has been described as a cytokineliberating organ(27). Cytokines such as interleukin-1 and interferon7 can induce the expression of iNOS mRNA leading to increased gut permeability by stimulating the production of $\mathrm{NO}(28)$.

Growth hormone and cholecystokinin: Though growth hormone has been shown to improve gut mucosal structure, it increases mucosal permeability to intestinal bacteria. A possible explanation for this apparent paradox may be that high growth hormone levels stimulate the release of somatostatin via negative feedback, which in turn inhibits cholecystokinin secretion by the enteroendocrine cells of the gut mucosa(29). Cholecystokinin modulates the function of secretory $\lg \mathrm{A}$, which is a major protective factor in preventing bacterial adherence and thus maintaining normal intestinal permeability. Gut resection or other damage to the gastrointestinal tract may result in a decreased number of enteroendocrine cells, less cholecystokinin and less secretory $\lg \mathrm{A}$. The final result is increased bacterial adhesion and an increase in bacterial translocation(29).

Disturbance in the normal gastrointestinal flora: Normal flora colonises the gut by binding to receptors on the luminal surface of enterocytes. Under normal conditions, the competition between the commensal and 
the pathogenic organisms offers a kind of protection against pathogenic invasion. Antibiotic medication disturbs the normal commensal bacteria, allowing colonisation by pathogenic bacteria with subsequent increase in their translocation. Pathogenic bacteria will colonise the gut by first adhering to the glycoconjugates of the microvillous membrane, which are receptors for various physiological ligands. By pirating the receptors of natural agents, the pathogenic bacteria activate signal transduction pathways leading to a series of biochemical processes which eventually facilitate its translocation into the interstitium(30). This translocation is facilitated by a) the production of molecules which open the tight junctions and so increase paracellular translocation and b) modification of the enterocyte actin composition with subsequent translocation by means of endocytosis (transcellular translocation). Exo- and endotoxins can, in the same way, activate enterocyte receptor-mediated intracellular pathways resulting in the release of proinflammatory cytokines, inflammatory tissue destruction, as well as NO-induced apoptosis $(12,13,30)$.

Tests for gut permeability: Intestinal permeability can be estimated by measuring the concentration of administered macromolecules or single sugars in the blood or urine (31-33). The types of molecules used as probes include sichromium-labelled ethylenediaminotetraacetate, the polyethylene glycols, horseradish peroxidase and proteins, and various sugars(31-33). siChromiumlabelled ethylenediaminotetra-acetate is given orally and measured in the urine by gamma counter. The results obtained are considered a fair reflection of intestinal permeability, though the test has the disadvantages associated with radioactive substances. The polyethylene glycols represent a mixture of ethylene glycol polymers. It is a non-invasive test as the probe is taken by mouth and the test performed on urine. Analytical procedures (gasliquid or high-performance liquid chromatography) and clinical interpretations of the results are complicated, which renders the ethylene glycol polymers unsuitable for clinical use in all but the more sophisticated laboratories. The horseradish peroxidases and proteins are not really biologically inert and may lead to complications such as immunological stimulation. Various sugars are used including the monosaccharides (D-mannitol, L-rhamnose and D-xylose) and the disaccharides (lactulose, cellobiosc, sucrose and lactose).

Changes in intestinal permeability can also be evaluated by the simultaneous oral administration of two different water-soluble probe molecules that are neither digested nor metabolised. One is usually a relatively small molecule that permeates moderately well through normal mucosa, and the other is usually a larger molecule with minimal permeation of the normal mucosa. These molecules cross the epithelium, are taken up into the circulation, and are then excreted in the urine. The amounts absorbed depend on their physicochemical features as well as the intestinal mucosal integrity. Differential absorption can then be ascertained by measuring the different concentrations of the probes excreted in the urine. The ratio of the two probes is an indication of intestinal permeability. The advantage of a differential absorption test, above that of using a single sugar, is that variables such as the volume of urine collected, the time interval between intake and testing will presumably influence both probes and the ratio will not be much affected. The mannitol and lactulose ratio is most frequently used. However, while it may be the best combination for the determination of gastrointestinal permeability, it is not suitable for rating the seriousness of conditions. Still, it remains a useful tool for screening for small intestinal disease, for evaluating the effectiveness of treatment and, perhaps, even as prognostic indicator $(31,32)$. Some studies indicate that the combination of lactulose (L) and 1rhamnose $(\mathrm{R})$ may provide satisfactory results $(32,33)$. The evaluation on this combination was done using both urine and blood samples and the ratio of the two sugars determined. Blood samples used to test for intestinal permeability have proven to be a valid alternative to urine collection and testing, and blood specimens show a lower test failure rate(32). A ratio for lactulose to rhamnose of $5 \mathrm{~g} / 0.5 \mathrm{~g}$ in solution is sufficient to discriminate between normal and increased permeability $(32,33)$. A recent report shows the polyethylene glycol 4000 marker (PEG4000) to be suitable for testing both intestinal integrity and bacterial translocation rate (34).

Treatment: Two major interesting trends in the nutritional support of critically ill patients, have surfaced over the last couple of years. The first is the shift away from intravenous administrated of nutrient to enteral feeding. The second is decreasing the quantity of nutrients while increasing the quality of the nutrient mix.

Enteral nutrition stimulates motility, mucus production and gastrointestinal hormone release. Maintenance of these processes plays a vital role in normal barrier function. It is suggested that enteral feeding helps to prevent starvation of the enterocytes during the hypermetabolic state of critical illness and helps to maintain normal immune function, while enhancing intestinal integrity and mucosal barrier function.

Substances included in the nutrient mix are amino acids (glutamine, arginine, ornithine), fatty acids (short chain $n$-3 polyunsaturated) and nucleotides (RNA)(35). Critically ill patients who receive these special nutrients are reported to have fewer complications, spend less time in hospital and have a decreased mortality rate(36) due to beneficial effects on their nutritional, metabolic and immune function. The correct enteral feeding mix was shown to modify hepatic Kupffer cell function, cytokinerelease and acute phase protein production $(35,37)$. However, some contradictions about the value of the individual nutrients exist. There are, for instance, indications that L-arginine, although in some way beneficial to mucosal barrier function, may also exacerbate inflammation and that the L-argininc-nitric oxide pathway 
may be instrumental in a number of deleterious effects(35). Clinical evidence with regard to ornithine is insufficient for making any substantiated judgement. The feasibility of L-glutamine supplementation is widely supported. Enterocytes (as well as fibroblasts, lymphocytes and macrophages) use glutamine as their principal metabolic fuel, and are dependent on preformed glutamine as they have little glutamine synthetase activity. Commercially available total parenteral nutrition (TPN) solutions do not contain glutamine, and administration of these solutions has been shown to lead to small intestine villous atrophy, which can be reversed by glutamine addition $(38,39)$. Glutamine supplementation by oral or intravenous routes during periods of catabolic stress has been shown to improve the function of the gut barrier, as well as various markers of immune function $(38,39)$.

Biotherapeutics comprise the combination of prebiotics (substances which support the proliferation of probiotics) and probiotics (commensal bacterial strains of human origin)(40). Many functions have been ascribed to probiotics including competitive inhibition against pathogen colonisation and immune stimulation. The reader is referred to the symposium proceedings of the American Society for Nutritional Sciences Annual Meeting(41) for a fairly comprehensive overview on the implications of probiotic bacteria for human health and to the results of the ENDO project (European Commission-funded project on non-digestible oligosaccharides) for a consensus on prebiotics(42). The ENDO project, in short, provides evidence for the positive prebiotic effect (i.e. food-induced increases in the number or activity of bifidobacteria and lactic acid bacteria in the human intestine) of non-digestible oligosaccharides.

\section{CONCLUSION}

A wide variety of factors can lead to an increase in gastrointestinal permeability with subsequent microbial translocation (Figure 2). Increased barrier permeability might have an early role in the development of several immune-related gastrointestinal diseases(6) and a number of chronic conditions are commonly associated with gastro intestinal hyperpermeability, including Crohn's disease, ulcerative colitis, inflammatory bowel disease, acute liver failure and cirrhosis, ankylosing spondylitis, and coeliac disease.

Furthermore, microbial translocation may be the cause of sepsis in critically ill patients, which may result in multiple organ failure and death. The development of increased permeability is, however, not limited to such serious complications as any factor that leads to metabolic suppression, enterocyte ATP-depletion, stimulation of proinflammatory cytokines or a disturbance in the natural gastrointestinal flora can lead to gastrointestinal hyperpermeability. Biotherapeutics and the correct enteral nutrition are increasingly recognised to be of importance for the maintenance, as well as the recovery, of normal gut permeability.

\section{REFERENCES}

1 Vander, J.A., Sherman, J.H. and Luciano, D.S. Human Physiology: The Mechanisms of Body Functions, pp. 561-600. McGraw-Hill Inc, New York, 1994.

2. Unno, N. and Fink, M.P. Intestinal Epithelial Hyperpermeability: Mechanisms and Relevance to Disease. Gastroenterol. Clin. North Am. 1998; 27: 289-307.

3. McKay, D.M. and Baird, A.W. Cytokine regulation of epithelial permeability and ion transport. Gut. 1999; 44: 283-289.

4. Coetzee, H.L., Loots, G.P. and Meiring, J.H. Menslike Histologie, pp. 43-46. JL van Schaile, Pretoria, 1997.

5. Smetanka, R.D., Lambert, G.P., Murray, R., Eddy, D., Horn, M. and Gisolfi, C.V. Intestinal permeability in runners in the 1996 Chicago Marathon.Int. J. Sport Nutr. 1999; 9: 326-433.

6. Menzies, I.S., Zuckerman, MJ., NukaJam, W.S. et al. Geography of intestinal permeability and absorption. Gut. 1999; 44: 483-489.

7. Hoffman, R.A., Zhang, G. and Nussler, N.C. et al. Constitutive expression of inducible nitric oxide synthase in the mouse ileal mucosa. Am. J. Physiol. 1997; 272: C383-C392.

8. Pique, L.M., Esplugues, J.V. and Whittle, B.J. Endogenous nitric oxide as a mediator of gastric mucosal vasodilation during acid secretion. Gastroenterology. 1992;102: 168-174.

9. Ford, H.R. and Rowe, M. Sepsis and related considerations. In: O'Neil, J.A. Jr, Rowe, M.I. and Grosfeld, LL. (eds). Pediatric Surgery. 1998; 135-155. Mosby-Year Book, St. Louis.

10. Boughton-Smith, NK, Evans, S.M. and Hawkey, C.J. Nitric oxide synthase activity in ulcerative colitis and Crohn's disease. Lancet. 1993; 342: 338-340.

11. Crow, J.P. and Beckman, L.S. Reactions between nitric oxide, superoxide, and peroxynitrite: Footprints of peroxynitrite in vivo. Adv. Pharmacol. 1995; 34: 17-34.

12. Salzman, A.L., Menconi, M.J. and Unno, N. Nitric oxide dilates tight junctions and depletes ATP in cultured caco- 2Bde intestinal epithelial monolayers. Am. J. Physiol. 1995; 268: G361-G373.

13. Nadler, E.P., Upperman, J.S., Dickinson, E.C. and Ford, H.R. Nitric Oxide and Intestinal Barrier Failure. Semin. Pediatr. Surg. 1999; 8: 148-154.

14. Kubes, P. Ischaemia-reperfusion in the feline small intestine: A role for nitric oxide. Am. J. Physiol. 1993; 264: G 143-G 149.

15. Hutcheson, I.K., Whittle, B.J. and Boughton-Smith, N.K. Role of nitric oxide in maintaining vascular integrity in endotoxin-induced intestinal damage in the rat. Brit. $J$. Pharmacol. 1990; 101: 815-820.

16. Callear, E., Garcia, A.B. and Falcao, R.P. Fas-mediated apoptosis with normal expression of blc-2 and p53 in lymphocytes from aplastic anaemia. Brit. J. Haematol. 1998; 100: 698-703.

17. Payne, D. and Kubes, P. Nitric oxide donors reduce the size in reperfusion-induced intestinal mucosal permeability. Am. J. Physiol. 1993; 265: G189-G195.

18. Kubes, P., Kanwar, S. and Niu, X-E Nitric oxide synthesis inhibition induces leukocyte adhesion via superoxide and mast cells. FASEB J. 1993; 7: 1293-1299.

19. Niu, X., Smith, W. and Kubes, P. Intracellular oxidative stress induced by nitric oxide synthesis inhibition increases endothelial cell adhesion to neutrophils. Circ. Res. 1994; 74: 1133-1140.

20, Qui, B., Pothoulakis, C, Castagliuolo, L, Nikulasson, Z. and LaMont, J.T. Nitric oxide inhibits rat intestinal secretions by Clostridium difficle toxin A but notVibrio cholerae enterotoxin. Gastroenterology. 1996; 111: 409-418.

21. Schleiffer, R. and Raul, F. Prophylactic administration of Larginine improves the intestinal barrier function after mesenteric ischaemia. Gut. 1996; 39: 194-198.

22. Sun, Z., Wang, X., Deng, X., Borjesson, A. and Wallen, R. 
Phagocytic and intestinal endothelial and epithelial barrier function during the early stages of small intestinal ischaemia and reperfusion injury. Shock. 2000; 13: 209-216.

23. Kuhne, W., Besselmann, M. and Noll, T. Disintegration of cytoskeletal structure of actin filaments in energy-depleted endothelial cells. Am. J. Physiol. 1993; 264: H1599-HI608.

24. Unno, N., Menconi, M.J. and Salzman, A.L. Hyperpermeability and ATP depletion induced by chronic hypoxia or glycolytic inhibition in Caco-2 monolayers. Am. J. Physiol. 1996; 270: G1010-G1021.

25. Siesjo, B.K., Bendek, G. and Koide, T. Influence of acidosis on lipid peroxidation in brain tissues in vitro. J. Cereb. Blood Flow Metab. 1985; 5: 253-258.

26. Rehncrona, S., Hauge, H.N. and Siejo, B.K. Enhancement of iron-catalyzed free radical formation by acidosis in brain homogenates: Differences in effect by lactic acid and $\mathrm{CO}_{2}$. J. Cereb. Blood Flow Metab. 1989; 9: 65-70.

27. McKay, D.M. and Baird, A.M. Cytokine regulation of epithelial permeability and ion transport. Gut. 1999; 44: 283-289.

28. de Vera, M.E., Shapiro, R.A. and Nussler, A.K. Transcriptional regulation of human inducible nitric oxide synthase (NOS2) gene by cytokines: Initial analysis of the human NOS2 promoter. Proc. Natl. Acad. Sci. 1996; 93: 1054-1059.

29. Eizaguirre, L., Aidazabal, P., Barrena, M.J., et al. Effects of growth hormone on bacterial translocation in experimental short-bowel syndrome. Pediatr. Surg. Int. 1999;15: 160-163.

30. Walker, W.A. Role of nutrients and bacterial colonization in the development of intestinal host defense. J. Paed. Gastr. Nutr. 2000; 30: S2-S7.

31. Uil, J.J., van Elburg, R.M., van Overbeek, F.M., et al. Clinical implications of the sugar absorption test: intestinal permeability test to assess mucosal barrier function. Scand. J. Gatroenterol. 1997; 223: 70-78.

32. Haase, A.M., Kukuruzovic, R.H., Dunn, K., Bright, A. and Brewster, D.R. Dual sugar permeability testing in diarrheal disease. J. Pediatr. 2000; 136: 232-237.

33. van Nieuwenhoven, M.A., Geerling, B.J., Deutz, N.E., Bronus, F. and Brurnmer, RJ. The sensitivity of the lactulose/rhamnose gut permeability test. Eur. J. Clin. Inves. 1999; 29: 160-165.

34. Amenno, H., Tani, T., Hanasawa, K. and Kodama, M. New method for the detection of bacterial translocation using intestinal permeability with polyethylene glycol 4000. Eur. Surg. Res. 2000; 32: 23-29.

35. Rowlands, B.J. and Gardiner, K.R. Nutritional modulation of gut inflammation. Proc. Nutr. Soc. 1998; 57: 395-401.

36. Majama, H. and Isolauri, E. Probioties: a novel approach in the management of food allergy.J. Allergy Clin. Immunol. 1997; 99: $179-185$.

37. Bengmark, S. and Gianotti, L. Nutritional support to prevent and treat multiple organ failure. World J. Surg. 1996; 20: 474-481.

38. Kong, S.E., Heel, K., McCauley, R. and Hall, J. The role of enterocytes in gut dysfunction. Pathol. Res. Pract. 1998; 194: 741-751.

39. Miller, A.L. Therapeutic considerations of L-Glutamine: A review of the literature. Alt. Med. Review. 1999; 4: 239-248.

40. Duffy, L.C., Laevens, A., Griffiths, E. and Dryja, D. Perspective on bifidobacteria as biotherapeutic agents in gastrointestinal health. Digest Dis. Sci. 1999; 44: 1499-1505.

41. ASNS Symposium Proceedings. Symposium: Probiotic bacteria: Implications for human health. J. Nutr. 2000; 130: S382-S 417.

42. Van Loo, J., Cummings, L, Delzenne, N., et al. Functional food properties of non-digestible oligosaccharides: a consensus report from the ENDO project (DGXII AIRII-CT94-1095). J. Nutr. 1999; 88: 121-132.

43. Madara, J.L. 1999. In: Yamada, T. (ed.) Textbook of Gastroenterology, pp. 141-155. Lippincott Williams \& Wilkins, Philadelphia. 
East African Medical Journal Vol. 80 No. 6 June 2003

PURULENT PERICARDITIS COMPLICATING SEPTICAEMIA: REPORT OF TWO CASES

A.A. Musa, FWACS, B.A. Salami, FMCS, FWACS and A.O. Tade, FWACS, FRCS Department of Surgery, Ogun State University Teaching Hospital, PMB 2001, Sagamu, Nigeria

Request for reprints to: Dr. A.A. Musa, Department of Surgery, Ogun State University Teaching Hospital, PMB 2001, Sagamu, Nigeria

\title{
PURULENT PERICARDITIS COMPLICATING SEPTICAEMIA: REPORT OF TWO CASES
}

\author{
A.A. MUSA, B.A. SALAMI and A.O. TADE
}

\begin{abstract}
Intrapericardial (Pericardial) abscess is quite rare as a complication of sepsis and as a cardiac complication of typhoid septicaemia. It is rapidly fatal if untreated. We report two cases of a schoolboy eight years old with septicaemia from pyomyositis of the right thigh and another of nine and a half years with typhoid perforation and typhoid septicaemia that developed pericardial abscesses. In well-developed centres, computerised tomography, ultrasonography and other radiological investigations are employed for both diagnosis and therapy. We emphasise that these can be accomplished by good clinical examination, radiography of chest and the use of 18-G intra-venous cannula for percutaneous pericardiocentesis without aggressive surgical intervention.
\end{abstract}

\section{INTRODUCTION}

Intrapericardial abscess (purulent pericarditis) is quite rare(1) but septic shock is quite common with approximately 200,000 cases recognised annually(2). Unfortunately, purulent pericarditis is a rare disorder in which fever and hypotension are common (as in septic shock). Classic signs and symptoms, such as chest pain, pericardial friction rub, elevation of jugular venous pressure are seen in only $50 \%$ of cases $(1,2)$.

Again, the diagnostic pitfall of purulent pericarditis presenting as an acute abdomen in children should be noted(3).Though, we emphasise on the use of chest Xray (CXR) in diagnosis, it should be noted that children with purulent pericarditis may have a normal size on radiograph(3).

\section{CASE REPORT}

Case 1: J. M., was an 8-year old student who sustained a blunt injury to the right thigh while playing football with his colleagues on the school playing ground. He could not walk properly afterwards and started having pains in the right thigh. His parents took him to a traditional bone healer where he spent four weeks without any improvement. He was subsequenty seen at Muslim Hospital, Saki Oyo State, Nigeria and findings on examination were a young chronically ill looking, wasted boy, pale (PCV 18\%) and septicaemic. The right thigh was swollen, shinny and tender with a rag tied round (from the herbalist). He could not walk.

A diagnostic needle aspiration was done which yielded $10 \mathrm{mls}$ of pus. A diagnosis of right thigh pyomyositis with septicaemia was made and the aspirate was sent for microscopy, culture and sensitivity, which grew staphylococcus aureus. Full blood count and X-ray of right thigh were done. He was rehydrated, had $500 \mathrm{mls}$ of whole blood and commenced on broad-spectrum antimicrobial-intravenous cefuroxime 500mg
8 hourly and I.V metronidazole 500mg 8 hourly. He subsequently had incision and drainage after full resuscitation. About $1,500 \mathrm{mls}$ of pus was drained from the right thigh.

Figure 1 shows radiological features of chronic osteomyelitis and there is suspicion of a dislocated right hip joint as well. He was subsequently placed on daily dressing with honey and full leg back-slab was applied. He had another $500 \mathrm{mls}$ of blood after drainage.

He improved remarkably and was gaining weight. His packed cell volume (PCV) had risen to $30 \%$ by the second week of admission. However, on the 18th day of admission, he was noticed to be dyspnoiec, tarchypnoiec and the neck veins were engorged and became more prominent. The heart sounds were distant and the pulse barely palpable. There were transmitted sounds in the chest. A tentative diagnosis of septic shock with possible pericardial effusion was made (Metastatic abscess). He had chest X-ray immediately which showed gross cardiomegally (Figure 2).

Figure 1

Right thigh with features of osteomyelitis 


\section{Figure 2}

Chest showing enlarged cardiac shadow (due to collection of pus within the pericardial space)

A final diagnosis of pericardial effusion was then made and a diagnostic pericardiocentesis done yielded $5 \mathrm{mls}$ of pus. Blood culture done earlier yielded staphylococcus aureus, sensitive to genticin, cefuroxime, and cefotaxime. This was drained urgently percutaneously by pericardiocentesis using size 18-G intravenous cannula going through the angle of Louis (Figure 3). About $500 \mathrm{mls}$ of frank pus was aspirated. The anitimicrobials cefuroxime and metronidazole were continued.

Repeat aspirations done on the second and third days yielded only $150 \mathrm{mls}$ and $10 \mathrm{mls}$ respectively while aspiration on the fourth day yielded nothing. A repeat chest X-ray about three weeks after showed a normal CXR (Figure 4). He had secondary closure of his right thigh wound after five weeks on admission and the wound healed satisfactorily. He could not walk properly initially but had physiotherapy for two weeks and responded well. He was followed up for three months and had since gone back to school.

\section{Figure 3}

The chest and the heart with the pericardial space and the angle of louis

\section{Figure 4}

Chest after percutaneous drainage showing normal cardiac size
Case 2: O. S. is a nine and a half year-old boy who was referred from a private clinic to muslim hospital, Saki Oyo State Nigeria on account of fever of two weeks duration and three days history of generalised abdominal pains. According to the referral note, he had had anti-malaria drugs, to no avail and was also given amoxicillin capsules before the generalised abdominal pains started. Findings revealed an acutely ill-looking boy, febrile, pale dehydrated and moribund.

$\mathrm{He}$ had features of generalised peritonitis. A clinical diagnosis of typhoid perforation with overwhelming sepsis was made. He was subsequently resuscitated and was transfused with $500 \mathrm{mls}$ of blood. He had laparotomy and two perforations about $10 \mathrm{~cm}$ apart, measuring $0.5 \mathrm{~cm}$ by $0.5 \mathrm{~cm}$ were found about $20 \mathrm{~cm}$ and $30 \mathrm{~cm}$ respectively from the ileocaecal junction. Closure was done after peritoneal lavage with 2 litres of warm normal saline.

He was commenced on I.V. cefuroxime 500mg 8hourly, chloramphenicol 500mg 6 hourly and 500mg metronidazole 8 hourly. He was responding well to treatment until 7 th day postoperative when he suddenly became dyspnoiec and tarchypnoiec and the pulse was thready. The heart sounds were distant and the neck veins became engorged.

A diagnosis of pericardial tamponade from pericardial effusion as a complication of typhoid septicaemia was made. $\mathrm{He}$ had a chest X-ray (Figure 5), which confirmed the diagnosis. An aspirate of the pericardial effusion was sent and yielded Salmonella typhii. Earlier blood culture also yielded the same organism.

An urgent percutaneous pericardiocentesis was done through the angle of Louis and about $450 \mathrm{mls}$ of pus was aspirated using size 18-G intravenous cannula. The post aspiration status was good and uneventful and the antimicrobials were continued for another one week.

\section{Figure 5}

Chest before drainage showing enlarged cardiac shadow (due to collection of purulent material within the pericardial space)

\section{Figure 6}

Chest after drainage showing normal cardiac sixe 
Repeat aspirations on the second and third days yielded $80 \mathrm{mls}$ and $10 \mathrm{mls}$ respectively while the fourth day was just $3 \mathrm{mls}$ of very light purulent aspirate. A repeat CXR about four weeks after was normal (Figure 6). He was discharged after spending about four weeks in the hospital and was followed up for two months and had since been doing quite well.

\section{DISCUSSION}

Pericardial abscess is a rare complication of sepsis and septic shock(1).The presentations could be many and varied and diagnosis difficult unless there is a high index of suspicion based on clinical signs and symptoms(1-3). The diagnosis is even more difficult in children with presentation varying from acute abdomen, confusion to asystolic cardiopulmonary arrest(1-4).

It is not only common with sepsis or septic shock following staphylococcal infection or Salmonella enteritidis(5) but cases have been reported following pneumococcal pneumonia, group A haemolytic streptococcal tonsillitis, non-encapsulated Haemophilus influenzae, Pseudomonas aeruginosa and even Streptocococcus Milleri which is a harmless commensal of oral cavity had been implicated. It has also been implicated in patients with oesophago-mediastinal fistula. Cases have also been reported following coronary angioplasty and stenting, cystic fibrosis, patients on long standing corticosteroid therapy and in immunocompromised patients $(1,6,7,8-10)$.

Most of the diagnostic equipments are not readily available but they are very useful in diagnosis e.g. CAT scanning, ultrasounds and echocardiography. Although, the classic signs and symptoms such as pericardial rub, pulses paradoxus, chest pain and elevation of jugular pressure are seen in only $50 \%$ of cases, the diagnosis can be easily made as seen in the two cases reported with a high index of suspicion and with a simple investigation like chest X-ray.

Treatment is both surgical and non-surgical. Some of the non-surgical techniques are the use of ultrasound guided percutaneous pericardiocentesis, closed catheter drainage as well as the use of streptokinase $(7,8,9,10$ 13).

The two cases reported here had simple percutaneous pericardiocentesis. The patients were laid supine on bed and under aseptic technique wearing surgical gloves and preparing the skin around the epigastrium with savlon, iodine and spirit. The patients were draped. Then with the size $18-\mathrm{G}$ intravenous troca and cannula directed towards the tip of the left shoulder the pericardial space was entered at the epigastrium (angle of Louis) with the depth of penetration about
$3-4 \mathrm{~cm}$. The troca and the small $2 \mathrm{mls}$ syringe were removed but replaced with a $20 \mathrm{mls}$ syringe. Then repeat and regular aspirations are done as a bedside procedure. One of the complications of purulent pericarditis is constrictive pericarditis(12) but this has not been observed in the two cases reported, as ECGs done before discharge were normal. It is part of further studies on these patients. This might be the first time in Africa that pericardial abscess with Salmonella enteritidis is reported.

\section{REFERENCES}

1. Capov, I., Wechsler, J., Pavlik, M. and Jadlicka, V. Pericardial abscess-a rare complication of sepsis. Acta Chirugical Hungarica. 1999; 38:19-21.

2. Asura, E.L, Kilgore, W.B, and Strategos, E. Purulent pericarditis misdiagnosed as septic shock. Southern Med. J. 1999; 3:285-288.

3. Donnelly, L.F., Kimball, T. R. and Barr, L.L. Purulent pericarditis presenting as acute abdomen in children: abdomen imaging findings. Clinical Radiology. 1999; 54:691-693.

4. Wass, A.R., Mann, P. and Wilson, J.I. Pneumococcal pericarditis presenting as out of hospital cardiopulmonary arrest. J. Accident and Emergency Med. 1997; 14:261-263.

5. Kuichi, K., Endo T., Nejima, J., et al. Purulent pericarditis with tamponade caused by Salmonella enteritidis. Japanese Circul. J. 1998; 62:139-141.

6. Amin, H., Munt, B. and Ignaszewski, A. Staphylococcus aureus pericarditis with tamponade complicating coronary angioplasty and stenting. Canadian J. Cardiol. 1998; 14:1148-1150.

7. Baysak, K., Sancak, R., Ozturk, F., Uysal, S. and Gauses N. Cardiac involvement due to Salmonella typhii infection in children. Annals of Tropical Paediat. 1999; 18:23-25.

8. Altimeier, W.A., Tonelli, M.R, and Aitken, M.L. Pseudomonas pericarditis complicating cyctis fibrosis. Paediatric Pulmonology. 1999; 27:62-64.

9. Rallidis, L.S., Thomaidis, K.P., VIasseros, I.N., et al. Successful treatment of staphylococcus pericarditis with early cather drainage and antibiotics. Acta cardiological. 1997; 52:437-443.

10. Muto, M., Ohtsu, A., Boku, N., Tajiri, H. and Yashida, S. Streptococcus milleri infection and pericardial abscess associated with oesophageal carcinoma: report of two cases. Hepato-Gastroneterology. 1999; 46:1782-1784.

11. Defouilby, C., Meyer, G., Slama, M., et al. Intrapericardial fibrinolysis: a useful treatment in the management of purulent pericarditis. Intensive care Medicine. 1997; 23:117118.

12. Juneja, R., Kothari, S.S. Saxena, R, and Joshi, A. Intrapericardial streptokinase in Pericarditis. Achive of disease in childhood. 1999; 80:275-277.

13. Ligtenberg, J.J., Van der, Werf, T.S., Zijlstra, J.G. et al. Non-surgical treatment of purulent pericarditis due to nonencapsulated Hemophilus influenzae in an immunocompromised patient. Netherlands J. Med. 1999; 5:151154. 
East African Medical Journal Vol. 80 No. 6 June 2003

SUPERIOR MESENTERIC ARTERY SYNDROME: CASE REPORT

P.G. Jani, MMed, FRCS, Department of Surgery, College of Health Sciences, University of Nairobi, P.O. Box 19676, Nairobi, Kenya

\title{
SUPERIOR MESENTERIC ARTERY SYNDROME: CASE REPORT
}

\author{
P.G. JANI
}

\section{SUMMARY}

\begin{abstract}
Superior Mesenteric Artery Syndrome (SMAS) is caused by trapping of the third part of the duodenum between Superior Mesenteric Artery (SMA) and aorta as result of narrowing of the angle between the two vessels due to acute loss of mesenteric fat which is secondary to rapid weight loss. A fifteen year old caucasian female on a mountain climbing expedition with an acute on chronic upper gastrointestinal obstruction is presented. The diagnosis was confirmed with a barium meal and at surgery, a bypass procedure performed to relieve the obstruction.
\end{abstract}

\section{INTRODUCTION}

SMAS is a rare form of duodenal destruction caused by compression of the duodenum between the SMA and aorta(1). Most commonly it occurs after rapid weight loss following trauma, burns and patients in casts are particularly susceptible (2).

The SMA normally leaves the aorta at an angle of 50 to 60 degrees and the distance between the two vessels is 10 to $20 \mathrm{~mm}$ through which the duodenum passes. In patients with the SMAS, the angle of origin of the SMA from the aorta decreases to approximately 20 degrees and the distance between the vessels drops to $2.5 \mathrm{~mm}(3)$. Acute loss of mesenteric fat due to rapid weight loss is main cause of the SMA dropping posteriorly, trapping the duodenum like a scissors(4).

The symptoms are typical of intermittant partial upper gastrointestinal obstruction and include epigastric bloating with cramps causing pain that is relieved by vomiting. Anorexia with pain after meals leads to malnutrition and weight loss that may lead to a further decrease of the mesenteric fat pad under the SMA.

A barium meal examination is a useful investigation and demonstrates a large stomach with dilated bulb and second part of the duodenum(2,5). When the patient is positioned in the knee chest position, the passage of barium may be suddenly unimpeded.

Other diagnostic modalities include angiography, contrast enhanced CT and abdominal echography but these are not recommended for routine evaluation of cases with a diagnostic barium meal(6). Malrotation with duodenal obstruction by congenistal bands and scleroderma are the main differential diagnosis.

Therapy in acute cases may comprise postural changes with relief obtained in the knee chest or prone positions. Chronic obstruction may require surgical division of the ligament of treitz with mobilization of the duodenum but more often a bypass procedure is performed. Laparascopic excision of the ligament of treitz and also laparascopic bypass have recently been successfully employed to treat $\operatorname{SMAS}(3,7,8)$.

\section{CASE RERORT}

Ms. R. G. a fifteen year old female was airlifted from Tanzania on 30th July 2002 at 2.00am with a seven-day history of vomiting.

The patient was from the United States who had come to Tanzania on an expedition to climb Mount Kilimanjaro. She had undergone vigorous physical training and diet control for a month prior to the onset of the climb resulting into marked weight loss. While on the mountain, she had eaten poorly and started vomiting intermittently and the vomitus comprised undigested food with bile. As a result she was dehydrated by the third day, and had to be brought down the mountain following which she required inpatient care with nasogastric aspiration and intravenous infusions. She improved only to restart vomiting upon feeding and was then advised on exploratory laparotomy. At this point she was airlifted and seen in the emergency department.

She gave a history of intermittent bouts of vomiting in the past and admitted to marked weight loss, which she felt was secondary to the intensive training and dieting for the mountain climbing trip. She also gave a history of epigastric cramps, heartburn, anorexia and nausea. She did not have any dysphagia but complained of early fullness and bloating on deglutition. She was obstipated for three days when seen.

Her drug history comprised of anti-malarials, proton pump inhibitors, non-steroidal antiinflammatory analgesics, metroindazole for suspected giardiasis and ciprofloxacillin for possible gastrointestinal infection, all prescribed by her accompanying physician.

Upon examination the patient was in fair general condition, not anaemic or jaundiced and with no palpable nodes. However she was wasted with notable bony prominences. The abdomen was scaphoid and showed epigastric fullness with no visible marks or veins. Upon palpation, there were no areas of tenderness or masses. Percussion revealed no ascites and upon auscultation there were no bowel sounds audible. Plain X-rays of the abdomen (Figure 1) revealed massive gastric dilatation and no dilated intestinal loops or fluids levels and for which a nasogastric 
tube was inserted and it drained 1.5 litres of bilious fluid. An intra venous infusion(IVI) was commenced and bloods were taken for routine works. They showed a potassium of $3.3 \mathrm{mmol} / 1$, sodium of $129 \mathrm{mmol} / 1$ and a WBC of $15.6 \mathrm{x}$ $109 / 1$ with polymorpho-leucocytosis of $82 \%$.

\section{Figure 1}

Plain X-ray of abdomen showing gross gastric dilation

An impression of high gastrointestinal obstruction was formed and in view of the bile in the nasogastric aspirate the obstruction was thought to be most likely distal duodenal or proximal jejunal.

After resuscitation with IVI and nasogastric aspiration together with correction of the electrolytes, the patient had a gastrograffin meal the following morning and this revealed intestinal obstruction involving the third part of the duodenum and reported as most probably secondary to bands (Figure 2).

\section{Figure 2}

Gastro grafin meal showing distal duodenal obstruction

In view of the marked weight loss in a young female an impression of superior mesentery artery syndrome with acute on chronic intestinal obstruction was formed, and a laparotomy planned. At laparatomy a large stomach with an oedematous and dilated bulb and second part of the duodenum were noted, with collapsed jejunal loops. There were enlarged mesenteric lymph nodes of which one was biopsied.

The rest of the abdominal examination was normal. The duodenum was then kocherised and the ligament of treitz severed. No adhesion bands around the third or forth part of the duodenum were noted and a diagnosis of SMAS formed. In view of the oedematous walls of the bulb and second part of the duodenum, a retrocolic isoperistaltic gastrojejunostomy was fashioned. The patient made an uneventful post operative recovery and was discharged on the third day post operatively following which she was noted to be progressing well when reviewed a week later. The histology of the lymph node revealed simple reactive changes.

\section{DISCUSSION}

SMAS is a rare clinical condition that should be considered in patients with long standing abdominal complaints in whom endoscopic and conventional Xray findings are often negative. Most often the patient in question is a thin nervous female who complaints of dyspepsia and intermittant vomiting. Being rare, a high index of suspicion is necessary and leads to an early diagnosis and avoids unnecessary suffering for the patient.

The pathophysiology of SMAS is explained on trapping of the third horizontal part of the duodenum between the SMA and aorta due to a decrease in the angle and space between the two vessels as a result of decrease in the mesenteric fat pad due to acute weight loss. However the fact that numerous other patients who have acute weight loss especially following surgery and do not suffer from the SMAS points to possible other factors like congenital malrotation with bands or vascular anomalies causing the obstruction.

In addition to a barium meal, the diagnosis in equivocal cases may be aided by angiographic evaluation of the decrease in angle and space between the SMA and aorta. Surgical exploration in chronic cases with exclusion of other causes like bands and anomalous vessels confirms the diagnosis of SMAS.

Therapeutic measures in early cases include medical therapy in the form of aggressive nutritional support with small frequent feeds, postural adjustments and vitamin supplements(4). Chronic cases with marked weight loss and frequent episodes of vomiting benefit greatly from surgical relief of obstruction either via release of the suspensory ligament of treitz or via a bypass procedure.

The most physiological bypass in duodenojejunostomy although in acute cases with a dilated and oedematous second part of duodenum, a gastrojejunostomy may also be fashioned(9). With the advent of laparascopic surgery, laparascopic management with severance of ligament of treitz and a duodenojejunal bypass have both been reported with good results $(3,7,8)$. 


\section{REFERENCES}

1. Raissi, B., Taylor, B.M. and Taves, D.H. Recurrent superior mesenteric artery (Wilkie's) syndrome: a case report. Can. J. Surg. 1996; 39: 410-416.

2. Murthi, G.V. and Raine, P.A. Superior mesenteric, artery syndrome in children. Scottish Med. J. 2001; 46: 153-154.

3. Richardson, W.S. and Surowiec, W.J. Laparoscopic repair of superior mesenteric artery syndrome. Amer. J. Sur. 2001; 181: $377-378$.

4. Milner. E.A., Cioffi, W.G; Mcmanus, W.F. and Pruitt, B.A. Superior mesenteric artery syndrome in a burn patient. $J$. Nutr. Clin. Pract. 1993; 8:2664-2666.
5. lwaoka, Y., Yamada, M., Takehira Y.K. et al. Superior mesenteric artery syndrome in identical twin brothers. Inter. Med. 2001; 40: 713-715.

6. Konen, E., Amitai, M., Apter, S. et al. CT angiography of superior mesenteric artery syndrome. . Am. J. Roentgenol. 1998; 171: 1279-1281.

7. Gersin, K.S. and Heniford, B.T. Laparoscopic duodenojejunostomy for treatment of superior mesenteric artery syndrome. J. Soc. Laparoendosc. Surg. 1998; 2: 281284.

8. Massoud, W.Z. Laparoscopic management of superior mesenteric artery syndrome. Int. Surg. 1995; 80: 322-327.

\section{EAMJ INTERNET ADDRESS}

The East African Medical J ournal is now available online as well as in print. Subscribers and readers interested in viewing the Internet version may access it using the following address: http:/ / www.biolineorg.br

The Online version is distributed by the non-profit service; Bioline Publications, a South/North partnership whose aim is to facilitate global access to bioscience and medical research publications, with emphasis on journals published in the developing world.

Subscription to the online version may be made by completing the Registration form available from the Bioline home page (http:/ / www.biolineorg.br). Readers may take out an annual subscription or purchase single documents. Abstracts are available without registration and free of charge. 